\title{
Beiträge zur Frage der oxydativen Leistungen der tierischen Zelle und deren allgemein biologischer Bedeutung.
}

\author{
Von \\ Dr. V. Sehläprer, \\ Assistenzarzt am Krankenhause Frauenfeld, Sommer 1905.
}

(Mit 1 Textfigur.)

So sehr die dominierende Bedeutung des Sauerstoffes für die tierische Zelle eine physiologisch allgemeine Würdigung gefunden hat, so wenig sind die tieferen der Verbrennung zugrunde liegenden Vorgänge bekannt, und die wenigen Tatsachen haben eine so ganz verschiedene Beurteilung und Erklärung gefunden, dass keine derselben als bindend angesehen werden kann. Da nun aber zur Lösung der dieser Arbeit zugrunde gelegten Aufgabe eine gewisse Grundanschauuing das Verständnis und die Darlegung ungemein erleichtert, so sei es mir gestattet, kurz auf die Prinzipien hinzuweisen, auf denen die Fragestellung und die ganze Versuchsanordnung aufgebaut wurden.

In einer Untersuchung über den Bau der Zellen des Plexus chorioideus des Frosches ${ }^{1}$ ) ergab sich die hypothetische Annahme, dass das tierische Zellplasma aufgebaut sei aus kleinsten eiweissartigen Kügelchen, Globoplasten, die, umbüllt von einer lipoidartigen Membran, eingebettet sind in ein drittes eiweissartiges Medium. Der eindringende Sauerstoff aber lagert sich entsprechend dem Prinzip der kleinsten Summe der Oberflächenspannung an der Grenze zwischen Eiweiss und der Lipoidhülle ab und führt so entsprechend seiner Spannung zu einer geringeren oder energischeren Verbrennung. Dieselbe bewegt sich in Etappen zwischen einem primären Oxydationsprozess und einer Reduktion, die die durch die primäre Spaltung

1) Schläpfer, Über den Bau und die Funktion der Epithelzellen des Plexus chorioideus des Frosches in Beziehung zur Granulalehre und mit besonderer Berücksichtigung der vitalen Färbungsmethoden. Beiträge zur allgem. Pathol. und pathol. Anat. Bd. 7 (Suppl.) 1905. Festschrift für Jul. A rnold. 
entstandenen chemischen Gegensätze unter weitergehender Zersetzung wieder auszugleichen bestrebt ist. Eine dieser Etappen kann nachgewiesen werden mit Hilfe der vitalen Färbung mit Methylenblau und Neutralrot, die dureh Entstehen ihrer Leukomodifikation die Reduktionsenergie der Zelle anzeigen. Bei reichlicher Anwesenheit von Sauerstoff oder überhaupt bei intensiver Verbrennung bleiben die Farbstoffe vermöge der grösseren Reduktionsenergie resp. des grossen Sauerstoffbedürfnisses der Zelle farblos und können auch nach dem Absterben derselben trotz der grossen Sauerstoffaffinität der Leukokörper nicht verküpen, weil bei Sauerstoffanwesenheit die oxydative Spaltung auch jetzt noch ähnlich wie intra vitam andauert mit Produktion von Spaltungskörpern, deren Reduktionsfähigkeit grösser ist als die der Leukofarbstoffe. Umgekehrt aber treten die Farbstoffe selbst intra vitam auf, wenn die Spaltungsprodukte nur geringes Reduktionsvermögen zeigen, d. h. z. B. bei geringem Sauerstoffvorrat oder überhaupt bei wenig intensiver Verbrennung, und bleiben alsdann unter Umständen auch nach dem Tode bestehen. Das heisst mit anderen Worten, die Verbrennungsprodukte sind je nach der Intensität und Art der Verbrennung verschieden, und je nach der Spannung des Sauerstoffs oder nach seiner Aktivität beginnt die oxydative Zersetzung als Autolyse bei Sauerstoffmangel, steigt an zum vitalen Masse, beim Plexus charakterisiert durch partielle Entfärbung und lebhafte Flimmerbewegung und überschreitet dasselbe, um als Autolyse bei Sauerstoffanwesenheit zum raschen Zerfall zu führen, wobei in der Überproduktion giftiger, $\mathrm{O}$-armer Spaltprodukte usw. und infolgedessen ungenügender Oxydation und Exkretion nach Pütter ${ }^{1}$ ) das Moment des Absterbens erblickt werden dürfte.

Das Moment, das diese auffallend grosse Aktivität des Luftsauerstoffs hervorzubringen vermag, so dass solche Spaltungen im Protoplasma in relativ kurzer Zeit möglich werden, ist offenbar ein Katalysator, eine Oxydase und Reduktase, deren Wesen vorderhand noch sehr problematischer Natur ist. Während bei Anwesenheit atmosphärischen Sauerstoffs seine Fähigkeit dem Verständnis noch relativ nahe liegt, bereitet die Erklärung grössere Schwierigkeiten unter-Berücksichtigung des sehr geringen Druckes, den der

1) Pütter, Die Atmung des Protozoen. Zeitschr. f. allg. Physiol. Bd. 5 Heft 4. 1905, 
Blutsauerstoff besitzt, selbst wenn der Sauerstoffdruck der Gewebe gleich Null gesetzt wird. Diese Schwierigkeit hat denn auch Schoenbein, His und Schmidt zur Annahme geführt, das Blut könnte imstande sein, den Sauerstoff zu ozonisieren. Allein verschiedene Gründe sprechen, wie Hermann ${ }^{1}$ ) sich ausdrückt, gegen eine solche Erklärung, und dies Phänomen entbehrt vorderhand nach ihm noch jeglicher einwandsfreien theoretischen Basis. Deshalb dürfte es gestattet sein, auf eine Möglichkeit der Erklärung hinzuweisen, die sich ergibt aus dem Wesen der tierischen Verbrennung selbst und dadurch, dass sie sich auf die biologisch grundlegende Erscheinung der in automatischer Ringbildung sich abspielenden physiologisehen Prozesse stützt, von vornherein einen gewissen Grad der Wahrscheinlichkeit beanspruchen darf.

In einer Untersuchung über die Luminiszenz ${ }^{2}$ ) der tierischen Gewebe glaubte ich den Nachweis erbracht zu haben, dass dem Blute, und zwar speziell dem Kaninchenblute, die Eigenschaft zukomme, eine gewisse, nicht näher definierte Art von Strahlen auszusenden, die photographisch wirksam sind, und dass diese Eigenschaft an das Vorhandensein von oxydativen Spaltungen höchst wahrscheinlich gebunden sei, die eine gewisse Intaktheit des Substrates zur Bedingung haben. Ferner schien mir die Annahme gestattet, dass die Pigmentverhältnisse der Haut resp. Lichteinflüsse eine bedeutende, das Strahlungsvermögen steigernde Rolle spielen.

Die weiteren genetischen und biologischen Beziehungen dieses Strahlenvermögens aber waren der folgenden Darlegung vorbehalten.

\section{Experimenteller Teil.}

Die experimentellen Untersuchungen bewegten sich zur Lösung der Aufgabe nach drei Richtungen hin:

Einmal wurde die Prüfung auf photoaktives Verhalten beim Mensehen und Frosch angestellt; sodann wurde der Einfluss des Sonnenlichtes auf die oxydativen Zellprozesse näher präzisiert, im Anhange auch der der Wärme, und endlich dessen Wirkung derjenigen der Photoaktivität gegenübergestellt.

1) Hermann, Lehrbuch der Physiologie, 13. Aufl. 1905 S. 526.

2) Schläpfer, Photoaktivé Eigenschaîten des Kaninchenblutes. Pflüg er's Arch. f. d. ges. Physiol. Bd. 108 S. 554-63. 


\section{Photoaktive Untersuchangen.}

In der ersten Untersuchung über diesen Gegenstand ergab sich die Tatsache, dass Blut albinotischer Kaninchen deutlich photoaktiv war, d. h. die photographisehe Platte durch Strahlung beeinflusste, während sich das Blut pigmentierter Tiere inaktiv verbielt. Vergiftung der Tiere oder des Blutes direkt mit Cyanwasserstoffsäure vernichtete die Photoaktivität. Vergiftung beider Kaninehenrassen durch intravenöse Injektion mit $\mathrm{KClO}_{3}$-Lösung hatte starke Steigerung des Lichtemissionsvermögens zur Folge. Ferner konnte ich auch die Beobachtungen von Molisch ${ }^{1}$ ) bestätigen, dass Papier, Stanniol usw. stark photoaktive Eigenschaften zeigen.

Die anfängliche Methodik bestand darin, dass Blut direkt aus der Ohrvene in ca. $6 \mathrm{~cm}$ Durchmesser haltende, $5 \mathrm{~mm}$ tiefe Paraffinglasschalen gegossen wurde. Darüber lag in ca. $3 \mathrm{~mm}$ Abstand von der Blutoberfiäche die Platte, eingewickelt in einen neutralen Schirm aus schwarzem Mattpapier, der einen dreieckigen Ausschnitt besass, zur deutlichen Charakterisierung einer eventuellen Wirkung. Hierbei konnte jeweils nur eine Prüfung vorgenommen werden, und ausserdem war ziemlich viel Blut erforderlich. Namentlich aus letzterem Grunde, der beim Menschen wie beim Frosche sehr hinderlich gewesen wäre, sah ich mich veranlasst, ein besseres Verfahren zu suchen. Dasselbe bestand darin, dass unter Kontrolle durch Methode I die üblichen Deckgläschen nach guter Reinigung mit Blut vollständig bedeckt wurden und in quadratförmige Vertiefungen einer ziemlich grossen Paraffin-Glasschale zu liegen kamen; darüber wurde ebenfalls in einem Abstand von $3 \mathrm{~mm}$ von der Blutoberfläche die Platte gelegt, die ebenfalls in den Schirm gehüllt war, der entsprechend der Zahl der Quadrate dreieckige, in die Mitte derselben zu liegen kommende Ausschnitte besass. Diese Methode II ermöglichte also neben geringer Blutmenge verschiedene Blutarten usw. auf ihr photoaktives Verhalten gleichzeitig zu prüfen unter Ausschaltung der mmerhin als Fehlerquelle fungierenden verschiedenen Empfindlichkeit der einzelnen Platten; damit war auch eine nähere Bewertung, des Intensitätsgrades erlanbt. Allerdings haften auch diesem Verfahren noch verschiedene Fehler an, so dass ich die Untersuchung noch nicht für abgeschlossen erklären möchte. 
Schliesslich schien es mir auch nicht unerwünscht zu sein, eventuell ohne den Schirm, der oft sich nur schwierig anbringen liess, die Versuche auszuführen, d. h. die Deckgläschen direkt auf die Platte zu legen. Das in diesem Sinne angestellte Experiment (Platte Nr. 31) gab kein ermutigendes Resultat, weil hier die Wirkung des Glases nicht ganz ausgeschlossen ist trotz des zur Kontrolle leer aufgelegten Deckgläschens, weiterhin aber die Entfernung der Gläschen am Schluss der Exposition oft grosse Schwierigkeiten macht und zudem eine Berührung der Platten mit den Fingern sich nicht vermeiden lässt. Die Methode III steht deshalb an Zuverlässigkeit hinter I und II zurück. - Die Expositionsdauer betrug meistens 16 Stunden bei I, II und III, die Belichtung jeweils ca. 10-12 Stunden.

Das Menschenblut gewann ich zuerst durch Venae sectio. Es stammte jeweils von einem Asthmatiker und plethorischen Manne und war bei beiden fast schwarz. Das Resultat war bei Untersuchung nach Methode I und II und mit und ohne Belichtung negativ (Platte Nr. 6, 7). Hierauf wurde arterielles Blut aus dem Ohrläppchen oder der Fingerspitze entnommen und nach Methode II verarbeitet. Die Platte war jeweils in geringem Grade beeinflusst, Belichtung schien nicht von deutlich entscheidbarer Wirkung zu sein (Platte Nr. 18).

Das Froschblut wurde durch Einstich aus den beiden Arteriae ophthalmicae gewonnen unter völliger oder teilweiser Entblutung ohne und mit vorheriger Kurarisierung. Im letzteren Falle zeigte sich nur der Unterschied, dass unmittelbar beim Herausquellen aus dem Gefäss das Blut infolge der durch das Kurare gelähmten Lungenatmung etwas kohlensäurereicher, $d$. h. dunkelrot war, sich aber an der Luft alsbald oxydierte zum hellroten Aussehen.

Unbelichtetes Blut nach I war in allen Fällen positiv (Platte Nr. 3, 4, 8, welch letztere ein auffallend scharfes Bild zeigt); nach II zeigten sich meistens auch Veränderungen der Platte (Nr. 10, 18), gelegentlich war das Resultat aber auch negativ (Platte Nr. 11, 23, 26). Das Alter des Blutpräparats war ohne nacbweisbaren Einfluss, indem der Ausfall noch nach sieben Wochen positiv sein konnte.

Belichtetes Blut, das unbelichtet positiv gewesen, ergab nach I negatives Resultat, weil das Paraffin in der Schale bei der Hitze (Juni 1904) geschmolzen war und das eingetrocknete Blut mit einer Kruste überzog. Es wurde deshalb zur Methode II übergegangen, 
wobei in den meisten Fällen Bilder entstanden, selbst wenn gleichzeitig exponiertes unbelichtetes Blut sich negativ verhielt. (Platte Nr. '14, 23, 26.)

Mit Papier und Stanniol wurden nur nach der Methode II Versuche angestellt in der Absicht, die Intensität der Blutstrahlung zu prüfen. Papier gab in allen Fällen positive Bilder ungefähr von derselben Deutlichkeit wie die des belichteten Blutes. (Platte Nr. 13, 14, 15), ebenso Stanniol (20) und Terpentin-Heftpflaster, das ich aus später zu erörternden Gründen berücksichtigte.

Auf den Versuch mit $\mathrm{KClO}_{3^{-}}$und CyH-Blut glaubte ich in Analogie $\mathrm{zu}$ früheren Untersuchungen verzichten zu können.

Nach Methode III wurden alle Blutarten und Papier geprüft (s. o.). Bemerkenswert ist nur, dass frisches feuchtes Blut, das beim Versuch die untere Fläche des Deckgläschens etwas verunreinigt hatte, an diesen Stellen die Platte sehr stark beeinflusste, während Wasser z. B. die Empfindlichkeit der Platte direkt vernichtet. Ausserdem zeigt sich bei diesem Versuch deutlich aktiv altes, d. h. von schon lange im dunklen Aquarium lebenden Fröschen stammendes unbelichtetes Blut, während dasselbe belichtete sich negativ verhielt, gleichwie frisches (d. h. von frisch eingetroffenen Fröschen) trockenes Blut, Menschenblut, Glas, Papier, welch letzteres nur ganz schwach angedeuteten Schatten gab.

\section{Lichtwirkungen.}

Das Objekt, das diesen und den unter Abschnitt 2, 3 u. 4 zu besprechenden Versuchen zugrunde gelegen hat, ist der PJexus chorioideus anterior des Frosches. Derselbe wurde unter folgenden Kantelen, falls keine besonderen Bemerkungen angebracht sind, gewonnen. Die Schädeldecke des kurarisierten Frosches ${ }^{1}$ ) wurde subperiostal abgehoben, so dass der Plexus unversehrt im Zusammenhang mit Gehirn und Gefässen zutage lag. Hierauf wurde das so präparierte Tier an den Hinterbeinen aufgehängt und mit dem Kopf so tief in eine Lösung von Methylenblau offic. und Neutralrot ãã 0,5 auf 100,0 Kochsalzlösung von $0,6 \%$ getaucht, dass die Wunde vollständig von der Lösung umspült wurde. Nach einer Suspensionsdauer von ca. $2^{1 / 2}$ Stunden wurde der Plexus unter sorgfältiger

1) Schläpfer, l. c. Über den Bau und die Funktion der Epithelzellen des Plexus chor. etc. 
Beiträge zur Frage der oxydativen Leistungen der tierischen Zelle etc. 307

Spülung mit $0,6 \%$ iger Kochsalzlösung entfernt; das brauchbare Präparat zeigte lehhafte Cilienbewegung und farblose Epithelzellen und intravaskuläre Erythrocyten, wogegen der aus Bindegewebe bestehende Stumpf in den meisten Fällen stark blaue Färbung aufwies. Sodann wurde der Plexus entweder in seiner Gesamtheit oder nach möglichst schonender Teilung in zwei gleiche Hälften in hängende Tropfen von $0,6 \%$ iger Kochsalzlösung gebracht und auf hohl geschliffenen Objektträgern in durch Vaselin gedichtete Kammern eingeschlossen.

Der weitere Gang der Untersuchung war folgender: Auf einem Brettchen wurden zwei ca. $0,8 \mathrm{~cm}$ tiefe, $10 \mathrm{~cm}$ breite und lange Kästehen aus schwarzem Mattpapier befestigt (siehe Fig. 1).

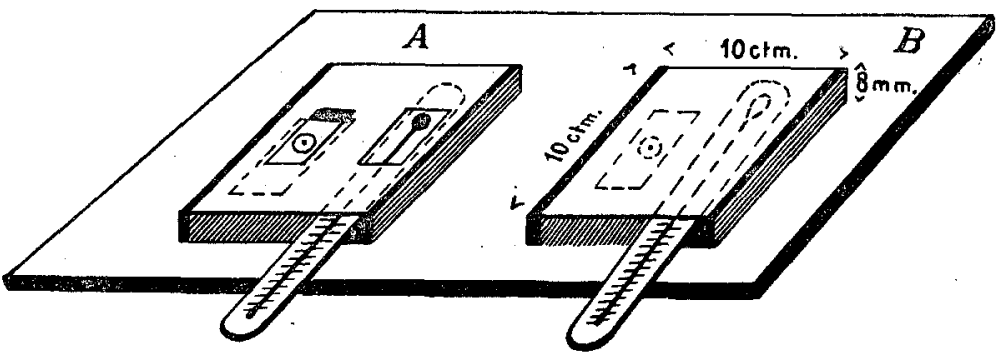

Fig. 1.

Das eine derselben, $A$, besass zwei ca. 2 qcm grosse Ausschnitte, $B$ war lichtdicht geschlossen. Je zwei Seitenwände dieser Kästchen wurden durch schwarze, $10 \mathrm{~cm}$ lange $1 \mathrm{~cm}$ breite und $0,8 \mathrm{~cm}$ tiefe Holzleisten verstärkt. In das Kästchen $A$ wurde ein Thermometer so eingelegt, dass die Kugel des Quecksilbers in einen Ausschnitt zu liegen kam, ebenso das Präparat. Bei $B$ waren beide durch das Mattpapier gedeckt im Dunkeln. Um nun an heissen Tagen bei beiden Präparaten dieselbe Temperatur zu erhalten, wurden beide Kästchen überdeckt mit zwei Glasschalen von zylindrischer Form, $2 \mathrm{~mm}$ Wanddicke und $10 \mathrm{~cm}$ Durchmesser, die auf den Holzleisten ruhten.

Hierauf wurde das Ganze an die Sonne gelegt zur Exposition, (August-Oktober), so dass das Präparat in $A$ immer von den Strahlen getroffen werden konnte. Durch Eingiessen von destilliertem Wasser in beide Schalen in bestimmter Menge und unter entsprechendem Wechseln derselben gelang es, die Temperatur, die immerhin bis zu einem bestimmten Maximum anstieg, beidseitig auf derselben Höhe zu halten. 
A.

a) Versuche mit Plexus, der eben dem lebenden Tiere entnommen ist. Belichtung mit weissem Licht.

Es wurde immer gleichzeitig mit der Belichtung ein Kontrollversuch mit im Dunkeln gehaltenen Präparaten vorgenommen und zwar teils mit Plexus zweier Tiere, teils mit völlig intakten Hälften desselben Plexus, was die eventuell in Betracht kommende Fehlerquelle einer verschiedenen vitalen Individualität mit ziemlicher Sicherheit auszuschliessen erlaubte.

In den folgenden Tabellen sind die Ergebnisse zusammengestellt (siehe Fig. 2, 3, 4, 5, 6, 7, 8, 9, 10).

a) Zuerst wurden Experimente bei beschränkter $\mathrm{O}_{2}$-Anwesenheit und bei hellem Sonnenlicht vorgenommen (hierzu Tabelle I Fig. 2 auf S. 309 und 310). Die Temperatur war stets gleich hoch bei beiden Präparaten und stieg in der Regel je nach der Jahreszeit zu einem Maximum von $28-30^{\circ}$ R., ohne einen merkbaren Einfluss auszuüben (vergl. S. 324-326).

In den im Dunkeln aufbewahrten Organen treten typische Veränderungen auf, die von allgemein grundlegender Bedeutung sind. Das nach der Suspension exhaltene farblose Präparat mit lebhafter Cilienbewegung bleibt ca. ${ }^{1 / 2}$ Stunde unverändert. Dann treten allmählich einzelne kleine mit Neutralrot gefärbte Körnchen, Globoplasten u. Globoplastengruppen oder Granula auf neben leicht blau gefärbten intravaskulären roten Blutkörperchen, die bei dem durchsichtigen Präparate sich leicht unterscheiden lassen ${ }^{1}$ ). Diese Elemente der Färbung werden immer zahlreicher und können diverse Tinktion vortäuschen. Neben roten treten blaue Granula auf. Die Energie der Cilienbewegung beginnt langsam abzunehmen, kann aber 24-48 Stunden andauern, wobei die Färbung ziemlich unverändert bleibt, gegen den Schluss des Lebens hin eher in den Plexuszellen etwas schwächer wird, während die Erythrocyten sich namentlich mit Methylenblau voll beladen, und mit dem Absterben bald in eine bläulich-violette Färbung übergeht, indem die Farbstoffe diffundieren. Die Plexuszellen sind auffallend gelblich körnig geworden und das Präparat häufig von einem kleinen Hof heller Sekrettropfen umgeben.

1) Schläpfer, I. c. Über den Bau und die Funktion der Epithelzellen usw. Zusammenfassung. 
Beiträge zur Frage der oxydativen Leistungen der tierischen Zelle etc. 309

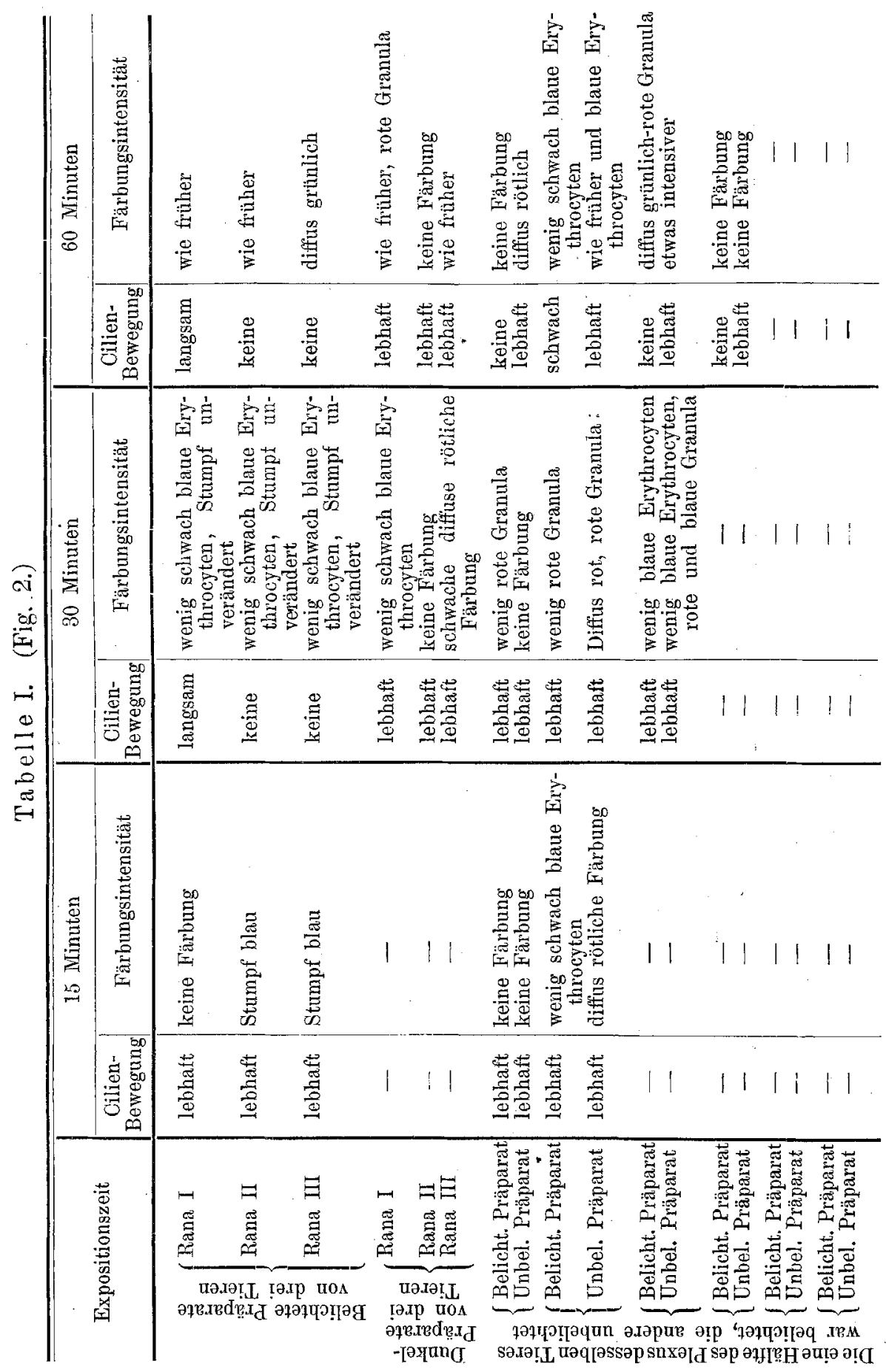


V. Schläpfer:

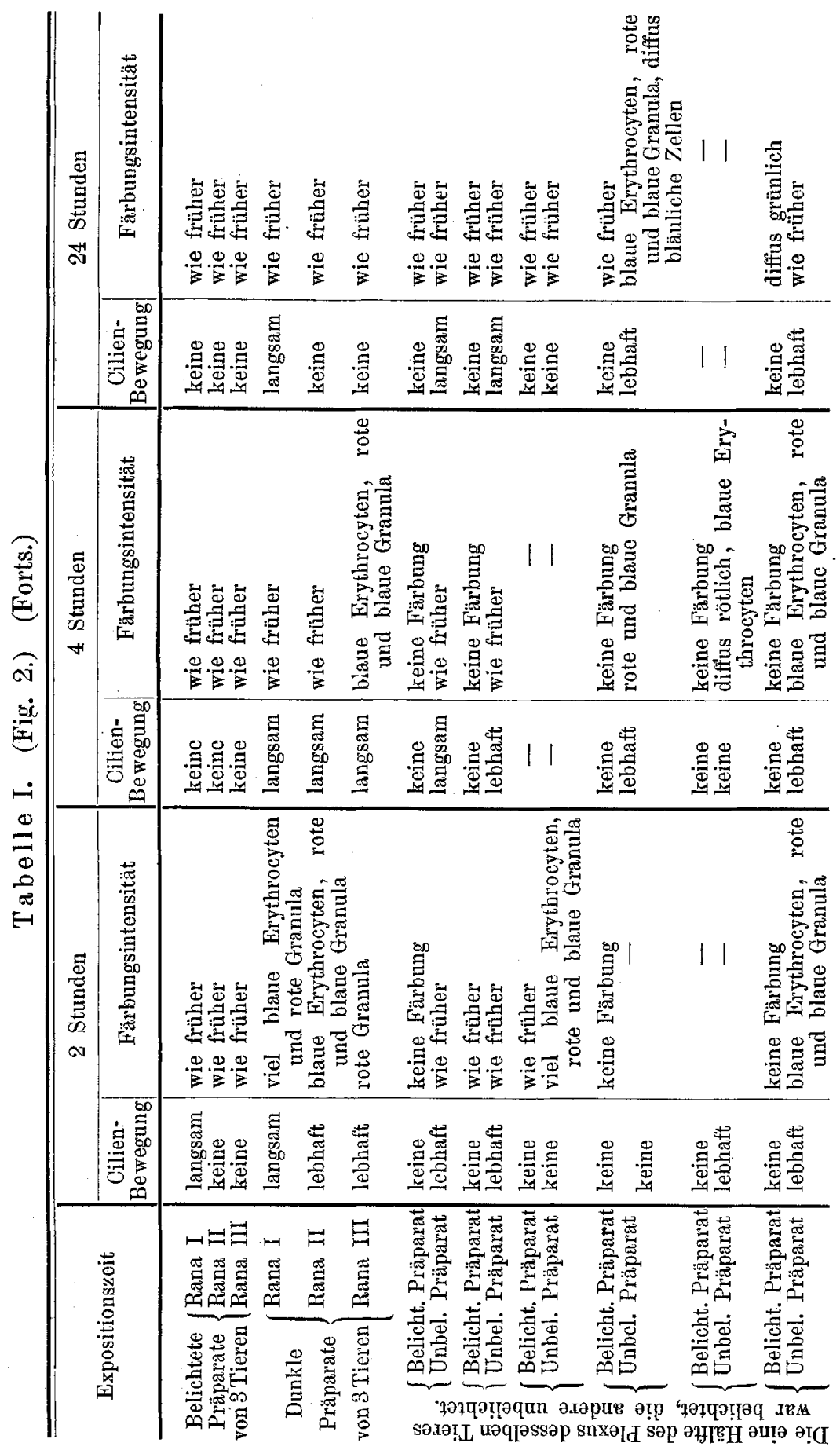


Beiträge zur Frage der oxydativen Leistungen der tierischen Zelle etc. 311

Beim Sonnenpräparat erleidet dieser Verlauf eine charakteristische Modifikation: Die Cilienbewegung zeigt nach 30 bis höchstens 60 Minuten eine plötzliche Verlangsamung, die rasch zum völligen Stillstand führt. Während dieser Zeit treten im Anfang, oft früher als im Dunkelpräparat; aber sehr selten einzelne rote Granula und blaue Erythrocyten auf, um meist vor Sistieren der Flimmerung oder kurz nachher wieder zu verschwinden oder in eine leichte diffus grünliche Färbung überzugehen. Das Präparat ist in der Regel nach 4-6 Stunden fast völlig farblos, wasserhell, gekörnt, und Sekretvakuolen sind meist nur sehr wenig zu sehen.

Eine Änderung in diesem Verhalten wird hervorgerufen, wenn unter sonst gleichen Umständen die verwand te Li chtmenge gering ist, d. h. statt des grellen Sonnen- diffuses trübes Tageslicht verwandt wird (vergleiche Tabelle II, Fig. 3), oder die Exposition am grellen Sonnenlicht nur kurze Zeit dauert (Tabelle III, Fig. 4).

Ta belle II. (Fig. 3.)

\begin{tabular}{|c|c|c|c|c|}
\hline \multirow{2}{*}{ Expositionszeit } & \multicolumn{2}{|r|}{30 Minuten } & \multicolumn{2}{|c|}{2 Stunden } \\
\hline & Cilien- & $\begin{array}{l}\text { Färbungs- } \\
\text { intensität }\end{array}$ & $\mid$\begin{tabular}{|} 
Cilien- \\
Bewegung
\end{tabular} & $\begin{array}{l}\text { Färbungs- } \\
\text { intensität }\end{array}$ \\
\hline Belichtete Plexushälfte & - & - & langsam & $\begin{array}{l}\text { Blaue Erythro- } \\
\text { cyten und rote } \\
\text { Granula }\end{array}$ \\
\hline Unbelicht. Plexushälfte & & - & lebhaft & Blaue Ery- \\
\hline Belichtete Plexushälfte & schwach & WenigblaueErythro & keine & wie früher \\
\hline Unbelicht. Plexushälfte & keine & $\begin{array}{l}\text { Viel blaue Erythro- } \\
\text { cyten, rote Granula }\end{array}$ & keine & wie früher \\
\hline \multirow{2}{*}{ Expositionszeit } & \multicolumn{2}{|r|}{4 Stunden } & \multicolumn{2}{|c|}{24 Stunden } \\
\hline & $\left|\begin{array}{c|}\text { Cilien- } \\
\text { Bewegung }\end{array}\right|$ & $\begin{array}{c}\text { Färbungs- } \\
\text { intensität }\end{array}$ & $\left|\begin{array}{c}\text { Cilien- } \\
\text { Bewegung }\end{array}\right|$ & $\begin{array}{l}\text { Färbungs- } \\
\text { intensität }\end{array}$ \\
\hline Belichtete Plexushälfte & keine & wie früher & $\ldots$ & — \\
\hline Unbelicht. Plexushälfte & langsam & wie früher & - & - \\
\hline Belichtete Plexushälfte & keine & wie früher & keine & wie früher \\
\hline Unbelicht. Plexushälfte & keine & wie früher & keine & wie früher \\
\hline
\end{tabular}

Bei diffusem trübem Lichte bleibt die Cilienbewegung beim Belichtungspräparat im Verhältnis zum Dunkelpräparat lange bestehen und nimmt nicht so plötzlich, sondern ganz langsam ab, um sehliess- 
lich unmerklich ins tote Stadium überzugehen. Gleichzeitig tritt die anfangs aufgetretene Färbung nur langsam zurück und kann bei ganz schwacher Belichtung bestehen bleiben.

Tabelle III. (Fig. 4.)

\begin{tabular}{|c|c|c|c|c|}
\hline \multirow{2}{*}{ Expositionszeit } & \multicolumn{2}{|c|}{60 Minuten } & \multicolumn{2}{|c|}{2 Stunden } \\
\hline & $\left|\begin{array}{c}\text { Cilien- } \\
\text { Bewegung }\end{array}\right|$ & $\begin{array}{c}\text { Färbungs- } \\
\text { intensität }\end{array}$ & $\begin{array}{c}\text { Cilien- } \\
\text { Bewegung }\end{array}$ & $\begin{array}{l}\text { Färbungs- } \\
\text { intensität }\end{array}$ \\
\hline $\begin{array}{l}\text { Belichtete Plexushälfte } \\
\text { Unbelicht. Plexushälfte }\end{array}$ & $\begin{array}{l}\text { keine } \\
\text { lebhaft }\end{array}$ & $\begin{array}{l}\text { wenig blaue Granula } \\
\text { diffus rötlich }\end{array}$ & $\begin{array}{l}\text { keine } \\
\text { lebhaft }\end{array}$ & $\begin{array}{l}\text { wie früher } \\
\text { wie früher, und }\end{array}$ \\
\hline Belichtete Plexushälfte & lebhaft & $\begin{array}{l}\text { diffus rötlich, wenig } \\
\text { blaue Erythro- } \\
\text { cvten }\end{array}$ & keine & wie früher \\
\hline Unbelicht. Plexushälfte & lebhaft & $\begin{array}{c}\text { wenig blaue Ery- } \\
\text { throcyten, rote u. } \\
\text { blaue Granula }\end{array}$ & lebhaft & wie früher \\
\hline \multirow{2}{*}{ Expositionszeit } & \multicolumn{2}{|r|}{4 Stunden } & \multicolumn{2}{|c|}{24 Stunden } \\
\hline & $\left|\begin{array}{c}\text { Cilien- } \\
\text { Bewegung }\end{array}\right|$ & $\begin{array}{l}\text { Färbungs- } \\
\text { intensität }\end{array}$ & $\mid \begin{array}{c}\text { Cilien- } \\
\text { Bewegung }\end{array}$ & $\begin{array}{l}\text { Färbungs- } \\
\text { intensität }\end{array}$ \\
\hline Belichtete Plexushälfte & keine & wie früher & keine & wie früher \\
\hline Unbelicht. Plexushälfte & langsam & $\begin{array}{l}\text { blaue Erythrocyten, } \\
\text { rote und blaue } \\
\text { Granula }\end{array}$ & langsam & wie früher \\
\hline $\begin{array}{l}\text { Belichtete Plexushälfte } \\
\text { Unbelicht. Plexushälfte }\end{array}$ & keine & wie früher & keine & wie früher \\
\hline Ondencmi. FTexustia & & wie früher & lebhatt & wle truher \\
\hline
\end{tabular}

Wird nach zweistündlicher Belichtung an greller Sonne das Präparat im Dunkeln aufbewahrt, so bleibt die Färbung unverändert; zeigt weder Abnahme noch dentliche Zunahme. Wird diese Prozedur unmittelbar nach Sistieren der Flimmerung vorgenommen, so trat dieselbe bei keinem Versuche wieder in die Erscheinung. Selbst wenn die Flimmerung noch eben wahrnehmbar vorhanden war, war vom Aufenthalt im Dunkeln kein wiederbelebender Einfluss zu erkennen.

Wurde dagegen zugleich die feủchte Kammer geöffnet, so dass der $\mathrm{O}_{2}$ der Luft zutreten konnte, so trat in den meisten Fällen wieder eine Beschleunigung der Cilienbewegung ein, die aber meist nur 1-10 Minuten dauerte und dann plötzlich sistierte. Wurde die Kammer erst nach Sistieren der Flimmerung und nach Entfärbung des Objektes geöffnet, so war das Cilienphänomen meist unverändert negativ, dagegen machte sich eine leichte bläulich rote, meist etwas verwaschene Färbung bemerkbar; gelegentlieh konnte man aber 
auch, namentlich wenn die Belichtung nicht allzu intensiv gewesen und bei nicht hoher Temperatur, $10-12^{\circ} \mathrm{C}$, vorgenommen worden war, eine mehr differenzierte Färbung auftreten sehen mit wieder beginnender Cilienbewegung, die oft zehn Minuten dauerte und unter Verschwinden der Färbung in der geschlossenen Kammer im Dunkeln verlief.

$\beta)$ Versuche mit unbeschränkter Sauerstoffmenge und hellem Sonnenlichte. Da ein im Dunkeln aufbewahrtes Präparat bei unbesehränkter Sauerstoffzufubr sich wesentlich anders verhielt als bei begrenzter ${ }^{1}$ ), so war eine Modifikation nach dieser Richtung hin beim belichteten Präparat von besonderem Interesse. Die Methode war die folgende: Der frische Plexus wurde statt im hängenden Tropfen in einem ca. 1 Fr.-Stück grossen Tropfen 0,6\%iger Kochsalzlösung auf einem Objektträger schwimmend exponiert. Durch Ersatz des. verdunstenden Wassers wurde einer Konzentrationserhöhung vorgebeugt, was durch Beobachtung und Wahrung des Umfanges der Tropfenbasis sich ohne Schwierigkeiten machen liess. Eine Zusammenstellung der Resultate gibt Tabelle IV, Fig. 5.

Während im Dunkelpräparat eine deutliche Färbung ausbleibt und die Cilienbewegung nach relativ kurzer Zeit ganz allmäblich erlischt, macht sich beim belichteten Präparat eine deutliche Verlängerung (in bezug auf das geschlossene Belichtungspräparat) der Cilienbewegung bemerkbar; ferner zejot sich die Färbung noch nach relativ längerer Zeit, um im Gegensatz zum Dunkelpräparat, bei dem stets eine sehr deutliche Vermehrung der Sekretkugeln sich zeigte, welche beim Belichtungspräparat nicht mit Sicherheit konstatiert werden konnte, sehr rasch zu verschwinden. Bei längerer Aufbewahrung macht sich bei ersterem nach ca. 8-10 Stunden ein intensiver Zerfall in kleinste Körnchen, Globoplasten, erkesnbar, während das Lichtpräparat schon nach 4-5 Stunden dasselbe Phänomen aufweist. Im Dunkeln geht der Zerfall sehr weit, bei Belichtung dagegen scheint eine gewisse Erlahmung dieses Prozesses einzutreten; doch gelang es mir nicht, hierüber genaue Resultate zu erzielen, da ich auf das Sonnenlicht angewiesen war und eine Expositionsdauer von länger als 10-12 Stunden ausserhalb der Grenze der Möglichkeit lag. Die Fehlerquelle einer Bakterieninfektion war beim Sonnenpräparat zu ver-

1) Schläpfer, Über den Ban und die Funktion der Epithelzellen des Plexus usw. S. 119. 
nachlässigen (vgl. S. 326), weniger beim Dunkelpräparat; es wurden deshalb beide Präparate in der bei jedem Versuch (auch später) sterilen Kochsalzlösung in grossen Petri'schen Glasschalen exponiert, so dass durch leichtes Heben des Deckels der Zutritt der Luft gut ermöglicht wurde, ohne dass Staubinfektion zu befürchten war.

Tabelle IV. (Fig. 5.)

\begin{tabular}{|c|c|c|c|c|}
\hline \multirow{2}{*}{ Expositionszeit } & \multicolumn{2}{|c|}{30 Minuten } & \multicolumn{2}{|c|}{60 Minuten } \\
\hline & \begin{tabular}{|c|} 
Cilien- \\
Bewegung
\end{tabular} & $\begin{array}{l}\text { Färbungs- } \\
\text { intensität }\end{array}$ & \begin{tabular}{|c|} 
Cilien- \\
Bewegung
\end{tabular} & $\begin{array}{l}\text { Färbungs- } \\
\text { intensität }\end{array}$ \\
\hline $\begin{array}{l}\text { Belichtete Plexushälfte } \\
\text { und unbegrenzter }\end{array}$ & lebhaft & keine & lebhaft & diffus grünlich \\
\hline $\begin{array}{l}\text { Unbelichtete Plexus- } \\
\text { hälfte und unbe- } \\
\text { grenzter Sauerstoff }\end{array}$ & lebhaft & keine & lebhaft & diffus grünlich \\
\hline $\begin{array}{l}\text { Belichtete Plexushälfte } \\
\text { und unbegrenzter } \\
\text { Sauerstoff }\end{array}$ & lebhaft & rötlich & lebhaft & keine \\
\hline Belichtete Plexushälfte & langsam. & rötlich & langsam & keine \\
\hline $\begin{array}{l}\text { Belichtete Plexushälfte } \\
\text { und unbegrenzter } \\
\text { Sauerstoff }\end{array}$ & lebhaft & $\begin{array}{l}\text { wenig blaue Ery- } \\
\text { throcyten }\end{array}$ & lebhaft & diffus grünlich \\
\hline Belichtete Plexusbälfte & lebhaft & $\begin{array}{l}\text { wenig blaue Ery- } \\
\text { throcyten }\end{array}$ & keine & diffus grünlich \\
\hline \multirow[b]{2}{*}{ Expositionszeit } & \multicolumn{2}{|c|}{2 Stunden } & \multicolumn{2}{|c|}{3 Stunden } \\
\hline & $\mid$\begin{tabular}{c|} 
Cilien- \\
Bewegung
\end{tabular} & $\begin{array}{l}\text { Färbungs- } \\
\text { intensität }\end{array}$ & $\mid$\begin{tabular}{c|} 
Cilien- \\
Bewegung
\end{tabular} & $\begin{array}{l}\text { Färbungs- } \\
\text { intensität }\end{array}$ \\
\hline $\begin{array}{l}\text { Belichtete Plexushälfte } \\
\text { und unbegrenzter }\end{array}$ & lebhaft & keine & keine & keine \\
\hline $\begin{array}{l}\text { Unbelichtete Plexus- } \\
\text { hälfte und unbe- } \\
\text { grenzter Sauerstoff }\end{array}$ & lebhaft & wie früher & langsam & keine \\
\hline $\begin{array}{l}\text { Belichtete Plexushälfte } \\
\text { und unbegrenzter } \\
\text { Sauerstoff }\end{array}$ & lebhaft & keine & keine & keine \\
\hline Belichtete Plexushälfte & keine & keine & keine & keine \\
\hline $\begin{array}{l}\text { Belichtete Plexushälfte } \\
\text { und unbegrenzter } \\
\text { Sauerstoff }\end{array}$ & langsam & keine & keine & keine \\
\hline Belichtete Plexushälfte & keine & keine & keine & keine \\
\hline
\end{tabular}

Sonst wurde im allgemeinen zum Zwecke einer Sterilisation möglichste (vgl. S. 325) Asepsis im Präparieren erstrebt, weitere Desinfektionsmassregeln aber nicht getroffen, da schliesslich jeder 
Beiträge zur Frage der oxydativen Leistungen der tierischen Zelle etc. 315

geringste Zusatz eines Desinfiziens, namentlich nach den Arbeiten Schade' $\mathrm{s}^{\mathbf{1}}$ ), das Resultat hätte beeinträchtigen können.

b) Versuche mit Plexus, der nach Entnahmevor der Belichtung 1-2 Stunden in dunkler Kammer aufbewahrt worden ist und blaue Erythrocyten und rote und blaue Granula enthält neben leicht herabgesetzter Cilienbewegung. Hierzu Tabelle V, Fig. 6 .

Tabelle V. (Fig. 6.)

\begin{tabular}{|c|c|c|c|c|c|}
\hline \multirow{2}{*}{\multicolumn{2}{|c|}{$\begin{array}{l}\text { Expositions- } \\
\text { dauer }\end{array}$}} & \multicolumn{2}{|c|}{ Vorstadium vor Exposition } & \multicolumn{2}{|c|}{15 Minuten } \\
\hline & & \begin{tabular}{c|} 
Cilien- \\
Bewegung
\end{tabular} & Färbung & $\begin{array}{c}\text { Cilien- } \\
\text { Bewegung }\end{array}$ & Färbung \\
\hline 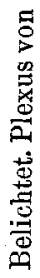 & $\begin{array}{l}\text { Rana II } \\
\text { Rana III }\end{array}$ & $\begin{array}{l}\text { langsam } \\
\text { lebhaft } \\
\text { lebhaft }\end{array}$ & $\begin{array}{l}\text { viel blaue Erythro- } \\
\text { cyten, rote und } \\
\text { blaue Granula, } \\
\text { diffus blaue Zellen } \\
\text { viel blaue Erythro- } \\
\text { cyten, roteGranula } \\
\text { schwach blaue Ery- } \\
\text { throcyten, diffus } \\
\text { rot, rote Granula }\end{array}$ & $\begin{array}{l}\text { lebhaft } \\
\text { langsam }\end{array}$ & $\begin{array}{l}\text { etwas schwächer } \\
\text { wie früher } \\
\text { wie früher }\end{array}$ \\
\hline
\end{tabular}

\begin{tabular}{|c|c|c|c|c|c|}
\hline \multirow{2}{*}{\multicolumn{2}{|c|}{$\begin{array}{l}\text { Expositions- } \\
\text { dauer }\end{array}$}} & \multicolumn{2}{|r|}{30 Minuten } & \multicolumn{2}{|r|}{5 Stunden } \\
\hline & & $\begin{array}{c}\text { Cilien- } \\
\text { Bewegung }\end{array}$ & Färbung & $\begin{array}{c}\text { Cilien- } \\
\text { Bewegung }\end{array}$ & Färbung \\
\hline 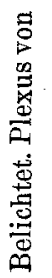 & $\left\{\begin{array}{l}\text { Rana I } \\
\text { Rana II } \\
\text { Rana III }\end{array}\right.$ & $\begin{array}{l}\text { keine } \\
\text { keine } \\
\text { keine }\end{array}$ & $\begin{array}{l}\text { wie früher } \\
\text { wenig blaue Ery- } \\
\text { throcyten, sonst } \\
\text { gleich } \\
\text { Heller als früher }\end{array}$ & $\begin{array}{l}\text { keine } \\
\text { keine } \\
\text { keine }\end{array}$ & $\begin{array}{l}\text { wenig rote Granula } \\
\text { und blaue Ery- } \\
\text { throcyten } \\
\text { sehr wenig blaue } \\
\text { Erythrocyten, rote } \\
\text { Granula } \\
\text { sehr wenig blaue } \\
\text { Erythrocyten, rote } \\
\text { Granula }\end{array}$ \\
\hline
\end{tabular}

Durch Belichtung bei hellem Sonnenschein zeigt sich nach Verlauf von 15 Minuten schon eine Abnahme der Cilienbewegung, die auch plötzlich sistiert. Die relativ intensive Färbung ist nach $5-6$ Stunden noch angedeutet, nicht sehr verwaschen, der Rückgang derselben erfolgt langsamer, aber sonst ungefähr in derselben Weise wie bei den sub a) besprochenen Präparaten und ist nur darin ein leichter Unterschied zu konstatieren, dass dies Körnerstadium auch einen deutlich gelben Sçhimmer besitzt wie reine Dunkelpräparate.

1) Schade, Über die katalytische Beeinflussung der Zuckerverbrennung. Münchener med. Wochenschr. Nr. 23. 1905. 
c) Versuche mit Plexus, der in dunkler Kammer aufbewahrt, keine Cilienbewegung besitzt. Die Belichtung war geliefert durch die grelle Sonne, die Sauerstoffmenge in der ersten Anordnung Tabelle VI, Fig. 7 beschränkt.

Tabelle VI. (Fig. 7.)

\begin{tabular}{|c|c|c|c|c|c|}
\hline \multirow{2}{*}{\multicolumn{2}{|c|}{$\begin{array}{l}\text { Expositions- } \\
\text { dauer }\end{array}$}} & \multicolumn{2}{|c|}{ Vorstadium vor der Belichtung } & \multirow{2}{*}{$\frac{1 \text { Stunde }}{\text { Färbung }}$} & \multirow{2}{*}{2 Stunden } \\
\hline & & $\mid \begin{array}{c}\text { Cilien- } \\
\text { Bewegung }\end{array}$ & Färbung & & \\
\hline \multirow{6}{*}{ 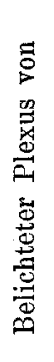 } & Rana I & keine & $\begin{array}{l}\text { viel blaue Erythrocyten, } \\
\text { wenig blaue und rote } \\
\text { Granula }\end{array}$ & wie früher & wie früher \\
\hline & & keine & $\begin{array}{l}\text { blaue Frythrocyten, viel } \\
\text { blaue und rote Granula }\end{array}$ & diffus grün & wie früher \\
\hline & Rana III & keine & diffuse rote. Färbung & wie & wie früher \\
\hline & Rana IV & keine & $\begin{array}{l}\text { diffuse blaue Ziellen und } \\
\text { Erythrocyten }\end{array}$ & wie & wie früher \\
\hline & Rana V & keine & viel stark blaue Erythro- & wie früher & wie früher \\
\hline & Rana VI & keine & $\begin{array}{l}\text { diffuse blaue Zellen and } \\
\text { Erythrocyten }\end{array}$ & wie früher & wie früher \\
\hline
\end{tabular}

\begin{tabular}{|c|c|c|c|c|c|}
\hline \multirow{2}{*}{\multicolumn{2}{|c|}{$\begin{array}{l}\text { Expositons- } \\
\text { dauer }\end{array}$}} & 3 Stunden & 4 Stunden & 5 Standen & 24 Stunden \\
\hline & & Färbung & Färbang & Färbung & Färbung \\
\hline 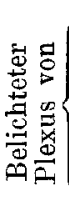 & $\left\{\begin{array}{l}\text { Rana I } \\
\text { Rana II } \\
\text { Rana III } \\
\text { Rana IV } \\
\text { Rana V } \\
\text { Rana VI }\end{array}\right.$ & $\begin{array}{l}\text { etwas heller } \\
\text { etwas heller } \\
\text { etwas heller } \\
\text { etwas heller } \\
\text { etwas heller } \\
\text { etwas heller }\end{array}$ & $\begin{array}{l}\text { verwaschen } \\
\text { noch heller } \\
\text { noch heller } \\
\text { etwas rötlicher } \\
\text { diffus grünlich } \\
\text { wie früher }\end{array}$ & $\begin{array}{l}\text { wie früher } \\
\text { wie früher } \\
\text { rote Granula } \\
\text { wie früher } \\
\text { wie früher } \\
\text { diff. grünlich, } \\
\text { bl. Zellkerne }\end{array}$ & $\begin{array}{l}\text { leicht grünlich } \\
\text { wie früher } \\
\text { wie früher } \\
\text { nur hellrötlich } \\
\text { wie früher } \\
\text { wie früher }\end{array}$ \\
\hline
\end{tabular}

Bei toten Präparaten tritt auch bei greller Beleuchtung nur langsame Abnahme der Färbung ein, ähnlich wie beim Stumpf lebender Objekte. Die diffuse Tönung erscheint erst nach ungefähr 4 Stunden, wobei Zutritt von Sauerstoff erfolglos bleibt, ausgenommen bei Präparaten die, wie bei Rana IV diffus rötlich geworden und die blaue Tinktion eingebüsst haben. Bei diesen tritt bei $\mathrm{O}_{2}$-zufuhr häufig leichte blaue Tönung ein, die bei weitergehender Belichtung wieder verschwindet. Diese rote Färbung, die oft tagelang bestehen bleibt, wird nur bei Präparaten beobachtet, die schon bei der Entnahme aus dem Körper total blauviolett gefärbt sind und nie Cilienbewegung aufgewiesen haben, also äusserst intensiv Farbstoff ab- 
Beiträge zur Frage der oxydativen Leistungen der tierischen Zelle etc. 317

sorbierten, weil sie durch irgendwelche Schädigung bei der Präparation abgetötet wurden ${ }^{\mathbf{1}}$ ).

In einer zweiten Anordnung, Tabelle VII (Fig. 8), wurde die Kammer von Anfang geöffnet, die $\mathrm{O}_{2}$-Zufuhr nicht beschränkt.

Tabelle VII. (Fig. 8.)

\begin{tabular}{|c|c|c|c|}
\hline \multirow{2}{*}{ Fxpositionszeit } & \multicolumn{2}{|c|}{ Vorstadium vor der Belichtung } & 1 Stunde \\
\hline & $\begin{array}{c}\text { Cilien- } \\
\text { bewegung }\end{array}$ & Färbung & Färbung \\
\hline $\begin{array}{l}\text { Belichtete Plexushälfte } \\
\text { mit unbegrenzter } \\
\text { Sauerstoffzufuhr } \\
\text { Belichtete Plexushälfte }\end{array}$ & $\begin{array}{l}\text { erloschen } \\
\text { erloschen }\end{array}$ & $\begin{array}{l}\text { blaue Erythrocyten, rote } \\
\text { Granula, blaue Zellen } \\
\text { blaue Erythrocyten, rote }\end{array}$ & $\begin{array}{l}\text { grünlich, blane Ery- } \\
\text { throcyten } \\
\text { wie früher }\end{array}$ \\
\hline $\begin{array}{l}\text { Belichtete Plexushälfte } \\
\text { mit unbegrenzter } \\
\text { Sauerstoffzufuhr }\end{array}$ & erloschen & $\begin{array}{l}\text { Granula, blaue Zellen } \\
\text { viel blaue Erythrocyten, } \\
\text { rote Granula }\end{array}$ & $\begin{array}{l}\text { grünlich, blaue Ery- } \\
\text { throcyten }\end{array}$ \\
\hline Belichtete Plexushälfte & erloschen & $\begin{array}{l}\text { viel blaue Erythrocyten, } \\
\text { rote Granula }\end{array}$ & wie früher \\
\hline
\end{tabular}

\begin{tabular}{|c|c|c|c|}
\hline \multirow{2}{*}{ Expositionszeit } & 2 Stunden & 3 Stunden & 4 Stunden \\
\hline & Färbung & Färbung & Färbung \\
\hline $\begin{array}{l}\text { Belichtete Plexushälfte } \\
\text { mit unbegrenzter } \\
\text { Sauerstoffzufuhr }\end{array}$ & $\begin{array}{l}\text { diff. grünlich, blaue } \\
\text { Erythrocyten }\end{array}$ & $\begin{array}{c}\text { blänlich, blasse } \\
\text { Frythrocyten }\end{array}$ & $\begin{array}{c}\text { gleichmässig } \\
\text { blaugrün }\end{array}$ \\
\hline Belichtete Plexushälfte & $\begin{array}{l}\text { diff. grünlich, blaue } \\
\text { Erythrocyten }\end{array}$ & $\begin{array}{c}\text { bläulich, blasse } \\
\text { Erythrocyten }\end{array}$ & $\begin{array}{c}\text { gleichmässig } \\
\text { blaugrün }\end{array}$ \\
\hline $\begin{array}{l}\text { Belichtete Plexushälfte } \\
\text { mit unbegrenzter } \\
\text { Sauerstoffzufuhr }\end{array}$ & $\begin{array}{l}\text { diff. grünlich, blaue } \\
\text { Erythrocyten }\end{array}$ & $\begin{array}{l}\text { grünlich, blasse } \\
\text { Erythrocyten }\end{array}$ & $\begin{array}{c}\text { gleichmässig } \\
\text { blaugrün }\end{array}$ \\
\hline Belichtete Plexushälfte & $\begin{array}{l}\text { diff. grünlich, blaue } \\
\text { Erythrocyten }\end{array}$ & $\begin{array}{c}\text { grünlich, blasse } \\
\text { Erythrocyten }\end{array}$ & $\begin{array}{c}\text { gleichmässig } \\
\text { blaugrün }\end{array}$ \\
\hline
\end{tabular}

Bei offenen toten Präparaten tritt die Abblassung etwas rascher ein als bei geschlossenen; doch gleicht sich die Intensität nach ca. zwei Stunden aus, wobei die Erythrocyten am längsten individuelle Färbung beibehalten, während die Granulafärbung schon nach einer Stunde nicht mehr deutlich erkennbar und diffus geworden ist.

\section{B. Versuche mit frischen Präparaten und flltriertem Sonnenlicht.}

Die Versuchsanordnung war die folgende: Die Filtration des stets grellen Sonnenlichts wurde erzielt durch Lösungen von Methylen-

1) Schläpfer, l. c., Über den Bau und die Funktion der Epithelzellen des Plexus chor. usw.

E. Pflüger, Archiv für Pọysiologie. Bä. 114. 
blau, Neutralrot und Froschbämoglobin in Aqua dest. Durch solche Lösungen wurde das in früheren Versuchen zur Wärmeabsorption verwandte Wasser ersetzt. Die Lösungen waren ungefäbr von derselben Färbungsintensität, bestimmt durch direkten Vergleich gefüllter gleichgrosser Reagenzgläschen auf hellem Grund im Sinne einer reinen Kolorimetrie. Die Höhe der Flüssigkeitssäule war, falls nicht spezielle Änderungen vorgenommen wurden, ca. $1 / 2 \mathrm{~cm}$. Das Hämoglobin wurde wach den Angaben Hermann's') direkt aus einer Halsarterie in sterilisiertes Aqua dest. getropft, wobei der Blutfarbstoff in kurzer Zeit austrat. Dann wurde filtriert und das Filtrat verwendet, das immer frisch hergestellt wurde. Die Lösung hatte zirka die Konzentration 1:20; nach der Intensität derselben wurden die übrigen Lösungen abgestimmt; sie hatten ungefähr die Konzentration 1:1000.

Die Hämoglobin- und Methylenblaulösung wurden vom Sonnenlicht kaum wahrnehmbar gebleicht in der in Betracht kommenden Zeitdauer, wogegen die Neutralrotlösung schon nach zirka einer Stunde ibre kirschrote Nuance verlor. Die Lösung trübte sich, wurde hellorange, und allmählich setzte sich ein ebenso gefärbter feinkörneliger Niederschlag zu Boden, wobei die Reaktion unverändert neutral blieb. Ein gleicher Niederschlag konnte sofort gewonnen werden durch Alkalizusatz; beide lösten sich wieder bei Ansäuerung zu kirschroter Farbe, die alsdann durch Belichtung nicht verändert wurde, wohl aber bei Alkalizusatz.

a) Filtration bei gleicher Höhe der Lösungen. (Siehe Tabelle VIII [Fig. 9]). Schichthöhe $0,5 \mathrm{~cm}$.

Die Temperaturen waren bei allen Präparaten nach Thermometerkontrolle ungefähr dieselben; es bestanden nur sehr geringe, zu vernachlässigende Unterschiede von $1 / 4-1 / 20 \mathrm{C}$., was um so weniger bedeuten dürfte, als diese Versuchsserie im Oktober 1905 vorgenommen wurde, die im Durchschnitt ziemlich kühl war, mithin also nur die Lichtstrahlen eine grössere Wirkung ausüben konnten. Aus Tabelle VIII eroibt sich, dass jede Filtration des Lichtes durch Farbstoffe gegenüber Aqua dest. eine Abschwächung seiner entfärbenden und die Cilienbewegung lähmenden Wirkung verursacht. Das gilt auch für das nicht rubrizierte Methylenblau, wenn man das Methylenblaupräparat mit dem Wasserpräparat vergleicht; allerdings ist dessen abschwächender Einfluss relativ klein.

1) Hermann, Lehrbuch der Physiologie, 13. Auf., S. 32 ff. 1905. 
Beiträge zur Frage der oxydativen Leistungen der tierischen Zelle etc.

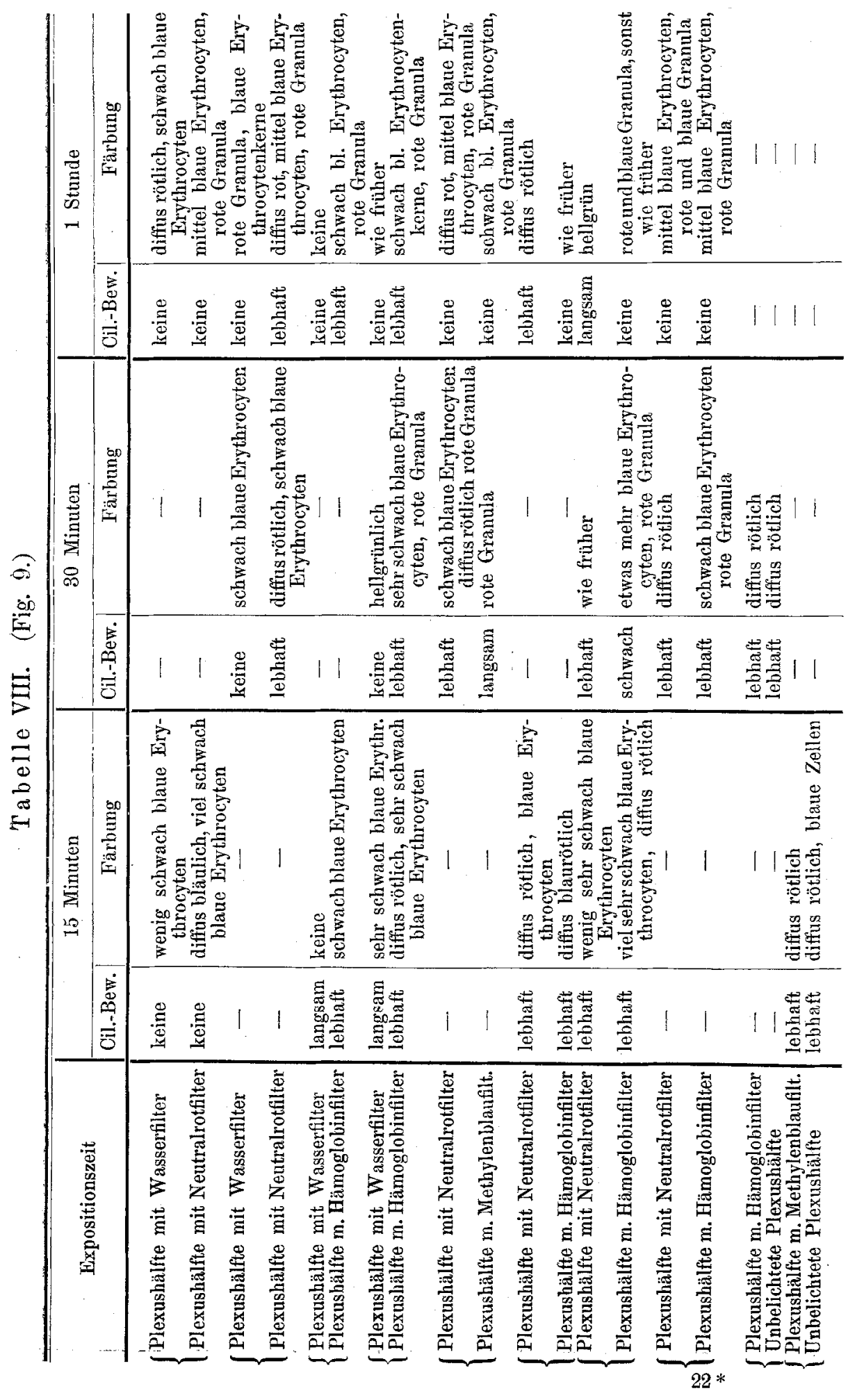


V. Schläpfer:

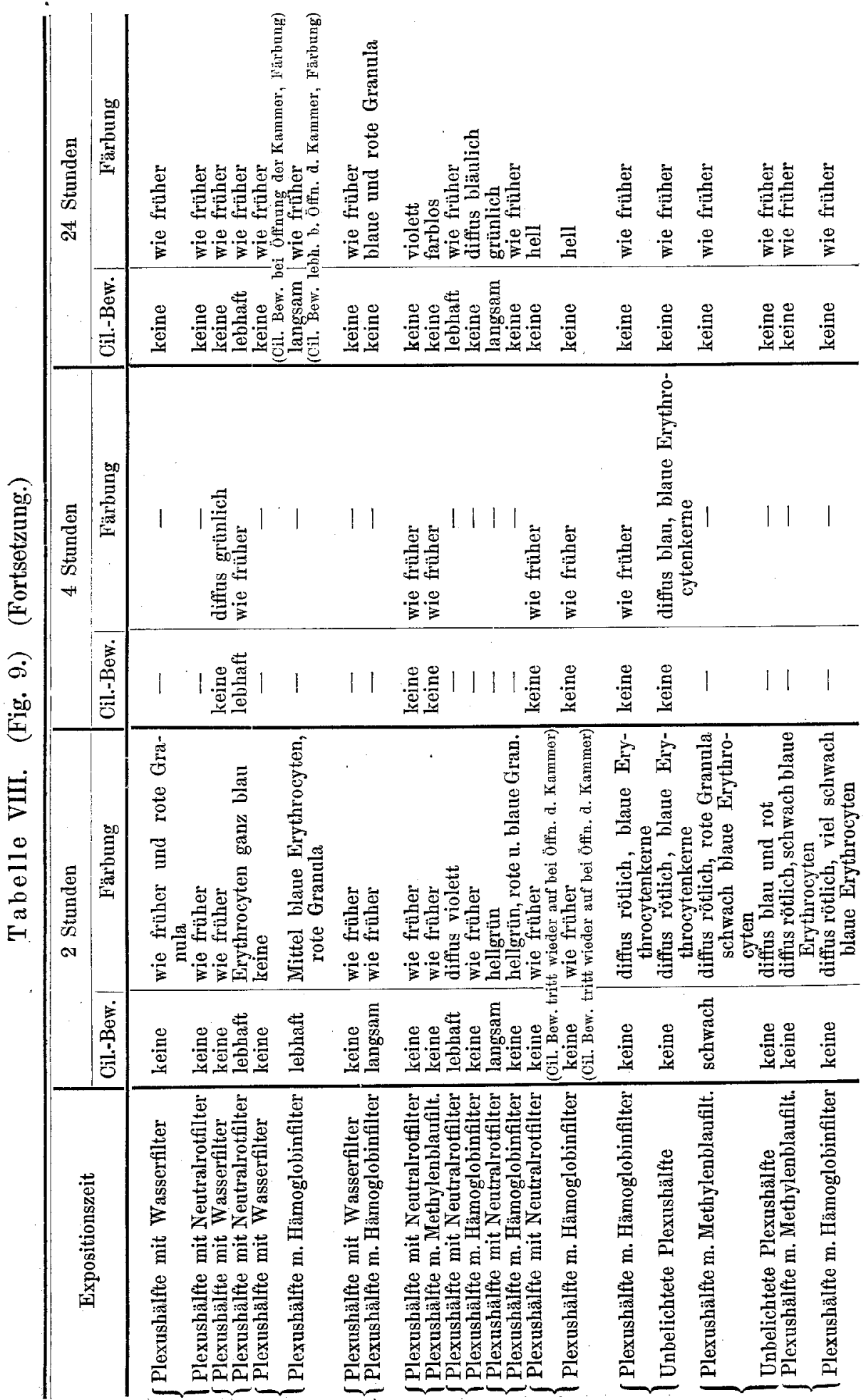


Während bei reiner Lichtwirkung nach 24 Stunden die meisten Präparate entweder ganz hell oder nur leicht diffus grünlich gefärbt sind, ist bei jeder Lichtfiltration noch eine deutliche Granulaoder Erythrocytentinktion zu unterseheiden; ebenso dauert auch die Cilienbewegung in der Regel länger. Ferner ergibt sich bei Vergleich der einzelnen Filter untereinander, dass bei gleicher Schichthöhe und gleicher ursprünglicher Lichtquelle deutlich eine spezifische Intensität des einzelnen Filters konstatiert werden kann, und es lässt sich, geordnet nach der zunehmenden schwächenden Wirkung folgende Reihe aufstellen: Wasserfilter $>$ blau $>$ Hämoglobin $>$ rot $>$ dunkel. Gestützt wird diese Skala nicht nur durch das Färbungsmoment, sondern auch durch die Cilienbewegung; das Verhalten vom Neutralrot- und Blutpräparat, wo bei zutretendem Sauerstoff die Cilienbewegung bei dem stärker gelähmten Blutpräparat wieder auftritt, nicht aber bei dem schwäeher bestrahlten Neutralrotpräparat, ist mehr ein zufälliges zu nennen.

Hier anschliessend möchte ich die Absorptionsspektren der in Betracht fallenden Lösungen kurz folgen lassen. Bestimmt wurden sie durch das übliche Handspektroskop, wie sie im klinischen Betrieb benutzt werden.

Absorptionsstreifen der Froschhämoglobin-

lösung . . . . . . . . . . $\lambda \lambda 800-705,470-400$, Absorptionsstreifen der Neutralrotlösung . $\lambda \lambda 800-705,590-400$, Absorptionsstreifen der Methylenblaulösung $\lambda \lambda 800-545$. Durchgehende Wellenlängen für Blut . . $\lambda \lambda$ 705-590-470, wobei in der Strecke $590-470$ zahlreiche

Linien und leichte Verdunklung . $\lambda \lambda 705-470$, für $\mathrm{N}-\mathrm{r} \quad \lambda \lambda \quad 705-590$, für $\mathrm{M}-\mathrm{b} \quad 2 \lambda 545-400$.

b) Filtration bei doppelter und einfacher Schicht$\mathbf{h}$ ö h e. Bei den einfachen Filterversuchen mit Aqua dest. von Tabelle I konnte ich trotz der verschieden hohen zur Wärmeabsorption benutzten Wassersäulen kaum einẹn Unterschied in der Wirkungsintensität wahrnehmen. Es fragte sich daher, ob sich auch die Farblösungen so, verhalten.

Wenn sich nun auch gegen die der Tabelle IX (S. 322 u. 323) ent. sprechende Versuchsanordnung vor allem einwenden lässt, dass infolge der Verdunstung und der an und für sich nicht absolut genauen Her- 
Tabelle IX.

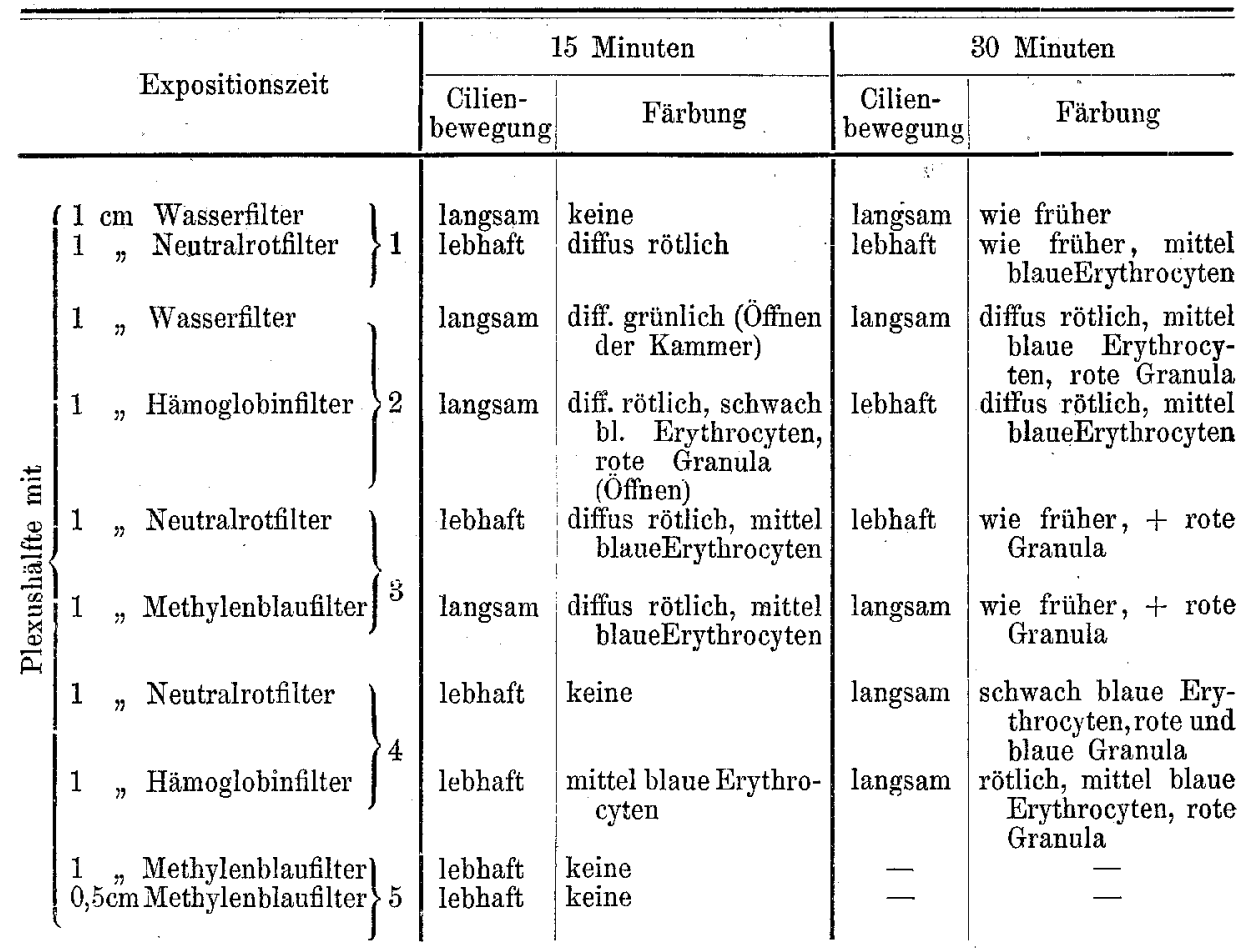

stellung einer bestimmten Schichthöhe die Resultate nicht eine so feine Interpretation erlauben, wie sie meiner Ansicht nach für Tab. VIII immerhin gelten dürfte, so schien mir das Erhaltene doch der Anführung wert; es lässt sich dadurch doch eine gewisse weitere Aufklärung erzielen, die auch praktische Wichtigkeit haben dürfte.

Aus Rubrik 5 ergibt sich, dass die doppelte Filterdichte eine zum mindesten doppelt so grosse Abschwächung zur Folge hat, während die anderen Rubriken keinen solchen Unterschied im Vergleich mit Tabelle VIII erkennen lassen, da heide ungefähr dieselbe Lichtintensität passieren liessen. Rubrik 1 und 2 zeigen ein Verhalten der Hämoglobin- und Neutralrotlösung, die der des Wassers sehr ähnlich ist, während Rubrik 3 wiederum in Parallele zu Rubrik 5 eine deutlich vergrösserte, abschwächende Wirkung des Methylenblaus erkennen lässt, im Gegensatz zu der neutral sich verhaltenden Neutralrotlösung. Es geht daher aus Tabelle VIII hervor, dass unter den in Betracht fallenden Momenten nur das Methylenblau einen der Schichthöhe entsprechend variablen abschwächenden Einfluss besitzt. 
Beiträge zur Frage der oxydativen Leistungen der tierischen Zelle etc. 323

(Fig. 10.)

\begin{tabular}{|c|c|c|c|c|c|}
\hline \multicolumn{2}{|r|}{1 Stunde } & \multicolumn{2}{|r|}{2 Stunden } & \multicolumn{2}{|c|}{24 Stunden } \\
\hline $\begin{array}{c}\text { Cilien- } \\
\text { bewegung }\end{array}$ & Färbung & $\begin{array}{c}\text { Cilien- } \\
\text { bewegung }\end{array}$ & Färbung & $\begin{array}{c}\text { Cilien- } \\
\text { bewegung }\end{array}$ & Färbung \\
\hline $\begin{array}{l}\text { langsam } \\
\text { lebhaft }\end{array}$ & $\begin{array}{l}\text { diffus bläulich } \\
\text { diffus rötlich, ganz } \\
\text { blaueErythrocyten }\end{array}$ & $\begin{array}{l}\text { wiefrüher } \\
\text { wiefrüher }\end{array}$ & $\begin{array}{l}\text { wie früher } \\
\text { wie früher }\end{array}$ & $\begin{array}{l}\text { keine } \\
\text { wiefrüher }\end{array}$ & $\begin{array}{l}\text { diffus grünlich } \\
\text { blaue Erythrocyten, } \\
\text { rote Granula }\end{array}$ \\
\hline keine & $\begin{array}{l}\text { schwach blane Ery- } \\
\text { throcyten }\end{array}$ & keine & keine & keine & keine \\
\hline langsam & $\begin{array}{l}\text { mittel blaue Erythro- } \\
\text { cyten, diffus rötl., } \\
\text { rote u. blaue Gran. }\end{array}$ & keine & wie früher & keine & $\begin{array}{l}\text { blaue Erythrocyten, } \\
\text { rote Granula }\end{array}$ \\
\hline lebhaft & $\begin{array}{l}\text { wie früher, + blaue } \\
\text { Granula }\end{array}$ & langsam & wie früher & wie früher & $\begin{array}{l}\text { mittel blaue Ery- } \\
\text { throcyten zahl- } \\
\text { reich }\end{array}$ \\
\hline keine & wie früher & keine & wie früher & keine & $\begin{array}{l}\text { mittel blaue } \\
\text { throcyten, } \\
\text { Granula }\end{array}$ \\
\hline langsam & $\begin{array}{l}\text { mittel blaue Erythro- } \\
\text { cyten }\end{array}$ & wie früher & $\begin{array}{l}\text { schwach blaue Ery- } \\
\text { throcyten, } \\
\text { Granula }\end{array}$ & wiefrüher & $\begin{array}{l}\text { mittel blaue Ery- } \\
\text { throcyten }\end{array}$ \\
\hline langsam & $\begin{array}{l}\text { mittel blaue Erythro- } \\
\text { cyten, rote Granula }\end{array}$ & wie früher & $\begin{array}{l}\text { mittel blaue Erythro- } \\
\text { cyten, rote und } \\
\text { blaue Granula }\end{array}$ & wiefrüher & $\begin{array}{l}\text { diffus blau, rote } \\
\text { Granula, blaue } \\
\text { Erythrocyten }\end{array}$ \\
\hline - & - & lebhaft & keine & wie früher & wie früher \\
\hline - & - & keine & $\begin{array}{r}\text { diff. rötlich, schwach } \\
\text { blaueErythrocyten }\end{array}$ & wie früher & wie früher \\
\hline
\end{tabular}

Parallel mit dem Plexus wurde auch die Cornea des Frosches auf ihr Verhalten gegen Licht bei Sauerstoffzutritt geprüft.

Es wurde - zu diesem Zwecke vor der Suspension die Nickhaut entfernt. Die Cornea war meist diffus rot oder blau gefärbt und verlor bei Belichtung ihre Tinktion in den meisten Fällen, bot also kein wesentlich anderes Verhalten dar als der Plexus. Ein Unterschied war nur insofern zu konstatieren, dass der Entfärbungsprozess auch bei ganz frischem Präparat immer sehr langsam vor sich ging, ähnlich wie beim toten, tingierten Plexus, so dass die Cornea nicht ein so empfindliches Objekt genannt werden kann wie jener.

\section{Wärmewirkungen.}

Wenn auch in den besprochenen Versuchen der Einfluss der Wärme dureh Herstellung möglichst derselben Temperaturen (wie auch in den folgenden Versuchen) so gut als möglich eliminiert war, so schien es mir doch geboten, noch spezielle Untersuchungen nach dieser Richtung hin anzustellen, um eine eventuelle Fehlerquelle 
aufzudecken, als auch um die Wirkung der Wärme genau zu präzisieren.

$\mathrm{Zu}$ diesem $\mathrm{Zwecke}$ wurden ebenfalls ganze Präparate und halbe im Dunkeln aufbewahrt, unmittelbar nach Entnahme aus dem Körper, die einen, Wärmepräparate, bei Zimmertemperatur von $20^{\circ} \mathrm{C}$, die anderen, Kältepräparate, in einem gleichmässig kühlen Raum von $6^{\circ} \mathrm{C}$. Bei den ersteren war meist schon nach ca. 12 Stunden eine starke Blau- und Rotfärbung der Granula, eine diffuse volle blaue Färbung der Erythrocyten neben leichter diffuser roter oder blauer Färbung des ganzen Präparates aufgetreten bei erhaltener Cilienbewegung. Nach ca. 24 Stunden hatte die Färbungsintensität noch etwas zugenommen, die Cilienbewegung war erloschen.

Bei den Kältepräparaten war nach 24 Stunden eine sehr deutliche intensive Granula- und Erythrocytenfärbung aufgetreten, die Cilienbewegung lebhaft. Dieser Zustand dauerte meist mehrere Tage an, um schliesslich in derselben Weise zu verschwinden wie bei den Wärmepräparaten.

Wurden diese Vorgänge näher verfolgt, so zeigte es sich, dass der Verlauf bei beiden Präparaten sich in derselben Weise abspielte; nur folgten sich die Etappen beim Wärmepräparat rascher.

Bei beiden (wie überhaupt bei vielen Präparaten trotz möglichst aseptischem Verfahren mit sterilen Lösungen und Instrumenten) traten schliesslich, aber stets erst einige Zeit nach Erlöschen der Cilienbewegung, unbewegliche und bewegliche Bakterien, Kurz- und Langstäbchen auf, parallel gehend mit einem körnigen, kaum angedeuteten Verfall des Präparates. Dass der frühere Eintritt des Todes bei den Wärmepräparaten durch diese Bakterien bedingt sein könnte, indem deren Entwicklung bei höherer Temperatur erleichtert war, schien sehr wahrscheinlich. Doch hatte ich nicht den Eindruck, dass diese Mikroorganismen das primäre schädigende Agens seien, weil sie sowohl hier als auch bei vielen anderen Präparaten erst, wie oben bemerkt, nach Eintritt des Todes eintraten und, was noch um so bedeutender ist, auch bei den Kältepräparaten sich in derselben Weise zeigten und entwickelten; die Vermutung lag nahe, anzunehmen, durch das noch lebende Präparat werde ihr Entstehen verhindert. Damit aber würden sie für die zugrunde liegende Frage ausser Betracht fallen und wären eine Sekundärerscheinung, die die zutage getretene Bedeutung der Wärme weiterhin stützen würden. Anhangsweise sei noch erwähnt, dass bei den dem vollen Licht 
Beiträge zur Frage der oxydativen Leistungen der tierischen Zelle etc. 325

exponierten Präparaten diese Bakterien häufig fehlten oder nur spärlich sich entwickelten.

\section{Die Wirkung der Photoaktivität.}

Da es sich bei diesen Untersuchungen nur um sehr feine Unterschiede der Intensitäten handeln konnte, wurden jeweils nur Plexushälften in Vergleich gezogen. Das Prinzip der Methode bestand darin, dass zwei völlig identische Hälften in der üblichen Weise im hängenden Tropfen im Dunkeln (dichte Kästchen aus schwarzem Mattpapier in einer dichten Pappschachtel) aufbewahrt wurden. Auf das eine Deckgläschen wurde die zu prüfende photoaktive Substanz gelegt und in Pausen Vergleiche vorgenommen. In den meisten Fällen wurde die photoaktive Substanz gleichzeitig durch Exposition der photographischen Platte auf ihren Wert geprüft. In Tabelle X bedeutet + positive Platte, - negative. Die Resultate bei dem Plexus zweier Tiere sind wegen der individuellen Schwankungen nicht so sicher wie bei den Plexushälften desselben Tieres.

A. Versuche mit Fröschen (Rana temporaria und esculenta), die ohne bestimmte Vorbehandlung während der Suspension mit einem $\mathrm{Tu} c \mathrm{he} u \mathrm{mh} u ̈ l l t$ wurden und meist $z i \mathrm{em}$ lich frisch eingefangene Exemplare waren.

I. Versuche mit Froschblut (Rana temp. und esculenta) als photoaktive Substanz.

a) Unbelichtetes Froschblut wurde direkt aus einer Art. ophthalmica entleert, auf ein gereinigtes Deckgläschen in stets ungefähr derselben Menge getropft und bis zum Beginn des Versuches jeweils im Dunkeln aufbewahrt. Eine Auswahl der Ergebnisse findet sich in Tabelle X (Fig. 11) zusammengestellt. Es ergibt sich, dass schon nach Verlauf von 3-4 Stunden nach Beginn der Exposition im Dunkeln zwei im Anfang völlig gleiche Plexushälften sich sowohl in der Intensität der Cilienbewegung als auch der Färbung verschieden verhalten. Das Blutplättchenpräparat zeigt in allen Fällen und in den vielen tabellarisch nicht angeführten sowohl bei photographisch positivem wie negativem Verhalten des Blutes eine schwächere Färbung und lebhaftere Cilienbewegung. Besonders auffallend wird diese Tatsache nach 5-18 Stunden, in dem regelmässig das Blutpräparat oft noch sehr lebhafte Cilienbewegung zeigt, namentlich aber eine bedeutend hellere Tinktion, die oft nicht so leicht sich beschreiben wie beobachten lässt. Häufig sind nicht nur 
V. Schläpfer:

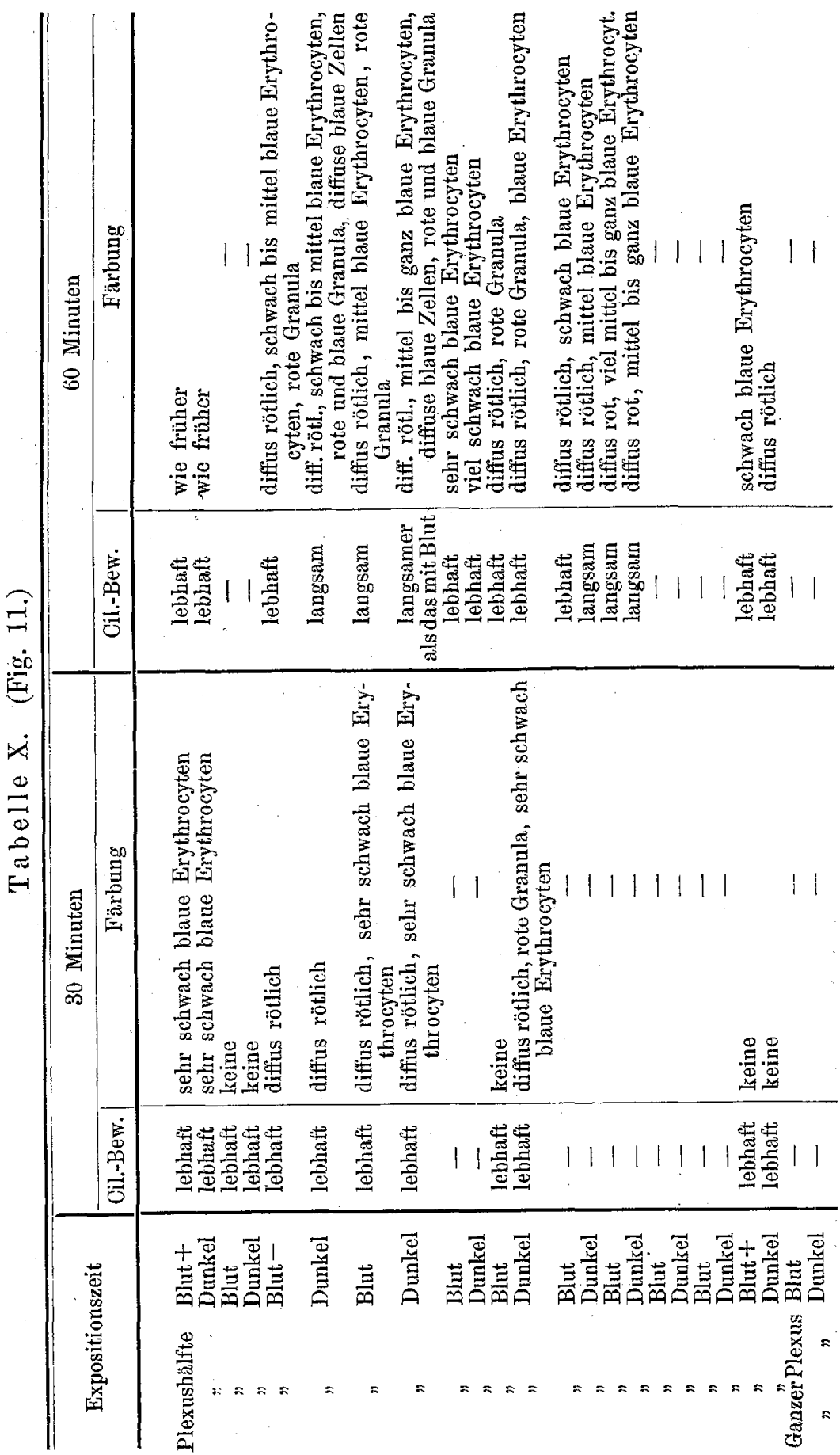


Beiträge zur Frage der oxydativen Leistungen der tierischen Zelle etc. 327

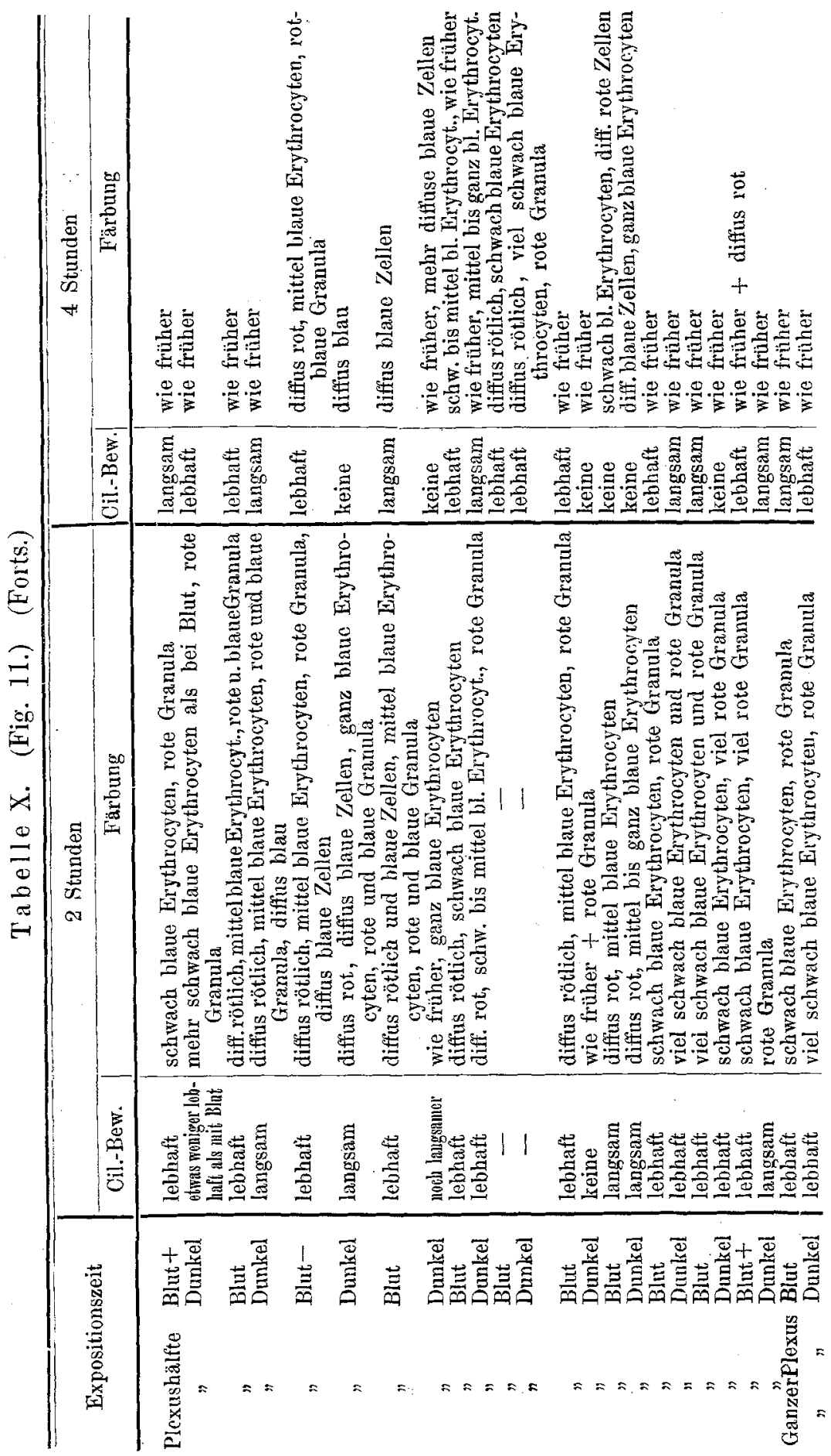


V. Schläpfer:

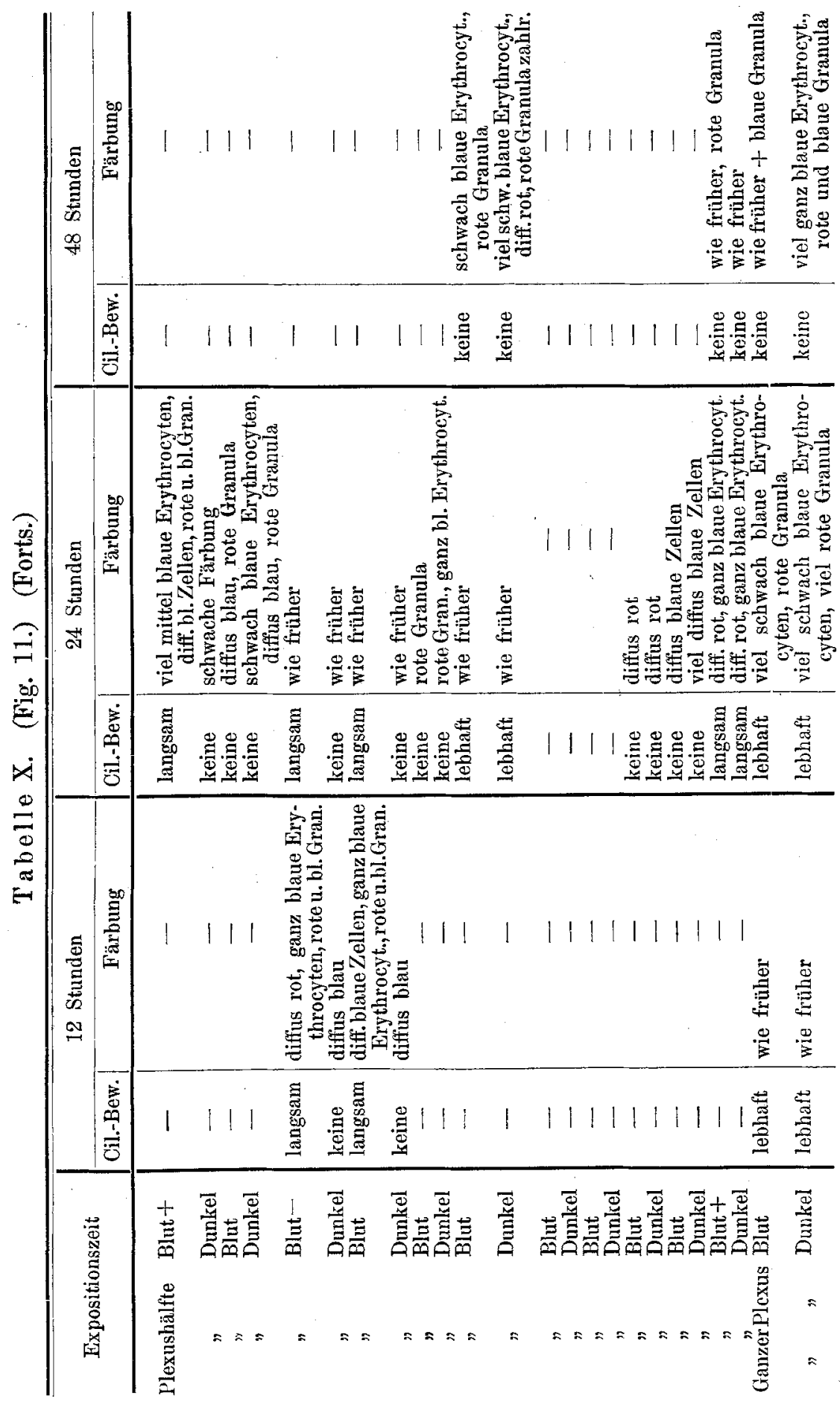


sehr spärliche Granula vorhanden, sondern auch ein relativ viel hellerer, wenig gelblich gefärbter Ton, während das Dunkelpräparat eine ganz ausgesprochene Blau- und Rotfärbung aufweist, oft träge oder keine Cilienbewegung zeigt und das schon besprochene gelblich gekörnte Aussehen angenommen hat.

Fine bei beiden Präparaten auffallende und auch bei den ferneren Versuchen fast überall zutage tretende Erscheinung ist weiterhin die, dass sowohl Färbung als Erlahmung der Cilienbewegung relativ rasch eine grosse Intensität erlangen, um dann wieder zurückzugehen und wiederum einer Periode der Zunahme zu weichen, die alsdann das Vorstadium des Todes ist. Diese, ich möchte fast sagen periodischen Schwankungen sind beim Dunkelpräparat nur angedeutet, finden sich aber sehr ausgesprochen beim Blutpräparat (vgl. später S. 381). Beim Dunkelprăparat zeigen die vitalen Äusserungen eine meist allmähliche, sichtbare Abnahme; beim Blutpräparat geschieht dies mehr ruckweise mit Pausen der Erholung, ein Phänomen, das oft zu Trugschlüssen verleiten könnte und eine lange Beobachtung erforderlich macht (siehe Tab. X Nr. 1 vierte Stunde).

Das am Schlusse der Tabelle angeführte Präparat, von zwei gleichen Fröschen stammend, macht zu dieser Darstellung keine Ausnahme, indem es sich um zwei völlig kongruente Präparate handelt. Da dies aber sich sehr selten erreichen lässt, so war diese Kategorie nicht sehr zu erweitern und dürfte dem angeführten Fall auch keine grosse Beweiskraft zukommen, wenn er auch als Vertreter einer gewissen Serie gelten darf.

b) Belichtetes Fr,oschblut entspricht dem unter a) besprochenen mit dem Unterschiede, dass das Deckgläschen mit Belag einige Stunden der Sonne exponiert wurde, bis es fast völlig oder auch total eingetrocknetes Blut zeigte, oft fast schwarzrot gefärbt. Eine Anzahl der Resultate gibt Tabelle XI. Der Unterschied in der Wirkung gegenüber dem gewöhnlichen Blutpräparat war meist sehr gering. Nicht verfärbte, eben trockene Blutdeckgläschen zeigten häufig eine relativ belebendere Wirkung als reine Blutgläschen, wogegen die stark eingetrockneten in ihrer Intensität hinter den Blutgläschen zurückblieben (siehe Nr. 2). Dem Einfluss auf die photographische Platte scheint auch hier keine deutliche Rolle zugeschrieben werden zu können.

c) Versuche mit Blut von Fröschen, denen vorher ca. 2 Stunden vor dem Entnehmen des Blutes 1 cem 
einer $5 \%$ igen $\mathrm{KClO}_{3}$-Wasserlösung in die grosse Bauchvene injiziert worden war. Der Exitus trat bei dieser Dosis häufig nicht oder erst sehr spät, nach 12-24 Stunden, ein, während eine Dosis von $2 \mathrm{cem}$ sehr rasch, nach $1 / 2-1$ Stunde, zum Tode führte, zu einer Art Totenstarre, bei der die hinteren Extremitäten starr ausgestreckt blieben.

Das 2 Stunden nach der Einspritzung gewonnene Blut wurde ebenfalls auf ein Deckgläschen getropft (siebe Tab. XII Fig. 13) und mit dem Blut verglichen. Es trat bei einwandfreien Präparaten jedesmal ein gegenüber dem Blutpräparat deutlich veränderter $\mathrm{Ab}$ lauf der Erscheinungen ein. Die Cilienbewegung zeigte häufig nach Verlauf von 2-3 Stunden eine gegenüber dem Blutpräparat deutliche Verlangsamung, um nach 8-10 Stunden regelmässig wieder an Intensität zu gewinnen und in der Regel länger anzudauern als im Blutpräparat. Ebenso blieb auch die Färbung an Intensität gegenüber dem Blutpräparat zurück. Die schon angedeutete Periodizität gewann bei dem $\mathrm{KClO}_{3}$-Blutpräparat den deutlichsten Ausdruck.

Mit $1 \mathrm{ccm} \mathrm{KClO}_{3}$-Lösung behandelte Tiere zeigten in ihrem Verhalten nach der Suspension keine wesentliche Änderung; ebenso war bei ihnen der Einfluss der Blutexposition deutlich wahrzunehmen.

d) Versuche mit eigenem und fremdem Blute, d. h. von anderen Fröschen stammend, aber derselben Spezies (siehe Tab. XIII Abschnitt II). Aus den angeführten und zahlreichen anderen Versuchen lässt sich kein deutlicher Einfluss erkennen von eigenem Blut gegenüber fremdem. Ein Unterschied ergibt sich dagegen, wenn man Blut zweier Spezies, Rana temporaria und esculenta, nimmt.

e) Versuche mit Blut zweier Arten. Rana temporaria und esculenta. Aus Tabelle XIII (II und III) ergibt sich, dass das Blutdeckgläschen mit Blut von Rana esculenta die Cilienbewegung eher anzuregen und die Färbung hintanzuhalten vermag gegenüber dem mit Blut von Rana temporaria. Dieser Einfluss zeigt sich sowohl bei Plexus von Rana temporaria als von Rana esculenta. Das Verhalten erinnert an die Wirkung von $\mathrm{KClO}_{3}$-Blut. Nur ist die Periodizität schwach wahrnehmbar. 
Beiträge zur Frage der oxydativen Leistungen der tierischen Zelle etc. 331

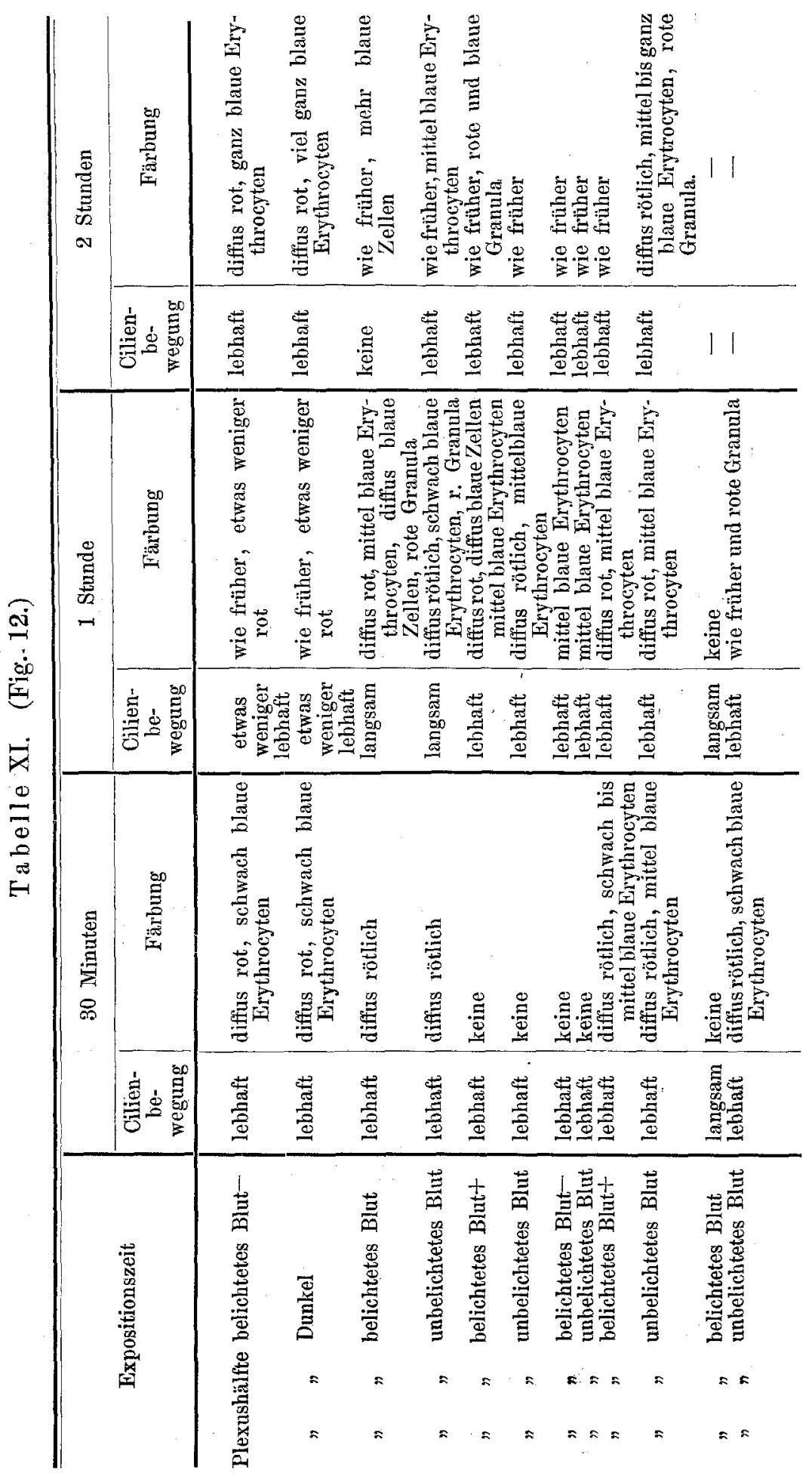


V. Schläpfer:

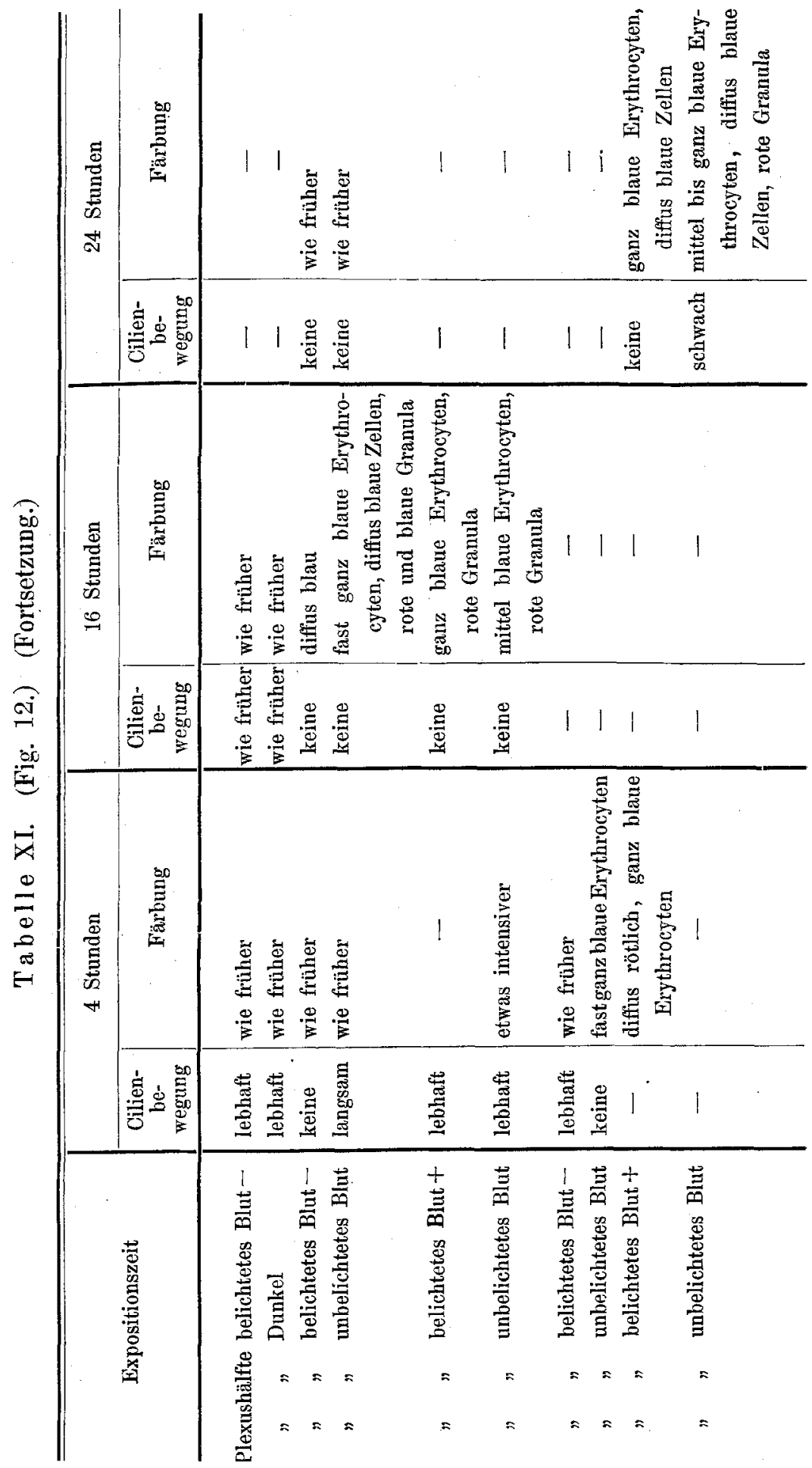


Beiträge zur Frage der oxydativen Leistungen der tierischen Zelle etc. 333

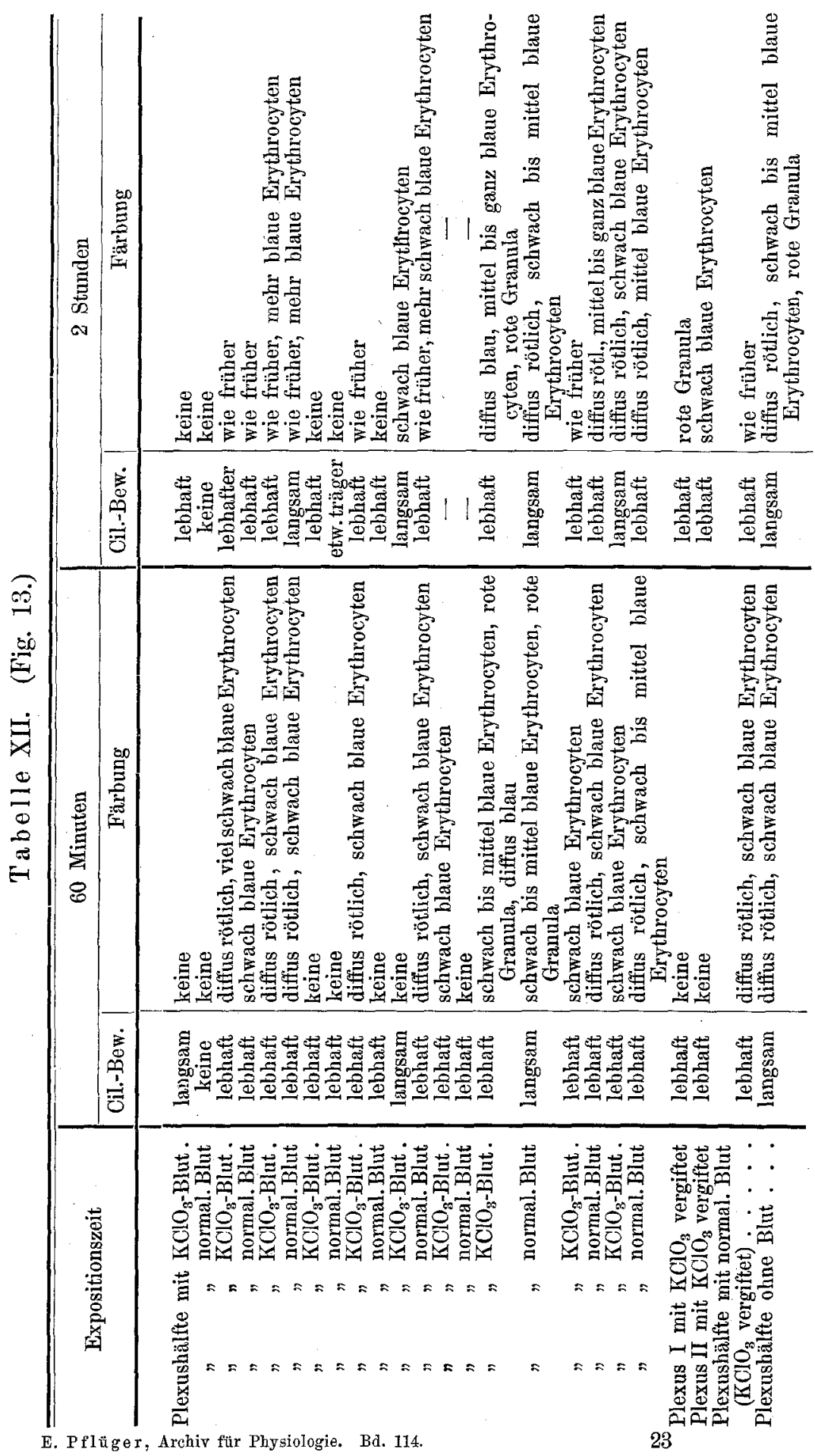


V. Schläpfer.

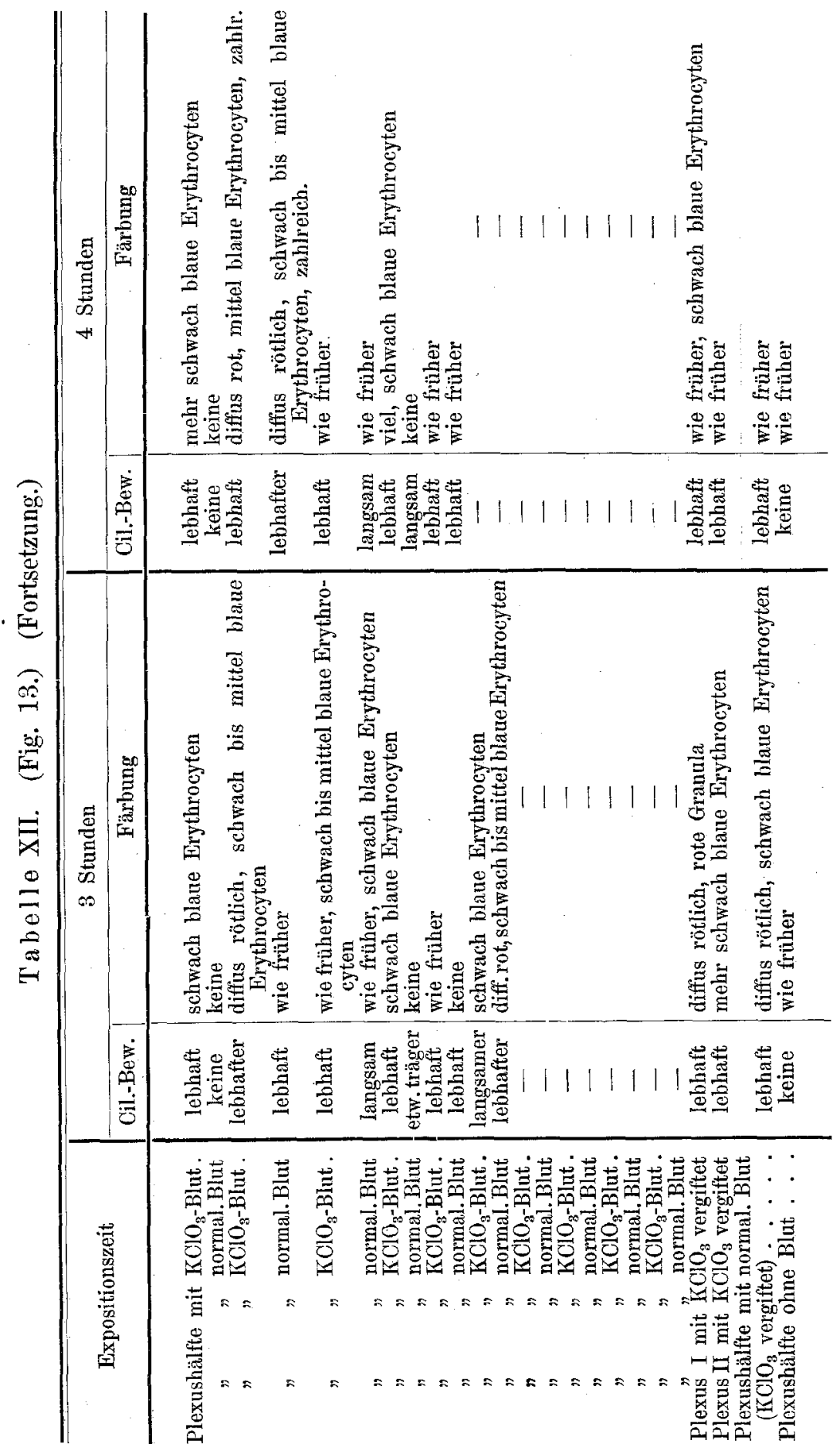




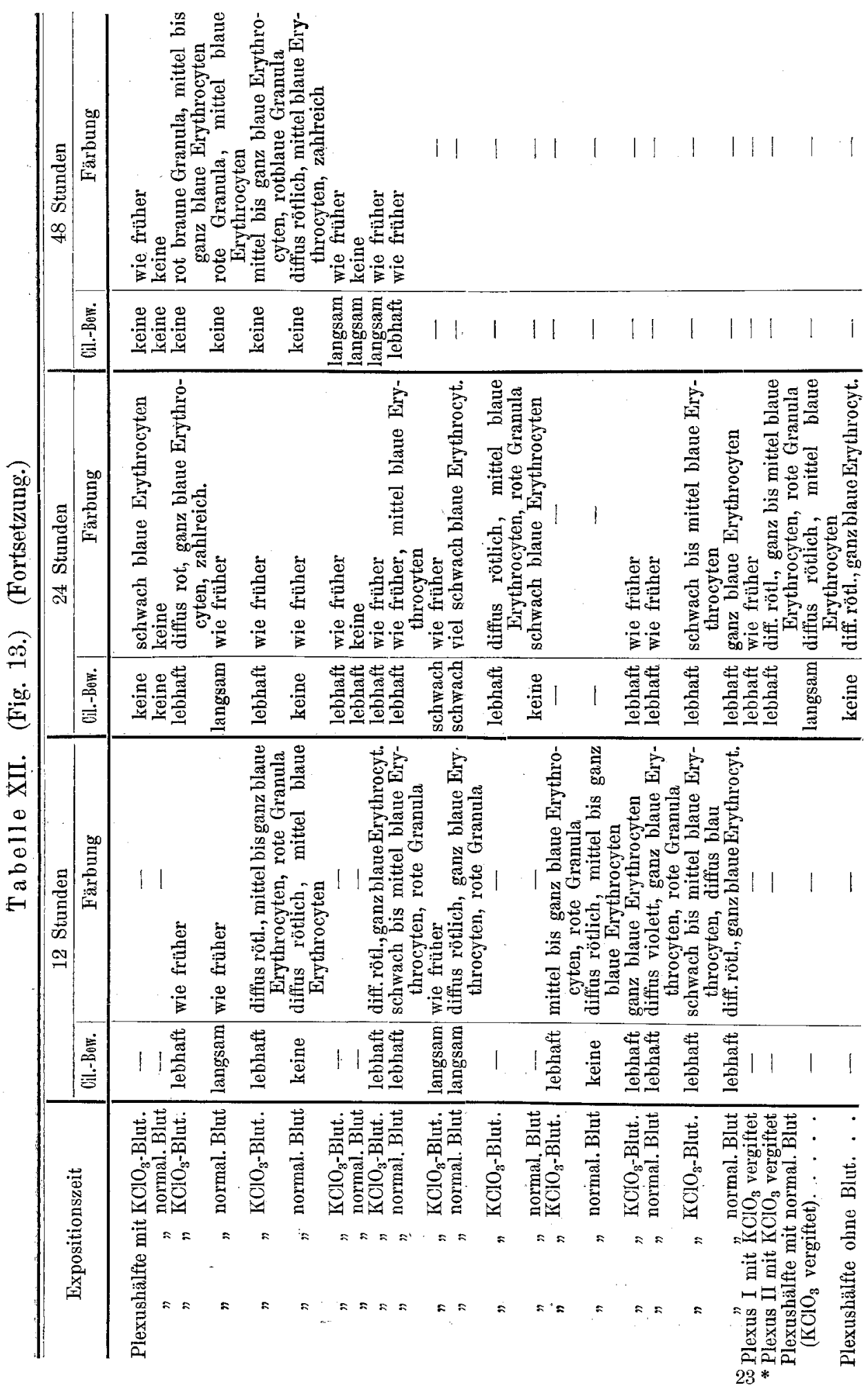


Tabelle XIII.

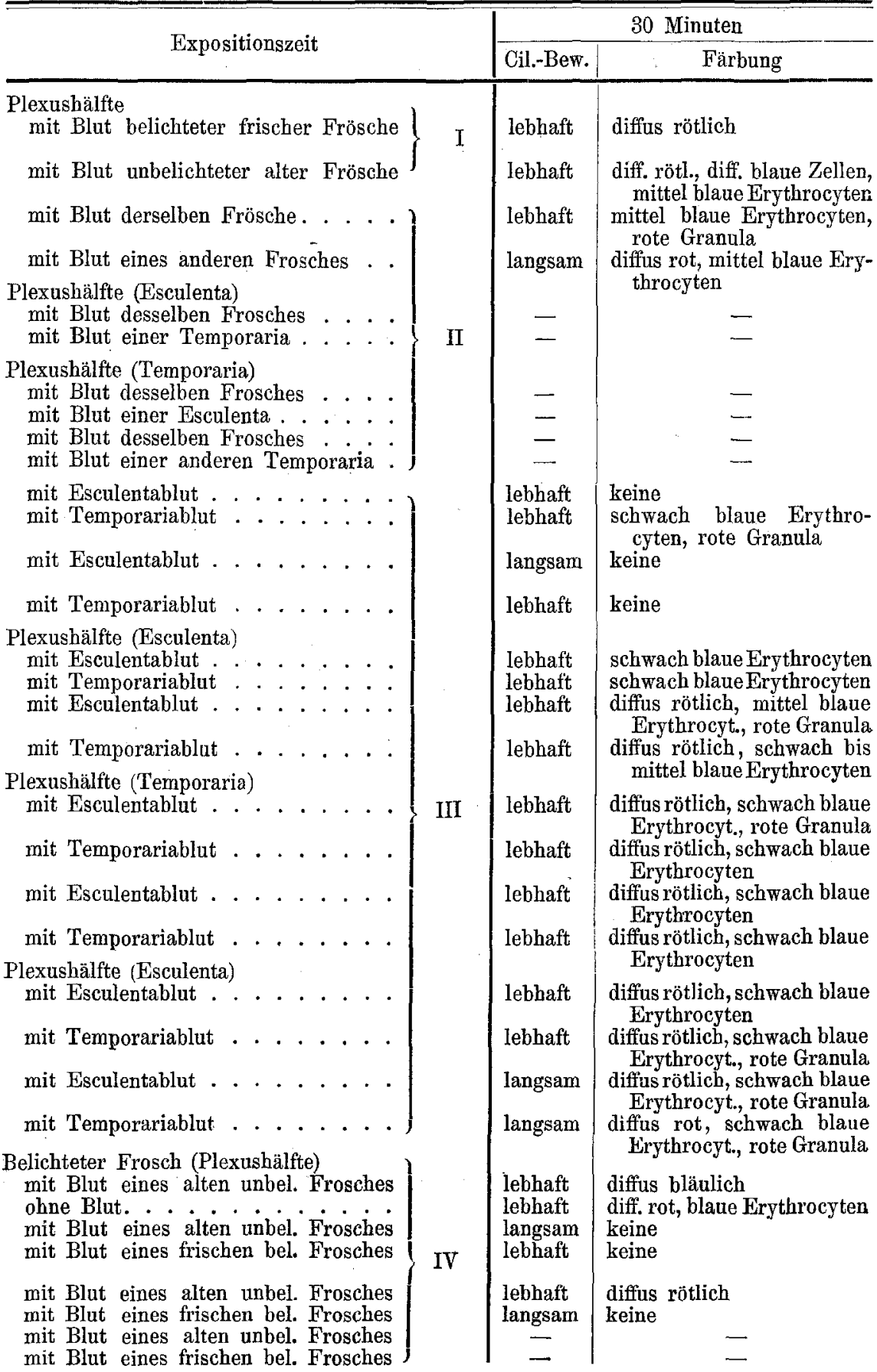


Beiträge zur Frage der oxydativen Leistungen der tierischen Zelle etc. 337

(Fig. 14.)

\begin{tabular}{|c|c|c|c|}
\hline \multicolumn{2}{|r|}{1 Stunde } & \multicolumn{2}{|r|}{2 Stunden } \\
\hline Cil.-Bew. & Färbung & Cil.-Bew. & Färbung \\
\hline lebhaft & $\begin{array}{l}\text { diffus rötlich, mittel blane Ery- } \\
\text { throcyten, rote Granula }\end{array}$ & - & - \\
\hline lebhaft & $\begin{array}{l}\text { wie früber, ganz blaue Ery- } \\
\text { throcyten }\end{array}$ & - & - \\
\hline-- & - & keine & wie früher \\
\hline- & - & langsam & wie früher \\
\hline- & - & - & 一 \\
\hline - & - & 一 & 一 \\
\hline - & - & - & - \\
\hline - & - & - & - \\
\hline - & - & 一 & - \\
\hline- & - & 一 & - \\
\hline $\begin{array}{l}\text { lebhaft } \\
\text { lebhaft }\end{array}$ & $\begin{array}{l}\text { keine } \\
\text { mehr schwach blaue Erythro- } \\
\text { cyten und mehr rote Granula }\end{array}$ & $\begin{array}{l}\text { lebhaft } \\
\text { langsam }\end{array}$ & $\begin{array}{l}\text { rote Granula } \\
\text { wie früher, rote und blaue } \\
\text { Granula }\end{array}$ \\
\hline lebhaft & schwach blaue Erythrocyten & lebhaft & $\begin{array}{l}\text { diffus rötlich, schwach blaue } \\
\text { Erythrocyten, rote Granula }\end{array}$ \\
\hline langsam & diff. rötl., schw. bl. Erythrocyt. & langsam & diff. rötl., schw. bl. Erythrocyten \\
\hline lebhaft & wie früher & Iebhaft & wie früber \\
\hline lebhaft & wie früher & langsam & mittel bl. Erythrocyt, diff. rötl. \\
\hline lebhaft & $\begin{array}{l}\text { diff. rötl., mittel bl. Erythrocyt., } \\
\text { rote Granula, diff. bl. Zellen }\end{array}$ & lebhaft & $\begin{array}{l}\text { diffus rötlich, schwach blaue } \\
\text { Erythrocyten }\end{array}$ \\
\hline lebhaft & wie früher & lebhaft & $\begin{array}{l}\text { diffus rötlich, viel schwach } \\
\text { blaue Erythrocyten }\end{array}$ \\
\hline- & - & lebhaft & $\begin{array}{l}\text { diff. rötl., viel schw. bl. Erythro- } \\
\text { cyten, rote und blaue Granula }\end{array}$ \\
\hline - & - & lebhaft & $\begin{array}{l}\text { wie früher + rote und blane } \\
\text { Granula }\end{array}$ \\
\hline- & - & lebhaft & wie früher \\
\hline- & - & lebhaft & $\begin{array}{l}\text { wie früher, schwach bis mittel } \\
\text { blaue Erythrocyten }\end{array}$ \\
\hline - & - & Iebhaft & $\begin{array}{l}\text { diffus rötlich, schwach blaue } \\
\text { Erythrocyten }\end{array}$ \\
\hline - & - & lebhaft & $\begin{array}{l}\text { diffus rötlich, schwach bis } \\
\text { mittel blaue Erythrocyten }\end{array}$ \\
\hline- & - & langsam & $\begin{array}{l}\text { diffus rot, schwach bis mittel } \\
\text { blaue Erythrocyten }\end{array}$ \\
\hline- & - & keine & $\begin{array}{l}\text { diffus rot, mittel blaue Ery- } \\
\text { throcyten }\end{array}$ \\
\hline keine & wie früher & keine & wie frü \\
\hline langsam & wie früher & langsam & diffus blaurot \\
\hline $\begin{array}{l}\text { langsam } \\
\text { lebhaft }\end{array}$ & $\begin{array}{l}\text { schwach blaue Erythrocyten } \\
\text { diffus rötlich, schwach blaue } \\
\text { Erythrocyten, rote Granula }\end{array}$ & $\begin{array}{l}\text { langsam } \\
\text { lebhaft }\end{array}$ & $\begin{array}{l}\text { schwach blaue Erythrocyten } \\
\text { diffus rötlich, schwach blaue } \\
\text { Erythrocyten, rote Granula }\end{array}$ \\
\hline $\begin{array}{l}\text { langsam } \\
\text { lebhaft }\end{array}$ & $\begin{array}{l}\text { diff. rötl., schw. bl. Erythrocyt. } \\
\text { diffus rot }\end{array}$ & $\begin{array}{l}\text { langsam } \\
\text { lebhaft }\end{array}$ & $\begin{array}{l}\text { schw, bl. Erythrocyt, diff. rötl. } \\
\text { diffus rot }\end{array}$ \\
\hline $\begin{array}{l}\text { langsam } \\
\text { langsam }\end{array}$ & $\begin{array}{l}\text { diff. rötl., mitt. bl. Erythrocyten } \\
\text { diff. rot, mitt. bis ganz bl.Erythr. }\end{array}$ & $\begin{array}{l}\text { langsam } \\
\text { langsam }\end{array}$ & $\begin{array}{l}\text { diff. rötl., m. bis ganz bl. Erythr. } \\
\text { diff. rot, mitt. bis ganz bl. Erythr. }\end{array}$ \\
\hline
\end{tabular}


Tabelle XIII.

\begin{tabular}{|c|c|c|c|}
\hline \multirow{2}{*}{\multicolumn{2}{|c|}{ Expositionszeit }} & \multicolumn{2}{|r|}{8 Stunden } \\
\hline & & Cil.-Bew. & Färbung \\
\hline $\begin{array}{l}\text { Plexushälfte } \\
\text { mit Blut belichteter frischer Frösche } \\
\text { mit Blut unbelichteter alter Frösche }\end{array}$ & I & - & - \\
\hline $\begin{array}{l}\text { mit Blut derselben Frösche. } \\
\text { mit Blut eines anderen Frosches } .\end{array}$ & & - & - \\
\hline $\begin{array}{l}\text { Plexushälfte (Esculenta) } \\
\text { mit Blut desselben Frosches . . . . }\end{array}$ & & - & - \\
\hline mit Blut einer Temporaria . . . . & II & - & - \\
\hline $\begin{array}{l}\text { Plexushälfte (Temporaria) } \\
\text { mit Blut desselben Frosches . . . . } \\
\text { mit Blut einer Esculenta. . . . . . }\end{array}$ & 11 & - & - \\
\hline mit Blut desselben Frosches . . . & & - & - \\
\hline mit Blut einer anderen Temporaria . & & - & - \\
\hline 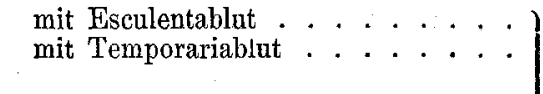 & . & $\begin{array}{l}\text { lebhaft } \\
\text { langsam }\end{array}$ & $\begin{array}{l}\text { wie früher } \\
\text { rote und blaue Granula, ganz } \\
\text { blaue Erythrocyten }\end{array}$ \\
\hline 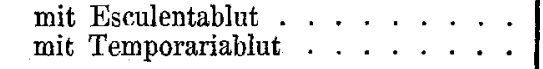 & & - & - \\
\hline 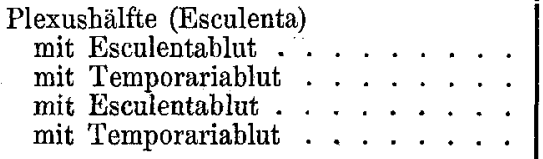 & & $\begin{array}{l}- \\
- \\
-\end{array}$ & E \\
\hline $\begin{array}{l}\text { Plexushälfte (Temporaria) } \\
\text { mit Esculentablut . . . . . . }\end{array}$ & III & 一 & - \\
\hline mit Temporariablut . . . . . . & & - & - \\
\hline 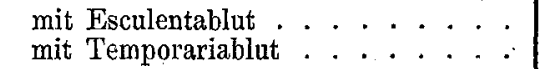 & & - & - \\
\hline $\begin{array}{l}\text { Plexushälfte (Esculenta) } \\
\text { mit Esculentablut } . \ldots . . .\end{array}$ & & - & - \\
\hline mit Temporariablut . . . . . & & - & - \\
\hline mit Esculentablut $\ldots \ldots \ldots$ & & 一 & - \\
\hline mit Temporariablut . . . . . & & - & - \\
\hline $\begin{array}{l}\text { Belichteter Frosch (Plexushälfte) } \\
\text { mit Blut eines alten unbel. Frosches } \\
\text { ohne Blut. } \\
\text { mit Blut eines aiten anbel. Frosches } \\
\text { mit Blut eines frischen bel. Frosches }\end{array}$ & & $\begin{array}{l}- \\
- \\
-\end{array}$ & $\bar{z}$ \\
\hline $\begin{array}{l}\text { mit Blut eines alten unbel. Frosches } \\
\text { mit Blut eines frischen bel. Frosches }\end{array}$ & & - & - \\
\hline $\begin{array}{l}\text { mit Blut eines alten unbel. Frosches } \\
\text { mit Blut eines frischen bel. Frosches }\end{array}$ & & - & - \\
\hline
\end{tabular}


Beiträge zur Frage der oxydativen Leistungen der tierischen Zelle etc. 339

(Fig. 14.) (Fortsetzung.)

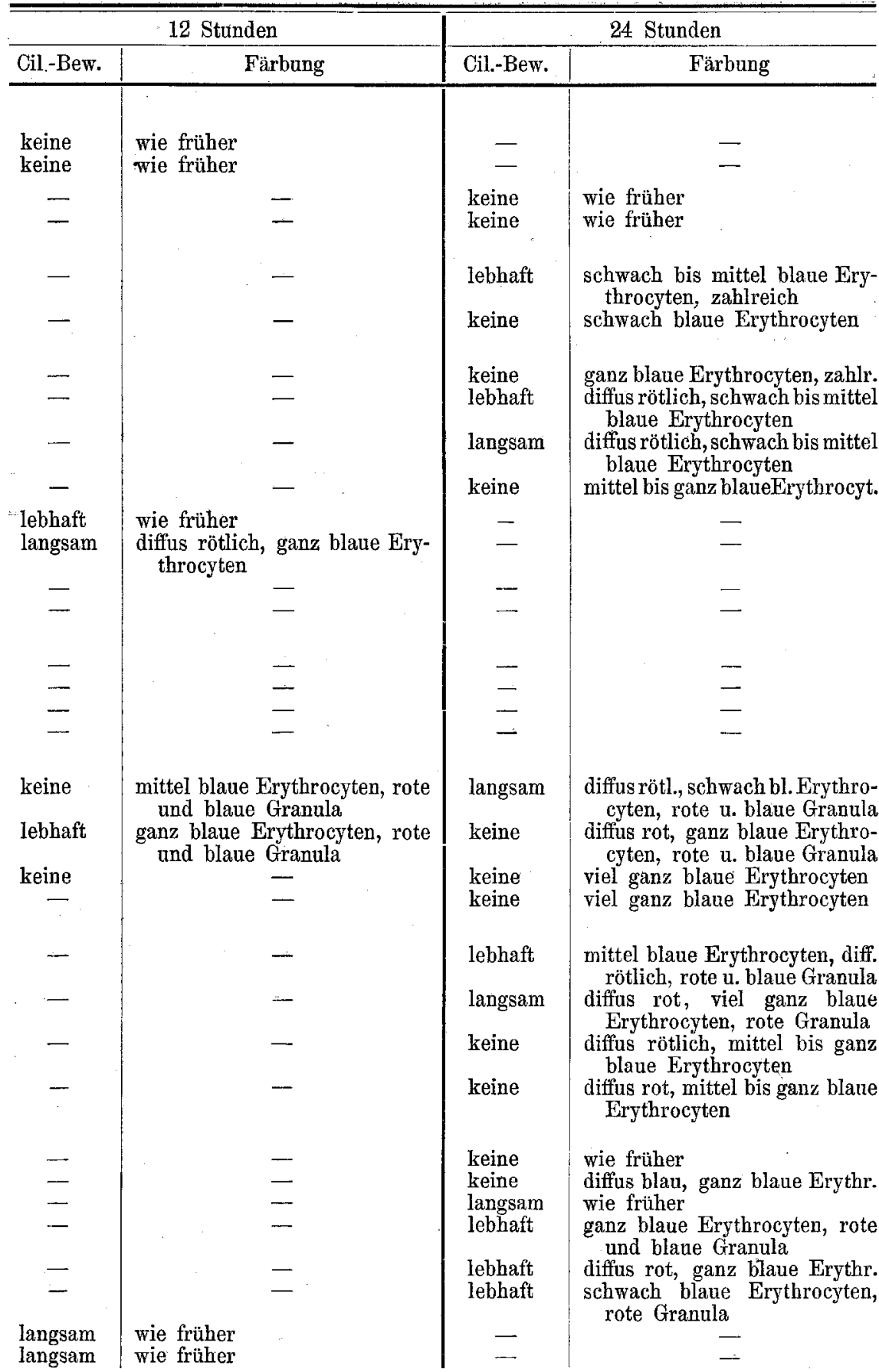


Tabelle XIII.

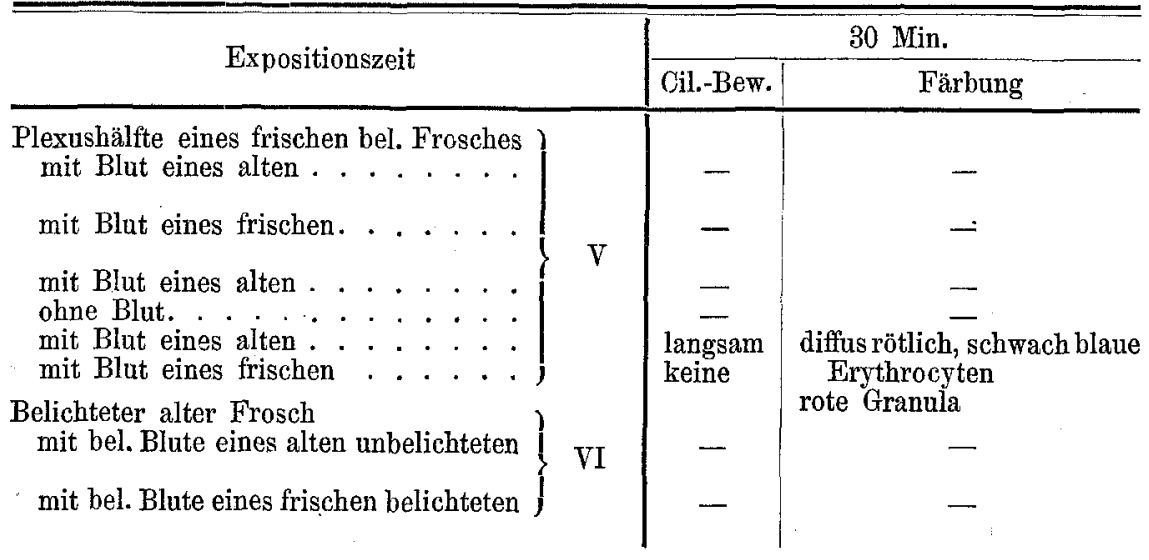

\begin{tabular}{|c|c|c|c|}
\hline \multirow{2}{*}{\multicolumn{2}{|c|}{ Expositionszeit }} & \multicolumn{2}{|c|}{3 Stunden } \\
\hline & & Cil.-Bew. & Färbung \\
\hline $\begin{array}{l}\text { Plexushälfte eines frischen bel. Frosches } \\
\text { mit Blut eines alten ....... } \\
\text { mit Blut eines frischen. . . . . }\end{array}$ & & 二 & $\overline{-}$ \\
\hline $\begin{array}{l}\text { mit Blut eines alten } \\
\text { ohne Blut. . . . . } \\
\text { mit Blut eines alten }\end{array}$ & V & $\underline{-}$ & $\underline{-}$ \\
\hline mit Blut eines frischen. . & & - & - \\
\hline $\left.\begin{array}{l}\text { Belichteter alter Frosch } \\
\text { mit bel. Blute eines alten unbelichteten } \\
\text { mit bel. Blute eines frischen belichteten }\end{array}\right\}$ & VI & - & - \\
\hline
\end{tabular}

II. Versuche mit Menschenblut, das in der früber beschriebenen Weise gewonnen wurde, auf Deckgläschen aufbewahrt. Aus Tabelle XIV (Fig. 15) und aus anderen Versuchen liess sich kein sicheres Urteil gewinnen über die Wirksamkeit von Menschenblut. Im Vergleich mit dem blutfreien Präparat war meist eine Verlängerung der Flimmerdauer und geringere Färbung vorhanden, und darf dieser Einfluss als ziemlich sicher angenommen werden. Die Stellung gegenüber dem Präparat mit Froschblut aber liess sich nicht scharf präzisieren, da die Unterschiede nicht ausserhalb der eo ipso vorhandenen Fehlergrenzen lagen.

III. Versuche mit Stanniol-, Papier- und Terpentinheftpflaster siehe Tabelle XV (Fig. 16). Auch hier war es sehr schwer, zu einem einwandfreien Schlusse zu gelangen. Eine dem Blute ähnliche Wirkung war beim Stanniol zu beobachten, während 
Beiträge zur Frage der oxydativen Leistungen der tierischen Zelle etc. 341

(Fig. 14.) (Fortsetzung.)

\begin{tabular}{|c|c|c|c|}
\hline \multicolumn{2}{|c|}{1 Stunde } & \multicolumn{2}{|r|}{2 Stunden } \\
\hline Cil.-Bew. & Färbung & Cil.-Bew. & Färbung \\
\hline lebhaft & $\begin{array}{l}\text { diffus blaurot, mittel bis ganz } \\
\text { blane Erythrocyten }\end{array}$ & lebhaft & wie früher \\
\hline lebhaft & $\begin{array}{l}\text { diffus rötlich, schwach bis } \\
\text { mittel blaue Erythrocyten }\end{array}$ & lebhaft & $\begin{array}{l}\text { diffus rot, mittel blaue Ery- } \\
\text { throcyten, rote Granula }\end{array}$ \\
\hline lebhaft & diffus rot & langsam & wie früher \\
\hline $\begin{array}{l}\text { keine } \\
\text { keine }\end{array}$ & $\begin{array}{l}\text { diffus rot } \\
\text { wie früher }\end{array}$ & keine & wie früher \\
\hline keine & $\begin{array}{l}\text { schwach blaue Erythrocyten, } \\
\text { diffus blaue Zellen }\end{array}$ & - & - \\
\hline langsam & $\begin{array}{l}\text { diffus rot, schwach blaue Ery- } \\
\text { throcyten, rote Granula }\end{array}$ & langsam & wie früher \\
\hline langsam & $\begin{array}{l}\text { diffus rötlich, schwach blaue } \\
\text { Erythrocyten, rote Granula }\end{array}$ & langsam & wie früher \\
\hline
\end{tabular}

\begin{tabular}{|c|c|c|c|}
\hline \multicolumn{2}{|r|}{12 Stunden } & \multicolumn{2}{|r|}{24 Stunden } \\
\hline Cil.-Bew. & Färbung & Cil.-Bew. & Färbung \\
\hline $\begin{array}{l}\text { langsam } \\
\text { keine }\end{array}$ & $\begin{array}{l}\text { diffus blau } \\
\text { ganz blaue Erythrocyten, rote } \\
\text { und blane Granula }\end{array}$ & - & - \\
\hline - & - & langsam & wie früher \\
\hline - & - & keine & $\begin{array}{l}\text { wie früher } \\
\text { mittel blane Ervthrociten, rote }\end{array}$ \\
\hline- & - & keine & $\begin{array}{l}\text { Granula } \\
\text { schwach blaue Erythrocyten, } \\
\text { diffus bĩau Zellen }\end{array}$ \\
\hline- & - & $\begin{array}{l}\text { langsam } \\
\text { langsam }\end{array}$ & $\begin{array}{l}\text { diffus rötl., ganz blaue Erythr. } \\
\text { diffus rötlich, rote und blaue } \\
\text { Granula }\end{array}$ \\
\hline
\end{tabular}

Papier- und Terpentinpflaster keine sicheren Resultate gaben. Das Stanniol war das übliche Blattzinn, wie es zur Konservierung von Nahrungsmitteln, Schokolade usw. verwendet wird; das Papier war weisses Zeichenpapier. Es wurden ca. $1 \mathrm{gcm}$ grosse Stücke ausgeschnitten und, wie das Blut, ohne Deckgläschen aufgelegt, das Terpentinpflaster mit der bestrichenen Seite nach unten.

B. Versuche mit Fröschen, die eben frisch eingefangen wurden, ferner mit schon monatelang im dunkeln Aquarium aufbewahrten Exemplaren.

Die Suspension geschah bei dieser Versuchsserie immer so, dass, wo nichts Spezielles bemerkt ist, die Tiere in einem dichten Kasten aus schwarzem Mattpapier aufgehängt wurden in der gewohnten Zeitdauer. Im übrigen war das Verfahren dasselbe. 


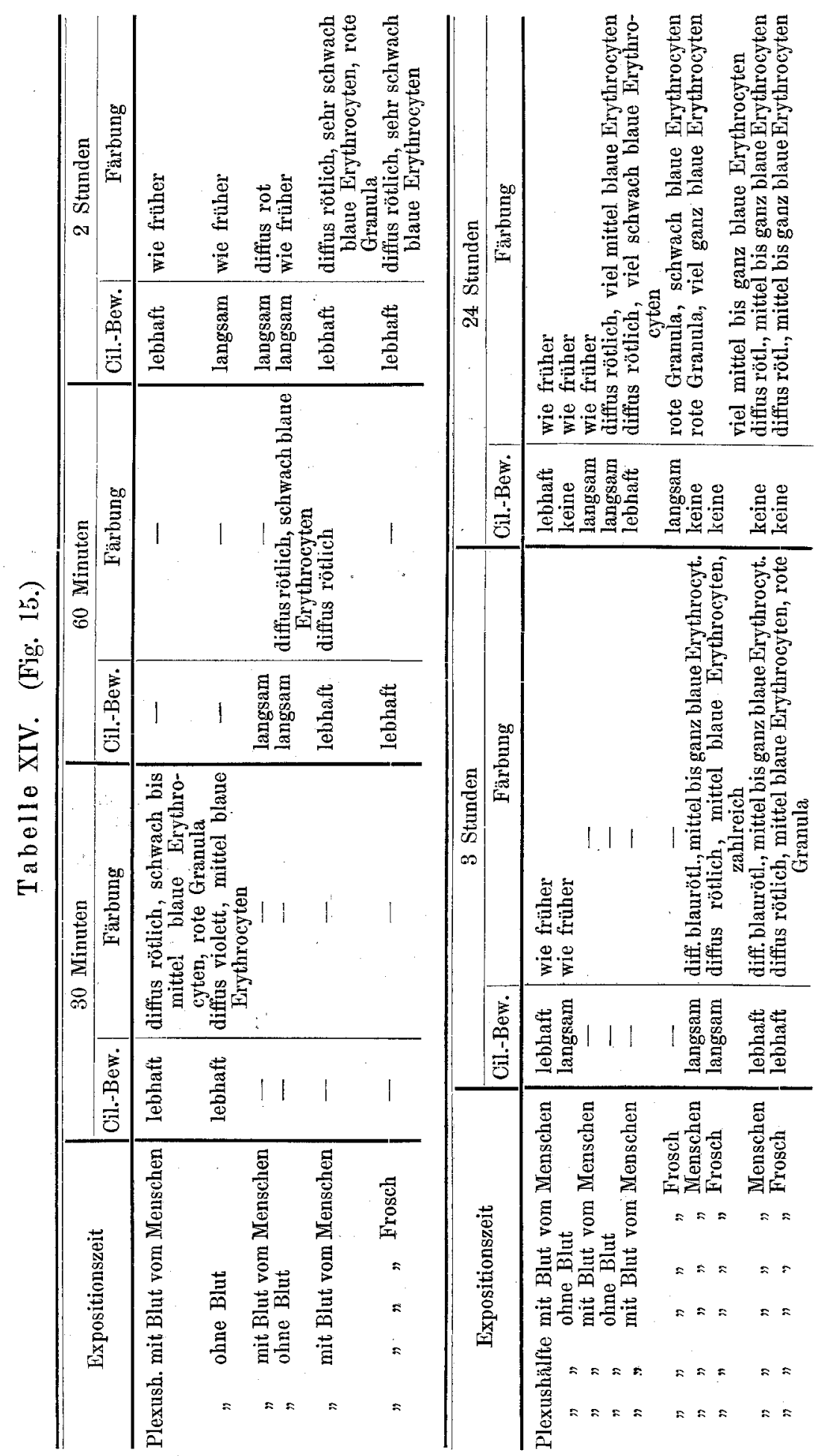


Beiträge zur Frage der oxydativen Leistungen der tierischen Zelle etc. 343

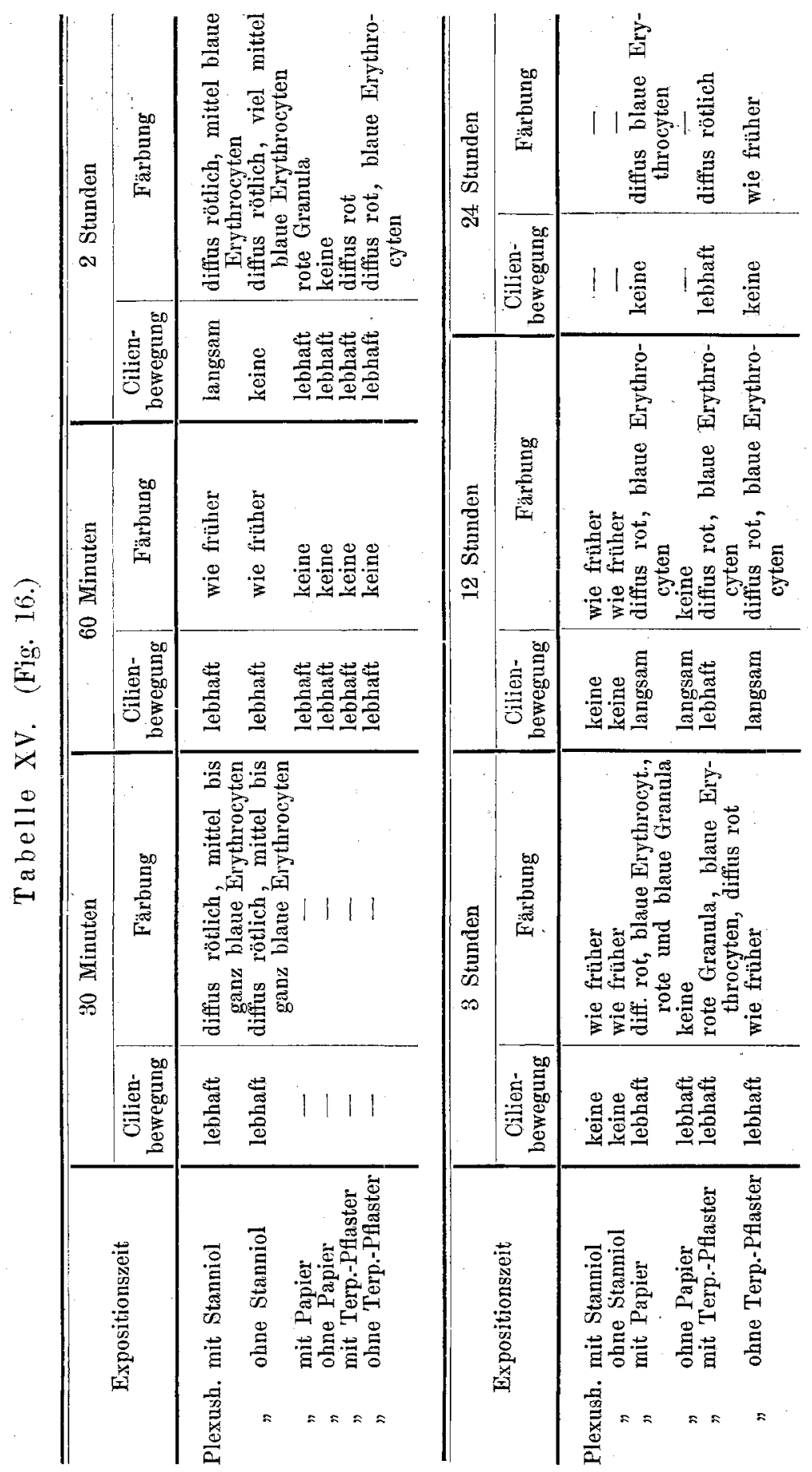


Bevor die speziellen Resultate zu erörtern sind, muss hier noch eine Modifikation angeführt werden, die wegen der spärlichen Zahl von Versuchstieren nur einmal ausgeführt werden konnte; trotzdem daher kein sicheres Ergebnis zu erzielen war, so glaube ich doch, die Versuche anführen zu dürfen, da ich mir weitere Untersuchungen vorbehalten werde.

Anstatt im dunkeln Mattpapierkästchen wurden eine Anzahl Ranae temporariae ausser im Dunkeln auch im vollen Sonnenlichte suspendiert während einer Dauer von je vier Stunden. Durch reichliche Befeuchtung wurde einem Eintrocknen vorgebeugt.

Nach der Entnahme zeigte der Plexus der im Dunkeln suspendirten Tiere in den ersten Stunden eine etwas schwächere Cilienbewegung und stärkere Färbung als der im Lichte suspendierten. In den folgenden zwölf Stunden glich sich jedoch dieser Unterschied vollkommen aus, und ist es bis dato nicht sicher zu eruieren, ob dieses verschiedene Verhalten mehr ein zufälliges genannt werden muss oder nicht.

Dass aber doch ein gewisser Einfluss der während der Suspension vorgenommenen Belichtung zuerkannt werden dürfte, ergibt sich aus dem folgenden.

Während nun im Abschnitt V (Tab. XIII) der Plexus von einem frisch eingefangenen Tiere mit Blut von einem alten, unbelichteten Frosch als Luminiszenzträger eher intensivere Cilienbewegung mit geringerer Färbung aufweist gegenüber dem Plexus mit Blut eines eben eingefangenen Frosches verhalten sich die beiden bei Belichtung gerade umgekehrt. Doch sind auch hier, wie am Beginn bemerkt ist, die Resultate wegen der kleinen Versuchsserie nicht einwandfrei.

Abschnitt VI (Tab. XIII) gibt einen ebenfalls nur beiläufig angeführten Vergleich zwischen belichtet suspendierten, lang aufbewahrten Fröschen.

\section{Besprechung der Ergebnisse.}

Im Gegensatz zur Biologie der Pflanzen hat das Licht in der Biologie der Tiere erst in neuerer Zeit die gebübrende Würdigung gefunden, zuerst wohl durch Pflüger ${ }^{1}$ ), wonach unter Belichtung

1) Jacobson, Über die Wirkung fluoreszierender Stoffe auf Flimmerepithelien. Zeitschr. f. Biol. Bd. 41 S. 444 ff. 1904. 
der Sauerstoffverbrauch und die Kohlensäureproduktion steigen. Durch die Arbeiten von Halberstädter ${ }^{1}$, Hertel ${ }^{2}$ ), Tappeiner ${ }^{8}$ ), Dreyer ${ }^{4}$ ) und Neisser ${ }^{5}$ ) und anderer wurde ferner festgestellt, dass die Wirkungsintensität der Absorption der Strahlen parallel gebe, und dass deshalb die kurzwelligen die grösste Intensität besitzen - eine Tatsache, die $\mathrm{Finsen}{ }^{6}$ ) zuerst in praktische Verwendung brachte. Was die Ursache der stärkeren Absorption kurzwelliger Strahlen ist, dürfte noch unbekannt sein; doch scheint mir eine Beobachtung Koenigsberger's ${ }^{7}$ ) nicht unwesentlich zu sein, wonach der Lichtabsorptionskoeffizient eines Körpers mit Erwärmen gegen das langwellige Spektralende steigt, in Parallele dazu aber das kurzwellige Ende fast spezifisch chemisch, d. h. intramolekular, das rote Ende dagegen intermolekular, d. h. thermisch wirkt, was auf das Molekulargefüge hinweisen könnte unter Berücksichtigung der Lichttheorie von $\mathrm{Maxwe}^{8}{ }^{8}$ ), als der Theorie der Druckwirkung der Ätherwellen.

Das Interesse an der biologischen Bedeutung des Lichtes hat alsdann von neuem eine Steigerung erfahren durch die Wirkung der Röntgen- und Radiumstrahlen und den Einfluss der sogenannten

1) Halberstädter, Mitteilungen über Lichtbehandlung nach Dreyer, Zur Theorie der Sensibilisierung und Prüfung einiger Sensibilisatoren. Münchener medizinische Wochenschrift 1904 S. 608.

2) Hertel, Über physiologische Wirkung von Strahlen verschiedener Wellenlängen. Zeitschr. f. allgem. Physiol. Bd. 5 H. 1. 1905.

3) Tappein er, Beruht die Wirkung der fluoreszierenden Stoffe auf Sensibilisierung? Münchener medizinische Wochenschrift. 1904 S. 714.

4) Straub, Über chemische Vorgänge bei der Einwirkung von Licht auf fluoreszierende Substanzen (Eosin und Chinin) und die Bedeutung dieser Vorgänge für die Giftwirkung. Münchener medizinische Wochenschrift. 1904 S. 1093 .

5) Edlefsen, Experimenteller Beitrag zum Studium der oxydierenden Wirkung fluoreszierender Stoffe. Münchener medizinische Wochenschrift. 1904 Nr. 36.

6) Axmann, Wundbehandlung mittelst ultravioletten Lichts. Münchener medizinische Wochenschrift. Bd. $52 \mathrm{Nr} .36$.

7) Königsberger, Über die Absorption des Lichts in festen Körpern. Habilitationsschrift, Freiburg in Breisgau 1900.

8) Le bedew, Die Druckkräfte der Strahlung. Jahrbuch der Radioaktivität und Elektronik Bd. 2 Heft 3. 1905. - Hasenöhrl, Über den Druck des Lichts. Jahrbuch der Radioaktivität und Elektronik Bd. 2 Heft 3. 1905. 
photodynamischen Stoffe auf lebende Gewebe, die ibre Erklärung darin finden, dass einmal beim Radium die oxydativen Zellprozesse sich wesentlich steigern, nach Werner ${ }^{1}$ ) unter Abspaltung von Cholin, das, weiterhin zersetzend wirkt, nach Sehlachta ${ }^{2}$ ) durch Erhöbung der die Oxydation eo ipso beschleunigenden Alkaleszenz ${ }^{3}$ ), nach Tappeiner ${ }^{4}$ ) bei den photodynamischen Stoffen durch Aufnahme von Sauerstoff und Wiederabgabe desselben unter Aktivierung bei Belichtung an die Gewebe, nach Busck ${ }^{5}$ ) unter Transformierung der längeren Wellen in kurze.

Die eigentlichen, unter dem Einflusse des Lichtes erfolgenden, chemisch-biologischen Prozesse sind demgegenüber nicht als abgeklärt zu nennen. Nach $\mathrm{Bie}^{6}$ ) z. B. soll die Wirkung des Lichtes auf Bakterien von Sauerstoff unabhängig sein, also nicht speziell mit der Zelloxydation zusammenhängen; nach $\mathrm{T}$ appein $\mathrm{r}^{6}$ ) dagegen ist es sehr wahrseheinlich, dass die Gegenwart von Sauerstoff zur biologischen Lichtwirkung unbedingt nötig ist, sei es nun in der Umgebung der Zellen oder in den Zellen selbst unter Annahme eines Sauerstoffdepots, das nach Pfeffer ${ }^{7}$ ) indessen keine unbestrittene Tatsache sein dürtte. Auch $\mathrm{Hertel}^{8}$ ) kommt in seinen Untersuchungen zur Anschauung, dass es vor allem die Oxydationsprozesse sein dürften,

1) Weirner, Zur Kenntnis und Verwertung der Rolle des Lecithins bei der biologischen Wirkung der Radium- und Röntgenstrahlen. Deutsche med. Wochenschr. 1905 H.'2 S. 3.

2) Schlachta, Zur Theorie der biologischen Strahlenwirkung. Münch. med. W ochenschr. 1905 Nr. 26.

3) Loeb, Über die physiologische Wirkung von Alkalien und Säuren in starker Verdünnung. Pflüger's Arch. Bd. 73.

4) Tappeiner, Über die Beteiligung des Sauerstoff's bei der photo'dynamischen Wirkung fluoreszierender Stoffe. Münch. med. Wochenschr. 1904 Nr. 26.

5) Mettler, Experimentelles über die baktericide Wirkung des Lichts auf mit Eosin, Erytbrosin und Fluorescein gefärbte Nährböden S. 51. Inauguraldissert. Zürich 1906.

6) Tappeiner und Jodlbauer, Über die Wirkung des Lichts auf Enzyme in Sauerstoff- und Wasserstoffatmosphäre, verglichen mit der Wirkung der photodynamischen Stoffe. Deutsch. Arch. f. klin. Med. Bd. 85 S. 386 ff. 1905.

7) Pfeffer, Über die lockere Bindung des Sauerstoffs in gewissen Bakterien. Zentralbl. f. Bakteriologie Bd. 2 Abt. 2. 1896.

8) Hertel, Über physiologische Wirkung von Strahlen verschiedener Wellenlänge. Zeitschr. f. allgem. Physiol. Bd. 5 Heft 1, 2. Mitteil. 1905. 


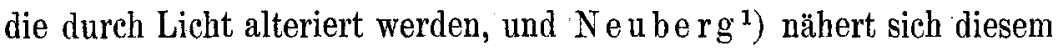
Standpunkt insofern, als er, die Radiumwirkung mit der des Lichtes vergleichend, darunter eine Art Autolyse verstanden wissen will, also einen Abbauprozess, der in der tierischen Zelle sich ja vorwiegend als Oxydation äussert. Die etwas dagegen sprechende Behauptung von Askinass und Caspari ${ }^{2}$ ), wonach Licht die Gewebeatmung schwäche, könnte vielleicht ihre Lösung darin finden, dass, wie unten dargelegt wird, die Lichtquelle sehr intensiv war und zu einem Inanitionstod führte.

Man kann daher wohl den gegenwärtigen Stand der Frage der biologisehen Lichtwirkung dahin definieren:

Die biologische Wirkung des Lichtes ist eine in ihren Einzelheiten noch unbekannte Modifikation der physiologischen oxydativen Zellzersetzung, ähnlich derjenigen der Röntgen- und Radiumstrahlen. Die am stärksten absorbierten kurzwelligen Strahlen wirken am intensivsten.

Eine genauere Präzisierung dieser Definition wird daher nur möglich sein nach weiterer Erkenntnis der bei der Verbrennung in der Zelle sich abspielenden Prozesse.

In der schon oben angeführten Untersuchung über den Bau des Plexus chorioideus des Frosches ${ }^{8}$ ) war es mir nun möglich, mit Benutzung der vitalen Färbungsmethoden einen gewissen Einblick in die sich dort abspielenden Oxydationsprozesse zu gewinnen.

Demnach scheint sich die Zelle zusammenzusetzen aus einer grossen Menge einzelner Eiweisskügelchen, Globoplasten, die von einer lipoiden Hülle umgeben und in einem eiweissartigen Medium zu einem Verband zusammengehalten sind. Dank dem Gesetze der Oberflächenspannung ${ }^{4}$ ) lagert sich nun der Sauerstoff der Atmosphäre an der Grenze von Lipoidhülle und Inhalt und verursacht so, dass

1) Werner, Erworbene Photoaktivität der Gewebe als Faktor der biologischen Strahlenwirkung und ihrer Imitation. Münchn. med. Wochenschr. 1906 S. 3.

2) Askinass und Caspari, Über den Einfluss dissoziirender Strahlen auf organisierte Substanzen usw. Arch. f. d. ges. Physiologie Bd. 86. 1901.

3) Schläpfer, Über den Bau und die Funktion der Epithelzellen des Plexus chor. des Frosches usw. Beiträge zur allg. Pathol. und pathol. Anat. Bd. 7 (Suppl.). Festschrift für A rnold.

4) Quincke, Über periodische Ausbreitung von Flüssigkeitsoberflächen und dadurch hervorgerufene Bewegungserscheinungen. Poggendorf's Annalen der Physik und Chemie Bd. 35 S. 580—642. 1888. 
an seiner Ablagerungsstelle die Oxydationsprozesse sich abspielen, und zwar nicht nur an einzelnen Globoplastenhaufen respektive Zellbezirken, wie $\mathrm{Bach}$ und $\mathrm{Chodat}^{1}$ ) annehmen, sondern, wie es auch bei der hohen vitalen Bedeutung (siehe unten) dieses Prozesses viel wahrscheinlicher erseheint, in der ganzen Zelle an jedem normalen Globoplasten. Die Oxydation spielt sich hierbei in zwei Etappen $a b$, als Oxydation des Plasmas und als Reduktion der bei der Oxydation frei werdenden Spaltprodukte. Diese sind höchstwahrscheinlich sauerstoffreiche und sauerstoffarme Körper, die durch Vermittlung eines Reduktionsfermentes, einer Reduktase ${ }^{2}$ ) den Sauerstoff gegenseitig umtauschen zur Erreichung eines Sauerstoffgleichgewichts. Bei starker Oxydation entstehen intensivere Spaltungen mit relativ mehr, immer sauerstoffärmeren Spaltprodukten, die dureh die spärlichen sauerstoffreichen Produkte nicht gesättigt werden können, weshalb ein Bedürfnis nach Sauerstoff, ein relativ hohes Redụtionsvermögen entsteht, das die vitalen Farbstoffe reduziert. Bei schwacher Oxydation entsteht eine flache Spaltung mit relativ viel, immer sauerstoffreicher werdenden Produkten, die umgekehrt kaum ein Reduktionsvermögen entstehen lassen. Eine starke oder schwache Oxydation tritt je nach reichlich oder spärlich vorhandenem Sauerstoff, d. $h$. relativ hoher oder niedriger Sauerstoffspannung, ein; es wird je nach den Verbältnissen mehr Sauerstoff und mehr Brennmaterial verzehrt, und wenn, wie beim Plexus, das letztere in gegebener Menge vorhanden ist, muss die Dauer der Verbrennung in umgekehrter Beziehung zur Intensität derselben kürzer oder länger ausfallen, wie die kurz dauernde Cilienbewegung bei reichlichem Sauerstoff, die lang dauernde bei beschränktem Sauerstoff zeigt.

Die Dauer lässt sich daher, da der vorhandene Sauerstoffdruck $P$ und der momentan konsumierte $p$ in einem annähernd konstanten Verhältnis stehen, $\frac{P}{p}=k$, und, wie der Versuch zeigt, bei einem gewissen Minimaldruck $P m$ der Prozess stillsteht, auch annähernd ausdrücken in:

$$
t=\frac{P-P}{k}-\frac{P}{k} \text { und } k=\frac{\log P_{1}-\log P_{2}}{t_{2}}
$$

wenn $P_{1}$ der Anfangsdruck ist u. $P_{2}$ der Druck nach der gegebenen Zeit $t_{2}$.

1) $\mathrm{Bach}$ und Chodat, Untersuchungen über die Rolle der Peroxyde in der Chemie der lebenden Zelle. Ber. d. deutsch. chem. Gesellsch. Bd. 35 S. 1275.

2) Eu ler, Zur Kenntnis der Katalasen. Beiträge zur chemischen Physiologie und Pathologie Bd. 7 Heft 1-3. 1905. 
Beiträge zur Frage der oxydativen Leistungen der tierischen Zelle etc. 349

Es erinnert dieser Ausdruck sowie das ganze Verhalten des Prozesses an einen sogenannten fermentativen Vorgang, wie er z. B. in der Zuckerinversion durch Mineralsäuren vorliegt; d. h. es wird, wie die Reduktion durch eine Reduktase, anch die Oxydation durch ein katalysatorisches Prinzip, eine Oxydase, vermittelt, wie es auch $\mathrm{B}$ ach und $\mathrm{Chodat}^{1}$ ) und $\mathrm{Loeb}^{2}$ ) annehmen. Der weitere Mechanismus wäre alsdann der, dass das Lipoid der Hülle gemäss der ihm nach $\mathrm{Czapek}^{3}$ ) zukommenden Eigenschaft, sich mit allen möglichen Stoffen leicht zu binden, ohne dabei seine Individualität eigentlich zu verlieren, mit Produkten des Innenkörpers, des eigentlichen Protoplasmas, sogenannten Seitenketten nach Ehrlich's ${ }^{4}$ ) Anschauung, sich verbinden würde zu einer Lipoid-Plasmaverbindung. Durch die Oxydase wïrde nun eine Verbrennung dieser Verbindung unter Zerfall und spezieller Oxydation der Plasmakomponente zustande kommen. Die Oxydase, über deren Lokalisation, eventuell in der Lipoidhülle, sich natürlich nur Vermutungen aufstellen lassen, könnte alsdann als ein Körper aufgefasst werden, der in Analogie zur Peroxydase von $\mathrm{Chodat}$ und zur Katalase von $\mathrm{Loeb}{ }^{2}$ ), ferner auch in gewisser Parallele zu den photodynamischen Körpern nach Tappeine $\mathrm{r}^{5}$ ) und zum Hämoglobin eine sehr hohe Affinität zum Sauerstoff besitzt, ihn aber ebenso leicht in aktivierter Form, einer Art statu nascendi nach Bach und Chodat ${ }^{1}$ ), Traube und Engler ${ }^{6}$ ) an oxydable Körper abgibt. Je höher nun der Sauerstoffdruck ist, desto energischer belädt sich die Oxydase mit demselben, und desto kräftiger vermag sie wiederum die zur Verfügung stehenden Brennstoffe zu oxydieren. Die Intensität der Verbrennung. wird daher nicht nur von der Spannung des Sauerstoffes, sondern auch von der Art und Menge der vorhandenen oxydablen Körper abhängen. Diese

1) Bach und Chodat, Peroxydbildung in der lebenden Zelle. Ber. d. deutsch. chem. Gesellsch. Bd. 35 S. 2466. - Oxydationsfermente als peroxyderzeugende Körper. Ebenda S. 3943.

2) L o eb, Katalase. Zeitschr. f. physikal. Chemie Bd. 48 S. 748.

3) Czapek, Biochemie der Pflanzen Bd. 1 S. 152 ff. 1905.

4) Ehrlich, Sauerstoffbedürfnis der Organismen. Berlin 1885.

5) Tappeiner, Beruht die Wirkung fluoreszierender Stoffe auf Sensibilisierung? Münch. med. Wochenschr. 1904 S. 714. - Über die Oxydation durch fluoreszierende Stoffe im Lichte und die Veränderungen derselben durch die Bleichung. Ebenda S. 44.1905.

6) Raudnitz, Lähmung der Platinkatalyse durch Gifte. Zeitschr. f. physik. Chemie Bd. 37. 
Körper aber sind offenbar das Produkt assimilierender synthetischer Prozesse, die wabrscheinlich sich auch wie die Oxydation in einer Exponentialgleichung ausdrücken liessen und auf die Kompliziertheit des gesamten vitalen Vorganges ähnlich einer Exponentialgleichung mit vielen Unbekannten ein interessantes Streiflicht werfen. Da die synthetischen Prozesse in der Regel endothermane sind, so liegt diese Annahme auch hier nahe, und es scheint mir die weitere Überlegung gerechtfertigt, im Sinne von Pfeffer ${ }^{1}$ ) in der Dissimilation, der Oxydation eine Energie- respektive Wärmequelle zu sehen, die die assimilierenden Prozesse speist. D. h. Assimilation und Dissimilation müssen bei normalem Leben stets in einem konstanten Verhältnis zueinander stehen; es wird stets so viel aufgebaut als gespalten worden ist. Dies wiederum ist offenbar dadurch ermöglicht, dass die Oxydation und die Assimilation stets in einer Etappe ohne Zwischenpausen bis zur gegebenen Grenze verlaufen, vielleicht im Sinne eines sogenanuten reversiblen fermentativen Prozesses ${ }^{2}$ ), und dass die Oxydation stets an denjenigen sensiblen Stellen ansetzt, die die grösste Affinität zum Sauerstoff besitzen. Denn dort besteht das grösste Potentialgefälle gegenüber der hohen Sauerstoffladung der Oxydase, während die bereits angegriffenen Brennstoffe einer weiteren oxydativen Spaltung einen immer grösser werdenden Widerstand entgegensetzen. Nur unter dieser Voraussetzung ist zu verstehen, dass die Lebensprozesse bei langsam abnehmender Sauerstoffspannung so lange andauern können, d. h. dass $P$ und $p$ in konstantem Verhältnis zueinander stehen, und dass bei hoher Spannung eine andere Proportion von sauerstoffreichen und sauerstoffarmen Spaltprodukten sich bildet als bei niedriger. Mit anderen Worten ist also die Oxydationsenergie allerdings der Spannung des Sauerstoffs entsprechend, wie

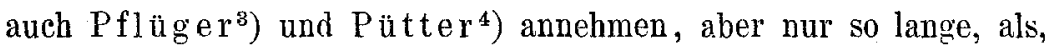
wie Pütter sich in seiner Arbeit ausdrückt ${ }^{3}$ ), "die Reaktionsmöglichkeiten zwischen lebender Substanz und Sauerstoff sich nicht

1) Pütter, Die Atmung der Protozoen. Zeitschr. f. allgem. Physiol. Bd. 5 H. 4. 1905. Zit. aus: Pflanzenphysiologie, 2. Aufl, Bd. 1 S. 521. 1897.

2) L oeb, Vorlesungen über die Dynamik der Lebenserscheinungen S. $22 \mathrm{ff}$. Leipzig 1906.

3) Pütter, Die Wirkung erhöhter Sauerstoffspannung anf die lebendige Substanz. Zeitschr. f. allgem. Physiol. Bd. 3 H. 4. S. 363-405, S. 402.

4) Pütter, zit. S. 395. 
ändern", ๙. h. solange die assimilierenden Prozesse normal funktionieren und die Oxydase sonst nicht geschädigt ist.

Ist dies nicht der Fall, so werden sich immer weniger Plasmaseitenketten bilden und mit dem Leeithin verbinden, d. h. sehliesslich

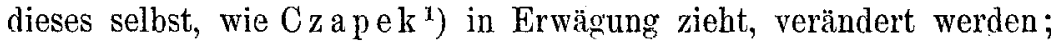
bei der Wichtigkeit dieses Stoffes aber bedeutet dies das Ende der Oxydation, das auch dann eintreten kann, wenn bei normaler Assimilation die Reduktase entweder nicht arbeitet oder die Spannung des Sauerstoffs zu hohe oder niedrige Werte angenommen hat.

Nach den Beobachtungen am Plexus tritt bei Sauerstoffmangel nach dem Sistieren der Cilienbewegung und Auftreten der Farbstoffe allmählich durch eine, wie mir schien, sogenannte Autolyse unter Sauerstoffabschluss ${ }^{2}$ ) eine diffuse Verfärbung und Aufquellung ein, bei sehr reichlichem Sauerstoffdruck dagegen unter Enthaltung der Färbung eine körnige Auflösung in einer sogenannten Autolyse unter Sauerstoffzufuhr ${ }^{2}$ ). In beiden Fällen tritt der Tod plötzlich ein, gleichsam unter dem Eindruck einer Vergiftung, meiner Ansicht nach dadurch erklärlich ${ }^{2}$ ), dass bei Sauerstoffmangel zu wenig oxydable und zu viel oxydierte Spaltprodukte auftreten, so dass letztere im Überschuss vorhanden sind und eine Art Giftwirkung ausüben, umgekehrt wie bei hohem Sauerstoffdruck, wo zuviel sauerstoffarme Körper entstehen, die nun nicht genügend oxydiert werden können und auch toxisch wirken, und zwar, wie es schien, bedeutend intensiver als die sauerstoffreichen. Worin diese Giftwirkung beruht, ob bei den sauerstoffreichen darin, dass das Sauerstoffgefälle abnimmt und die Anlagerung des Sauerstoffs erschwert ist, oder ob auch die geringe Wärmeproduktion des an sich schwachen Oxydationsprozesses eine Rolle spielt, ob bei den sauerstoffarmen in einer Schädigung anderer Prozesse oder auch infolge von Inanition nach zu intensivem Verbrauch, mit ungenügender Kompensation durch die Assimilation, scheint mir vorderhand noch eine offene Frage zu sein. Höchstwahrscheinlich aber ist, dass, wie auch $\mathrm{Loe}^{\mathbf{3}}$ ) für seine Katalase annimmt, die Reduktase, die der Katalase entsprechen würde, während

1) Czapek, Biochemie der Pflanzen Bd. 1 S. 152 ff. 1905.

2) Schläpfer, Über den Bau und die Funktion der Epithelzellen des Plexus chorioideus des Frosches, in Beziehung zur Granulalehre und mit besonderer Berücksichtigung der vitalen Fürbungsmethoden. Beitr. z. allgem. Pathol. u. pathol. Anat. Bd. 7 (Suppl.) S. 149-152. 1905.

3) Loeb, Katalase. Zeitschr. f. physikal. Chemie Bd. 48 S. 748. 
die Oxydase in Parallele zur Peroxydase von $\mathrm{Bach}^{1}$ ) zu stellen wäre, eine sogenannte entgiftende Rolle spielt, ein sogenannter entgiftender Katalysator ist nach $\mathrm{Loeb}^{2}$ ).

Vom Standpunkte der Oxydation aus lässt sich dabei das Leben kurz folgendermassen definieren:

Die Lebenserscheinungen, d. h. die Zellfunktionen, sind bedingt durch den Wechsel von Abbau und Aufbau, Oxydation und Assimilation, die in einem konstanten Verhältnis stehen müssen bei normalem Ablauf des Lebens. Unter dieser Voraussetzung beginnt dasselbe bei einem Minimal-Sauerstoffdruck und endigt bei einem Maximaldruck, innerhalb welcher die Reduktase die Spaltprodukte gleichsam zu neutralisieren imstande ist. Ausserhalb derselben aber liegt die Autolyse mit Sauerstoffmangel, der noch unbekannte Prozesse zugrunde liegen, und die Autolyse bei Sauerstoffzufuhr, die einen anormal gesteigerten Verbrennungsprozess vorstellt; sie sind gekennzeichnet durch veränderte Funktion der Reduktase, durch welche sie sich vom normalen Abbau, der vitalen Autolyse, unterscheiden. Im Grunde aber besteht der Unterschied darin, dass die Energieproduktion an sich nach unten gegen die Autolyse unter Sauerstoffabschluss hin zu gering ist, um noch eine Assimilation zu ermöglichen, und dass nach obenhin zuviel oxydiert wird, d. h. mehr Energie produziert wird, als in der Assimilation verwertet werden kann. Dadurch kommt ein Missverhältnis zwisehen Assimilation und Dissimilation und eine Störung in der Reduktion zustande, die zum vorzeitigen Tod durch Vergiftung führt.

Unter Voraussetzung dieser Anschauung der Oxydationsprozesse wird nun die weitere Frage sein, wie durch das Licht die einzelnen Vorgänge beeinflusst und welche am meisten verändert werden, und wodurch diese Veränderung erzielt wird.

1) Bach und Chodat, Untersuchungen über die Rolle der Peroxyde in der lebenden Zelle. Ber. d. deutsch. chem. Gesellsch. Bd. 35 S. 1275.

2) Loeb, Spielt Wasserstoffsuperoxyd eine Rolle in der lebenden Zelle? Ber. d. deutsch. chem. Gesellsch. Bd. 35 S. 2487. 
Eine allgemeine, durchgehende Frscheinung ist die, dass beim vorbehandelten Plexus bei Belichtung keine Färbung, d. h. keine Verküpung, der als Leukokörper aufgenommenen Farbstoffe eintritt, während bei Lichtabschluss dies eine regelmässig wiederkehrende Tatsache ist. Das belichtete Präparat verhält sich daher wie ein bei unbeschränkter Sauerstoffzufuhr aufbewahrtes, d. h. es zeigt eine lebhaftere Reduktionsenergie, also eine energischere Oxydation als das Dunkelpräparat, falls nicht unter dem Ausbleiben der Färbung einfach ein Bleichungsvorgang verstanden werden muss.

Die Möglichkeit einer solchen Érklärung muss unbedingt eingeräumt werden bei Berücksichtigung der Tatsache, dass Neutralrot bei Belichtung in einer Wasserlösung in eine graurote, unlösliche Modifikation übergeht, und dass nach Edlefsen ${ }^{1}$ ) auch das Methylenblau ein, von mir nicht beobachtetes, offenbar erst bei langer Belichtung eintretendes abbleichendes Verhalten zeigt. Eine Berücksichtigung aller Beobachtungen fübrt jedoch zu einer anderen Anschauung und scheint mir diesen allerdings fundamentalen Einwand sicher zu widerlegen. Einmal wird bei der Vorbehandlung aus vorderhand nicht sicher nachweisbaren Gründen der bindegewebige Stumpf des Präparats stets mehr oder weniger gefärbt, während die Epithelzellen farblos sind. Bei Belichtung nun verschwindet diese Färbung nicht, sondern bleibt mehr oder weniger deutlich bestehen. Eine Bleichung des Farbstoffs kann also nicht in Frage kommen. Gegen eine Vernichtung des Leukokörpers aber, die ja schliesslich auch eintreten könnte, spricht mit ebenso grosser Sicherheit das Wiederauftreten der Färbung beim Belichtungspräparat auf Tabelle I nach Erlöschen der Cilienbewegung bei Öffnen der Kammer. Die Leukomodifikation ist also mehr oder weniger unverändert im Präparạt enthalten.

Die bleibende Entfärbung dureh Belichtung kann also nicht von Bleichung oder Schädigung der Leukomodifikation herrühren, sondern sie ist die Folge eines anderen Prozesses.

Da vorgefärbte Präparate, d. h. solche, die einige Zeit in der dichten Kammer im Dunkeln aufbewahrt worden sind, ihre Färbung langsam verlieren, und zwar um so langsamer, je träger die Cilienbewegung ist, und da tote gefärbte Präparate noch nach Tagen (siehe Tab. VII) eine, wenn auch bald diffus werdende Färbung

1) Edlefsen, Experimenteller Beitrag zum Studium der oxydierenden Wirkung fluoreszierender Stoffe. Münchner med. Wochenschr. Nr. 36 S. 2904. 
zeigen, so lässt dies mit ziemlicher Sicherheit annehmen, dass die Verhinderung der Färbung durch Licht auch an die Lebensprozesse geknupft ist wie beim Dunkelpräparat mit unbeschränkter $\mathrm{O}_{2}$-Menge auf Tabelle IV, d. h. da die Entfärbung auf Oxydation beruht und die Cilienbewegung. nach den früheren Untersuchungen am Plexus ${ }^{1}$ ) und nach: $K \ddot{u} h n \mathrm{e}^{2}$ ) an einen geringen, aber kontinuierlichen Verbrennungsprozess geknüpft ist, ist damit postuliert, dass das Licht einen Einfluss auf die Oxydationsprozesse besitzt, in dem Sinne, dass es die Reduktionsenergie steigert, $d$. h. die Intensität der Oxydation überhaupt hebt und in gewisser Beziehung einen ähnlichen Effekt hervorzubringen vermag wie Steigerung der Sauerstoffspannung.

Da aber tote Präparate nie unwesentlich verändert werden, die Wirkung des Lichts im Gegenteil sich am intensivsten an den vitalsten Präparaten äussert, so ist damit ferner bewiesen, dass es im Gegensatz zu $\mathrm{Bie}^{3}$ ) keine biologische Wirkung des Lichtes an sich gibt, sondern dass das Licht nur indirekt durch Modifizierung einmal der Oxydationsprozesse, vor allem biologisch zu wirken vermag, also ein sogenanter Oxydationsreiz ist.

Über die Art dieser Modifizierung ergeben sich zwei Wege der Erklärung, ein rein chemischer und ein chemisch-physiologischer, d. h. das Licht kann, wie Werner ${ }^{4}$ ) z. B. bei der Wirkung der Radiumstrahlen anzunehmen geneigt $\mathrm{zu}$ sein scheint, in Parallele zum Radium direkt der Oxydation zugrunde liegende Substanzen verändern, oder aber es kann durch die Lichtstrahlen das Oxydationsferment, wie $\mathrm{Hertel}^{5}$ ) für wahrseheinlich halten will, verändert werden.

1) Schläpfer, Über den Bau und die Funktion der Epithelzellen des Plexus chorioideus des Frosches usw. Beitr. z. allgem. Pathol. und pathol. Anat. Bd. 7 (Suppl.) S. 156.

2) Jacobson, Über die Wirkung fluoreszierender Stoffe anf Flimmerepithel. Zeitschr. f. Biol. Bd. 41 S. 444 ff. 1901.

3) Tappeiner und Jodlbauer, Über die Wirkung des Lichtes auf Enzyme in Sauerstoff- und Wasserstoffatmosphäre, verglichen mit der Wirkung der photodyn. Stoffe. Dentsches Arch. f. klin. Med. Bd. 85 S. 387.1905.

4) Werner, Experimentelle Untersuchungen über die Wirkung der Radiumstrahlen auf tierische Gewebe und die Rolle des Lezithins bei derselben. Zentralbl. f. Chirurgie 1904 Nr. 43.

5) Hertel, Über physiologische Wirkung von Strahlen verschiedener Wellenlänge. Zeitschr. f. allgem. Physiol. Bd. 5 Heft 1. 1905. 
Bevor nun auf diese Anschaungen, die beide ihre gute Berechtigung haben können, weiter eingegangen werden soll, scheint es mir angezeigt zu sein, einige Resultate der Untersuchungen über die Wirkung des Lichtes auf einfachere Körper und Prozesse anzuführen. Von der Beschleunigung der Chlorwasserstoff - Gasbildung in einem Gemisch von $\mathrm{Cl}$ und $\mathrm{H}$ durch Sonnenlicht und anderen Tatsachen dürfte hierbei abgesehen werden.

Was einmal die Beeinflussung der Oxydation organischer Stoffe durch Licht anbelangt, so geht schon aus den Arbeiten von Radzis zewskil) hervor, dass bei der Beschleunigung der Oxydation von Benzol durch Licht nicht etwa der vorhandene Sauerstoff speziell modifiziert wird, sondern das Benzol, d. h. der belichtete Körper, da die Oxydationsbeschleunigung im Dunkeln fortdauert. Die Untersuchungen von Bredig und Pensel ${ }^{2}$ ) aber haben diese Behauptung bestätigt. Diese Oxydationsbeschleunigung nun erfolgt ausserdem am raschesten und intensivsten in alkalischer Lösung nach Radziszewski ${ }^{1}$ ) und steht hiermit in Übereinstimmung mit den Anschauungen $\mathrm{L}_{0} \mathrm{e} \mathrm{b} \mathrm{s}^{3}$ ) ) über die Alkaliwirkung und deren Übertragung durch Schlachta ${ }^{4}$ ) auf die Radiumphänomene; vielleicht kann sie auch aufklären über die Veränderung der Neutralrotlösung durch Licht oder Alkalisieren.

Über den chemischen Charakter der durch Licht veränderten organischen Stoffe geben leider die zitierten Arbeiten keinen Aufschluss. Auch die Beobachtung von Schultze und Winterstein ${ }^{5}$ ), wonach das Lecithin und Cholestearin sich bei Belichtung verändert, in dem Sinne, dass der Schmelzpunkt niedriger wird, und einige typische Reaktionen sich ändern, gibt über den chemischen Charakter des Belichtungsproduktes keine genaueren Angaben, und Sacharoff

1) Radziszewski, Über die Phosphoreszenz der organischen und organisierten Körper. Liebig's Annalen d. Chemie Bd. 203 S. 315 u. 320.1880.

2) Bredig und Pensel, Über die vermeintliche Aktivierung des Luftsauerstoffs durch Belichtung. Arch. f. wissensch. Photographie Bd. 1 Heft 2.

3) Loeb, Über die physiologische Wirkung von Alkalien tind Säuren in starker Verdünnung. Pflüger's Arch. Bd. 73.

4) Schlachta, Zur Theorie der biologischen Strahlenwirkung. Münchener med. Wochenschr. 1905 Nr. 19.

5) Schultze und Winterstein, Über das Verhalten des Cholestearins gegen das Licht. Zeitschr. f. physiolog. Chemie Bd. 43 Heft 3 u. 4 S. 316-319. 
und $S a \operatorname{chs}^{1}$ ) erwähnen nur, dass Licht im allgemeinen eine Umwandlung einer Orthonitro- in eine Nitrosogruppe und eine intramolekulare Oxydation eines Alkohols zu einer Säure zustande zu bringen vermöge.

Ebenso wenig abgeklärt sind die Kenntnisse über die Wirkung des Lichtes auf die sogenannten Enzyme. Nach Emerling ${ }^{2}$ ) soll eine solche überhaupt kaum in Frage kommen, während $\mathrm{Czapek}^{3}$ ) im Gegenteil eine deutliche Beeinflussung annimmt und darunter eine Oxydation glaubt verstehen zu müssen. Auch Reichel und Spiro $^{4}$ ), Pauli $^{5}$ ), Dauwe ${ }^{6}$ ), Hardy $^{7}$ ) Höber ${ }^{8}$ ) u. a., Gillot ${ }^{9}$ ) usw. bejahen eine Wirkung des Lichtes auf Enzyme, ohne die Art derselben indes näber auseinanderzusetzen. Nach Ferni und Per$n 0 \mathrm{si}^{10}$ ) werden Pepsin und Trypsin in feucbtem, nicht aber in trockenem Zustand in ihrer Wirkung geschwächt, nach D.ownes und $\mathrm{Blunt}{ }^{11}$ ) auch andere Fermente, wie z. B. Bakterientoxine und

1) Sacharoff und Sachs, Über die hämolytische Wirkung der photodynamischen Stoffe. Münchener med. Wochenschr. Bd. 51 Nr. 7. 1905. Daselbst weitere Literatur.

2) Emerling, Die Einwirkung des Sonnenlichts auf die Enzyme. Ber. d. deutschen chem. Gesellsch. Bd. 34 S. 3811.

3) Czapek, Biochemie der Pflanzen Bd. 1 S. 71 u. 72.1905.

4) Reichel und Spiro, Fermentwirkung und Fermentverlust. Hofmeister's Beitr. Bd. 6 S. 68. 1904.

5) Pauli, Untersuchungen über physikalische Zustandsänderungen der Kolloide. Hofmeister's Beitr. Bd. 6 Heft 6 .

6) Dauwe, Über die Absorption der Fermente durch Kolloid. Hofmeister's Beitr. Bd. 6 Heft 9 u. 10. 1905.

7) Hardy, The structure of cell protoplasme. Journal of physiology ed. by Forster vol. 24 p. 158 ff. 1899.

8) Schläpfer, Über den Bau und die Funktion der Epithelzellen des Plexus chor. des Frosches usw. Beitr. z. allgem. Pathol. und pathol. Anat. Bd. 7 (Suppl.). 1905. Zit.

9) Gillot, Sur la marche de l'inversion du saccharose par les acides minéraux dans ses rapports avec la nature et l'intensité des rayons lumineux. Bull. de l'Ac. roy. Belge t. 40 p. 863.1901.

10) Ferni und Pernossi, Über die Enzyme. Zentralbl. f. Bakteriol. Bd. 15. 1894 .

11) Werner, Erworbene Photoaktivität der Gewebe als Faktor der biologischen Strahlenwirkung und ihrer Imitation. Münchener med. Wochenschr. Nr. 1. 1906. 
Beiträge zur Frage der oxydativen Lieistungen der tierischen Zelle etc. 357

Antitoxine nach Tappeiner ${ }^{1}$ ), Mettle ${ }^{2}$ ), Huber ${ }^{3}$ ) usw.; nach Bergall und Braunstein dagegen sollen z. B. die $\alpha$-Strahlen die tryptischen Fermente aktivieren, während nach $\mathrm{Namias^{4 }}$ ) das Licht exothermane Prozesse beschleunigt, endothermane hemmt.

Aus dem Dargelegten geht also hervor, dass sowohl die rein chemische als auch die chemisch-physiologische Erklärung der biologischen Lichtwirkung ihre Basis hat.

Die im ersten Teil niedergelegten Beobachtungen aber scheinen mir einwandfreier durch die rein chemische Theorie erklärt werden zu können.

Der Annahme einer Aktivierung der Oxydase müsste offenbar die Anschauung zugrunde gelegt werden, dass dieselbe unter Belichtung sich in Analogie ungefähr zu den photodynamischen Körpern 'Tappeiner's intensiver oxydiert und den Sauerstoff leichter abgibt. Eine solche Voraussetzung würde in der Tat den grössten Teil der Erscheinungen verständlich machen, wie die Verhinderung der Verküpung, die raschere Entfärbung frischer wie alter Präparate und bei reichlicherem wie spärlichem Sauerstoffdruck und anderes mehr; sie lässt aber mehr oder weniger im Stiche gegenüber der Tatsache, dass ein gewisser Einfluss auch bei der sogenannten Autolyse unter Sauerstoffabschluss bemerkbar ist, wo eine Oxydasetätigkeit ausgeschlossen ist, namentlich aber gegenüber der Beobachtung, dass die Autolyse unter Sauerstoffzufuhr, wo die Oxydase unbeschädigt weiterarbeiten muss, durch Licht eher gehemmt und dass auch die Sekretionstätigkeit bei Belichtung abgeschwächt wird (S. 313).

Diese letzteren Phänomenè, die weiter unten noch näher erörtert werden sollen, sprechen mit ziemlicher Sicherheit dafür, dass es zum mindesten nicht die Oxydaseaktivierung allein sein kann,

1) Tappeiner und Jodlbauer, Über die Wirkung fluoreszierender Stoffe auf Diphtherietoxin und Antitoxin. Münchn. med. Wochenschr. 1904. S. $737 \mathrm{ff}$. Über die Wirkung fluoreszierender Stoffe auf Toxine. Deutsehes Arch. f. klin. Med. Bd. 85 S. 408 u. 410.1905.

2) Mettler, Experimentelles über die bakterizide Wirkung des Lichts auf mit Eosin, Erythrosin, Fluorescein gefärbte Nährböden. Inaug.-Diss. Zürich 1905.

3) Huber, Weitere Versuche mit photodynamischen, sensibilisierenden Farbstoffen. Prüfung der Wirkung des Tágeslichts auf Lebensfähigkeit und Virulenz von Bakterien, auf Toxine und Antitoxine und auf das Labferment. Arch. f. Hygiene Bd. 54 Heft 1. 1905.

4) Namias, Photochemische und thermochemische Betrachtungen. Gaz. chim. italienne t. 26 fasc. 35.1896. 
die die biologische Lichtwirkung vermittelt, sondern dass noch ein weiteres Moment in Frage kommen muss, ein Moment, dass auch nach Sistieren des Lebens wirksam ist und über den Rahmen des Oxydationsprozesses hinausragt, đ. b. man gelangt zur Anschauung, dass möglicherweise das Licht überhaupt das Gewebe an sich modifiziert, und dass es dadurch in die eigentümliche nahe Beziehung zur Oxydation gelangt, dass diese Modifikation des Gewebes vor allem für die Oxydation von spezieller Bedeutung ist, oder mit anderen Worten: das Licht verändert die Gewebe, diese Veränderung ist aber so gering, dass sie an sich kaum wahrgenommen werden kann, sondern nur dadurch manifest wird, dass sie speziell einen grossen Einfluss auf die Verbrennung besitzt, die sichtbar verändert wird; da aber die Verbrennung am intensivsten am frischen Präparat erfolgt, so muss auch, falls die Intensität des Lichtes gross genug ist (vgl. unten S. 380 ff.), am frischen Objekt sich der Einfluss des Lichtes am deutlichsten zeigen, am toten Organ dagegen beinahe versehwinden, falls keine oxydierenden Prozesse sich darin abspielen.

Macht man nun die Voraussetzung, die Wirkung des Lichtes sei eine stets vom Leben unabhängig eintretende chemische Veränderung der Gewebe, so lassen sich alle Erscheinungen einheitlich erklären, und die chemisch-physiologische Anschauung wird überflüssig.

Die weitere Frage wird nun die sein, in welcher Art diese chemische Wirkung zustande kommt. Es liegt in der Natur der Sache, dass bei den mangelhaften Kenntnissen über die Veränderung: der organischen Körper durch Belichtung die Antwort hierauf nicht mit Sicherheit gegeben werden kann; es lässt sich nur unter Berücksichtigung des bisher Dargelegten eine Vermutung aufstellen, die mir aber doch insofern erwähnenswert erscheint, als sie zur Klarlegung der Verbältnisse einigermassen beiträgt.

Die Beobachtungen Winterstein's und Schultze's über die Wirkung des Lichtes auf Lecithin und Cholestearin, die Bedeutung, die diesen Stoffen nach der Globoplastentheorie im Haushalt der Zelle, speziell in der Oxydation zukommt, die Hemmung der Autolyse bei Sauerstoffzufuhr, die Beschleunigung der Autolyse unter Sauerstoffabschluss, machen es sehr wahrscheinlich, dass, wie weiter auseinanderzusetzen ist, die am meisten und vor allem vom Licht modifizierten Bestandteile der Zelle die Lipoide sind.

Im normalen Verlauf entsteht eine Lipoid-Plasmaverbindung, die unter Oxydation der letzteren Komponente wieder zerfällt, 
während die Lipoidkomponente die Oxydation vermittelt. Bei Belichtung nun ist möglich, dass durch unbekannte Modifikation offenbar einer im Sinne der Oxydation erfolgenden Veränderung, nach Radziszewski ${ }^{1}$ ), der Lipoidkomponente der Zerfall der Verbindung leichter und die Bindung des Sauerstoffs, der unter der Hülle gelagert ist, rascher vonstatten geht. Durch das Licht wird die Lipoid-Plasmaverbindung gleichsam gelockert, der Widerstand gegen die Oxydation dadurch vermindert und die Tätigkeit der Oxydase so erleichtert, d. h. die Spaitung wird bei gleichbleibendem Sauerstoffdruck tiefer.

Da nun der Plexus chorioideus des Frosches auch ungeachtet einer Beobachtung Tappeiner's ${ }^{2}$ ), wonach Lichtstrablen durch das Schädeldach des Frosches hindurch zu dringen vermögen, ein Organ ist, das normal vor Licht geschützt ist, so ist er offenbar gegen Licht empfindlich; $d$. h. die chemische Wirkung desselben ist eine ziemlich intensive, weshalb es verständlich wird, dass das Lichtpräparat von Tabelle I sich mit seinem niedrigen Sauerstoffdruck ungefähr gleich verhält wie ein Dunkelpräparat mit unbeschränkter $\mathrm{O}_{2}$-Menge von Tabelle IV mit atmosphärischer Sauerstoffspannung.

Infolge des geringen Spaltungswiderstandes wird viel Sauerstoff konsumiert. Es tritt daher ein Überschuss an sauerstoffarmen Spaltprodukten und starke Reduktion auf. Da aber im Gegensatz zum Dunkelpräparat mit unbeschränkter $\mathrm{O}_{2}$-Menge das Quantum Sauerstoff sehr begrenzt ist, so wird es bei dem grossen Konsum rasch aufgebraucht, und die Cilienbewegung, $d . h$. die Oxydation, muss rasch sistiẹren, rascher als beim Dunkelpräparat mit unbeschränkter $\mathrm{O}_{2}$ Menge und beim Dunkelpräparat, wo infolge des geringen. Konsums das vorhandene Quantum länger ausreicht. Dass nun bei Belichtung trotz des immer geringer werdenden Sauerstoffdruckes stets eine Spaltung mit Überschuss sauerstoffarmer Produkte, d. h. hoher Reduktion stattfindet, beruht offenbar darauf, dass eben die Wirkung des Lichtes sehr intensiv ist; da zudem der Sauerstoff so viel freie Vakanzen sättigt, als vorhanden sind, so wird wahrscheinlich in der Zeiteinheit mehr Sauerstoff verbraucht als im Dunkelpräparat bei höchster Sauerstoffspannung im Beginn. Nach wenigen Minuten wird also die vorhandene Sauerstoffmenge aufgezehrt und der Prozess, wie

1) Radziszewski, Über die Phosphoreszenz der organischen und organisierten Körper. Liebig's Annalen der Chemie Bd. 203 S. 305-306. 1880.

2) Tappeiner und Jodlbauer, Über die Wirkung fluoreszierender Stoffe auf Toxine. Deutsch. Arch. f. klin. Med. Bd. 85 S. 408-410. 1905. 
das Beispiel zeigt, stillstehen, nicht nur wegen fehlendem Sauerstoff, sondern, wie schon dargetan, jedenfalls auch durch Vergiftung infolge toxischen Überflusses sauerstoffarmer Körper, die durch die Reduktase wegen ihrer Menge nicht reduziert werden konnten. Hierauf beruht wohl auch die Tatsache, dass nur selten und nur nach raschem Öffnen der Kammer und Zufuhr von Sauerstoff die Cilienbewegung wieder beginnt, weil eben die Oxydase in der Regel gelähmt ist. Dadurch wird auch begreiflich, dass gelegentlich hierbei eine leichte Färbung wieder auftritt, wenn man ausserdem bedenkt, dass der Überschuss von reduzierenden Stoffen wohl ziemlich bedeutend ist, immerhin aber durch die letzten Spaltungen vormindert wird, weil diese nur noch wenig energisch erfolgen können, mit relativ mehr sauerstoffreichen Produkten.

Die sauerstoffarmen sind wohl noch reichlicher, aber nicht in der Menge vorhanden, dass sie auch bei freiem Sauerstoffzutritt eine Verküpung der Leukokörper hindern könnten im Gegensatz zum Dunkelpräparat mit unbeschränkter $\mathrm{O}_{2}$-Menge, wo dies darum stattfindet, weil dort bis zum Erlöschen des Prozesses bedeutend mehr sauerstoffarme Spaltprodukte entstehen müssen mit stärkerer Reduktionskraft. Darin zeigt sich ein funtamentaler Unterschied zwischen Lichtpräparat und Dunkelpräparat mit unbeschränkter $\mathrm{O}_{2}$-Menge. Bei letzterem werden stets alle vorhandenen Vakanzen gesättigt, bei ersterem dagegen gegen das Ende hin nicht mehr, weil nach dem ganzen Bilde die Spaltung durch das Licht tiefer geht als die Intensität der Oxydation. Es hat dies höchstwahrscheinlich ein Defizit im Energiehaushalt zur Folge, indem der durch das Licht gesteigerten Dissimilation, die nicht dieselbe Energie produzieren kann wie eine nur durch Sauerstoffspannung erhöhte, eine schwächere Assimilation infolgedessen entsprechen muss.

Dass der frühe Tod beim Lichtpräparat nicht nur die Folge einer Vergiftung, sondern mehr noch eine Art Erstickung ist, uicht, wie beim Dunkelpräparat, mit immer abnehmender Intensität der Verbrennung, sondern mit plötzlichem Sistieren in voller Energie, dafür spricht nicht nur das Verhalten der Färbung, sondern namentlich auch die Ergebnisse von Tabelle IV, wo bei offener Kammer mit unveränderlicher Sauerstoffzufuhr die Cilienbewegung beim belichteten Präparat wohl etwas kürzer dauert als beim unbelichteten, unbedingt aber länger als bei geschlossener Kammer und Lichtzutritt. Wenn die Vergiftung durch Überschuss sauerstoffarmer Produkte die Todesursache wäre, so würde diese Zeitdifferenz nicht verständlich sein, 
da dann der Tod beinahe noch rascher eintreten müsste; sie wird es nur unter der Annahme, dass beim Lichtpräparat die Frstickung die eigentliche Hemmung bildet.

Wie diese Erscheinungen, so lässt sich nun weiter auch die Tatsache von Tabelle $V$ erklären, dass bei Präparaten mit bereits leichte Färbung aufweisenden Stellen die Entfärbung immer langsamer erfolgt, je intensiver diese Färbung am Anfange der Belichtung ist, ferner dass vorbelichtete fast farblose Präparate bei Verlegen in die dunkle Kammer keine sogenannte Erholung oder umgekehrt auch kein Nachwirken des Lichtes erkennen lassen (nach Tabelle II und III), und dass die sogenannte Vitalität des Organs ebenfalls von Bedeutung ist, indem bei gleichartiger unbeschränkter Sauerstoffspannung und Belichtung ein mehr vorgefärbtes Präparat sich ebenfalls langsamer entfärbt als ein weniger vorgefärbtes.

Im ersteren Falle liegt es auf der Hand, dass das stärker gefärbte Präparat unter sonst gleichen Verhältnissen als Ausdruck ,einer bereits ziemlich schwach gewordenen Oxydation respektive Reduktion anzusehen ist mit relativ wenig Sauerstoff, das weniger gefärbte dagegen eine relativ höhere Oxydation repräsentiert. Unter der im letzten Absatz angeführten Vitalität aber dürfte eine mehr oder weniger grosse Unversehrtheit der Zellprozesse von den durch den Stoffwechsel sich bildenden Giften, die nicht mit den oben angeführten oxydativen Spaltungsprodukten identisch sein können, verstanden werden. Nach Pütter ${ }^{1}$ ) kommt in einem aus dem Zusammenhang gerissenen Organ bei Sauerstoffbeschränkung nicht nur die Erstickungsgefahr in Betracht, sondern vor allem auch die Vergiftung infolge der unter den veränderten Verhältnissen zweifellos nicht mehr normal funktionierenden Exkretion. Wenn auch im allgemeinen unter den gewöhnlichen Versuchsbedingungen dieses Moment hier wenig in Frage kam, so muss dies ohne weiteres dann eintreten, wenn die eine primäre Rolle spielende Oxydation und Erstickung durch Zufuhr reichlichen Sauerstoffes gleichsam, wie im letzten Absatz angedeutet, in zweite Linie gerückt ist ähnlich wie beim Dunkelpräparat mit unbeschränkter $\mathrm{O}_{2}$-Menge, wo vielleicht die Intoxikation bedeutender ist, als die Inanition, ja dieselbe gerade$\mathrm{zu}$ bedingt. Nur unter Kombination dieser beiđen Überlegungen lässt sich alsdann die Erklärung der schwebenden Fragen geben.

1) Pütter, Die Atmung der Protozoen. Zeitschr. f. allgem. Physiol. Bd. 5 H. 4. 1905. 
Werden die in dichter Kammer aufbewahrten, stärker und schwächer gefärbten Präparate belichtet, so tritt ohne weiteres eine erhöhte Oxydation, d. h. ein gesteigerter Sauerstoffverbrauch, ein, der bald so weit führt, dass die Cilienbewegung sistieren muss. Da die Differenz der ursprünglich vorhandenen Sauerstoffmengen gering ist, so wird das Sistieren der Flimmerung bei beiden ungefähr in derselben Zeit erfolgen, und spielt hierbei die Vitalität keine wesentliche Rolle, wohl aber bei der gleichzeitig sich abspielenden Entfärbung. Da diese noch einige Zeit fortschreitet, so ist damit gesagt, dass die Reduktion respektive Oxydation noch länger dauert, offenbar aber in so geringer Intensität, dass dabei die frei werdende Energie zur Speisung der Cilienbewegung nicht genügt; ausserdem aber. lässt dies vermuten, dass der der Flimmerung zugrunde liegende Chemismus gegen die Stoffwechselgifte und die Oxydationsspaltprodukte empfindlicher ist als der die Oxydation vermittelnde, wodurche die so rasche Cilienlähmung erst ins eigentliche rechte Licht gestellt wird.

Aber auch diese Oxydationsprozesse zeigen nun Unterschiede des Verhaltens, die sich nur bei Voraussetzung einer langsamen Intoxikation verstehen lassen, da dadurch wohl nicht die Wirkung des Lichtes, wohl aber die Anlagerung des Sauerstoffs durch Schädigung der Oxydase erschwert wird.

Die Tatsache, dass belichtete Präparate sich im Dunkeln nicht wesentlich verändern respektive stärker färben, beruht offenbar auch zum Teil auf Lähmung der Oxydase, die bei dem niedrigen Sauerstoffdruck nicht mehr recht funktionieren kann, um den Überschuss sauerstoffarmer Spaltprodulste durch Erzeugen sauerstoffreicher in normaler Weise auszugleichen. Ungekehrt ist daher das Ausbleiben starker Färbung auch nicht als Andauern der Lichtwirkung aufzufassen, wie es bei der chemisch-physiologischen Erklärung eventuell möglich wäre, bei der chemischen dagegen auszuschliessen ist, sondern darunter eben eine relativ starke restierende Reduktion zu verstehen, da der Überschuss sauerstoffarmer Spaltprodukte nur langsam sich vermindert.

Durch die Erscheinung der frühzeitigen Sistierung der Flimmerung gegenüber der fortbestehenden Oxydation ist dokumentiert, dass, da das Leben der Flimmerzelle wohl am"deutlichsten sich in der Cilienbewegung äussert, die Oxydationsprozesse wohl zum. Teil in einer bestimmten Periode ihrer Intensität ein Faktor des Lehens sind, 
dass sie aber auch nach dem Tode, wo eine Sanerstoffzufuhr keine Wiederbelebung der Flimmerung zur Folge bat, noch in ähnlicher Art weiterbestehen und, wie die Beobachtung in der früheren Untersuchung ${ }^{1}$ ) zeigt, allmählich nach der einen Seite in die sogenannte sauerstofffreie, auf der anderen in die sauerstoffreiche Autolyse übergehen - zwei Prozesse, die an sich sehr wesensverschieden sind [vergl. 1) S. $121 \mathrm{ff}$. und S. $149 \mathrm{ff}$.] und durch die Veränderung bei Belichtung sowohl die Natur der Lichtwirkung präzisieren können als auch selbst eine gewisse Klarstellung erfabren.

Wie schon erwähnt, geht das gewöhnliche unbelichtete Präparat bei Abwesenheit von Bakterien allmählich in einen homogen gequollenen Zustand über. Die am Beginn vorhandene Granulafürbung, die nach der früheren Beobachtung ${ }^{1}$ ) auf' einer gewissen Intaktheit der Lipoidhülle als Lösungsmittel der vitalen Farbstoffe beruht, wird zu einer verwaschenen Färbung.

Diese diffuse Tinktion nun tritt in der Regel beim Belichtungspräparat rascher ein als beim im. Dunkeln aufbewahrten und zeigt gegenüber jenem noch den Unterschied, dass die nicht gefärbten Zellbezirke relativ wasserhell sind anstatt der gelblichen Nuance, die alle Präparate zeigen, welche unter geringer Sauerstoffspannung aufbewahrt wurden, während die bei unbeschränkter Sauerstoffzufuhr gehaltenen auch nach Sistieren der Cilienbewegung ihr anfangs vorhandenes wasserhelles Aussehen stets fast unverändert beibehalten. Da nun bei niedrigem Sauerstoffdruck respelstive schwacher Oxydation mehr sauerstoffreiche Spaltprodukte entstehen, so liegt es nahe, die gelbliche Färbung auf diese zurückzuführen, sei es, dass sich die Lipoid-Plasmaverbindung oder die Lipoide allein ändern, die helle Färbung dagegen dem Überwiegen der sauerstoffarmen Körper zuzuschreiben ist. Alsdann muss nach der gegebenen Definition der Lichtwirkung das belichtete Präparat trotz geringem Sauerstoffdruck wasserhell erscheinen, weil es auch eine relativ intensive Oxydation aufweist. Da nun trotz des Überwiegens sauerstoffarmer Körper doch auch bei diesem wiederum die Autolyse unter Sauerstoffabschluss in derselben Weise wie beim unbelichteten Präparat eintritt, so

1) Schläpfer, Über den Bau und die Funktion der Epithelzellen des Plexus chorioideus in Beziebnng zur Granulalehre und mit spezieller Berücksichtigung der vitalen Färbungsmethoden. Beitr. zur allgem. Pathol. u. pathol. Anat. Bd. 7 (Suppl.) S. 155 ff., S. 151. 1905. 
haben wir es bei diesem Prozess offenbar mit einem Vorgang zu tun, der vom Verlauf der Oxydation, d. h. überhaupt von der Verbrennung, mehr oder weniger unabhängig ist und wahrscheinlich auf einer durch unbekannte Ursache herbeigefuhrten Veränderung der Lipoide beruht. Da diese Veränderung nun durch Licht beschleunigt wird, das Licht aber auch die Verbrennung fördert, so ist fernerhin möglich, dass einmal die spontan eintretende autolytische Umwandlung der Lipoide derjenigen ähnlich ist oder identisch, die das Licht verursacht, und dass diese Veränderung möglicherweise von Bedentung. für die Oxydation ist, $d$. $h$. bei derselben eine wesentliche Rolle spielt, ohne von ihr indessen abhängig zu sein, und die nach Tabelle VII bei belichtetem abgestorbenem Präparat mit unbeschränkter Sauerstoffmenge etwas schneller erfolgende diffuse Färbung gegenüber dem gleichen ohne Sauerstoff kann darauf beruhen, dass durch den hohen Sauerstoffdruck die Verküpung der Leukokörper, die ja auch wiederum verändert sein können nach $H e r t e r^{1}$ ), beschleunigt wird, während beim anderen freier Sauerstoff sehr wahrscheinlich fehlt, die Annahme von Sauerstoffdepots aber, wie schon erwähnt, kaum angängig ist, da Sauerstoff nur in Form sauerstoffreicher Spaltprodukte aufgespeichert wird und nur durch Vermittlung der Reduktase verwertet werden kann.

Vorausgesetzt nun, dass das Licht speziell die Lipoidhülle zu verändern imstande ist, lässt sich auch die sogenannte Hemmung der sauerstoffreichen Autolyse und die Abschwächung der Sekretion erklären. Nach Tabelle IV sistiert die Cilienbewegung im belichteten sauerstoffreichen Präparat früher als im unbelichteten Präparat, d. h., da Licht und hoher Sauerstoffdruck die Oxydation beschleunigen, muss im belichteten sauerstoffreichen eine Summation beider und eine wesentlich gesteigerte Oxydation zustande kommen, die auch rascher zur Intoxikation der Flimmerbewegung führt. Da nun auch hier wiederum der Oxydationsprozess trotz dem sehr wahrscheinlichen Zelltod andauert, ist er also auch gegen diese Vergiftung durch sauerstoffarme Spaltprodukte weniger empfindlich als die Cilienprozesse und geht in die sogenannte sauerstoffreiche Autolyse über. Da aber, wie der frühe Zerfall eines solchen autolytischen Präparates zeigt,

1) Herter, Über die Anwendung reduzierbarer Farbstoffe beim Studium der Verteilung von Giften und ihrer Wirkungen auf die Zelltätigkeit. Zeitschr. f. physiol. Chemie Bd. 42 S. $493-501$.' 
nicht nur die Cilienbewegung, sondern auch die synthetischen Prozesse stillstehen, ob dureh Lähmung respektive Vergiftung, was sehr wahrscheinlich ist, oder durch Mangel an Nährstoffen, bleibe dahingestellt, so findet keine Neubildung plasmatischer Seitenketten und damit auch keine Regeneration sogenannter Lipoid-Plasmaverbindungen statt, d. h. das Lipoid, das anfänglich gleichsam intakt geblieben ist, wie es den Anschein hat, geschützt durch die viel oxydableren Plasmakomponenten, wird jetzt, wie auch $\mathrm{Czapek}^{1}$ ) einräumt, schliesslich auch oxydiert respektive zerstört, bei Belichtung in gesteigertem Masse. Da aber die Lipoidhülle für die Anlagerung des Sauerstoffs von fundamentaler Bedeutung ist, so muss ein weitergehender Abbau derselben bald die Oxydation erschweren, d. h. die Autolyse, die am unbelichteten Präparat stets bis zu einem gewissen Grade zu einer Auflösung des Zellkörpers in einzelne Körner führt, vorher sistieren.

Auf einer ähnlichen Überlegung, die die Theorie einer spezifischen Beeinflussung der Lipoidkomponente ebenfalls zu stützen imstande ist, beruht auch die Erklärung der Sekretionsdifferenz beim belichteten sauerstoffarmen und unbelichteten sauerstoffreichen Präparat. Da beide Objekte eine gesteigerte Oxydation zeigen, begleitet von einer geringen respektive sehr intensiven Selrretion, so kann einer lebhaften Oxydation nicht unbedingt eine lebhafte Sekretion entsprechen, d. h. die Sekretion ist ein eigentümlicher Prozess, in gewissem Grade mit der Oxydation nicht identisch.

Der bei der Sekretion des Plexus tätige Mechanismus ist nach früheren Untersuchungen ${ }^{2}$ ) der, dass einzelne Globoplasten sich differenzieren, aufquellen und zu kleinen Sekrettropfen verschmelzen, wobei die Lipoidhülle wahrscheinlich an den Berührungsflächen resorbiert wird. Da nun die hierbei gebildeten Tropfen sich häufig färben, so spricht dies dafür, dass in ihrem Bezirke die oxydativen Spaltprozesse bereits an Intensität verloren haben, die reichliche Sauerstoffzufuhr, die die Sekretion anregt, dies offenbar nicht etwa nur indirekt tun kann durch Steigerung der Oxydation, sondern möglicherweise durch direkte Beteiligung des Sauerstoffs an dem

1) Czapek, Biochemie der Pflanzen Bd. 1 S. 152 ff. 1905.

2) Schläpfer, Über den Bau und die Funktion der Epithelzellen des Plexus chorioideus des Frosches usw. Beiträge z. allgem. Pathol. und pathol Anat. Bd. 7 (Suppl.) S. 138. 
Prozess, z. B. in synthetiseher Richtung, da der Sauerstoff nicht nur. am Abbau teilnehmen kann - wenn dies vielleicht auch seine vornehmste Aufgabe in der höheren Zelle ist, - sondern auch, wie auch Hoppe-Seyler ${ }^{\mathbf{1}}$, aus anderen Gründen veranlasst, annimmt, bei der Synthese eine Rolle spielt.

Sehr wahrscheinlich aber ist nun, dass die Lipoidveränderung bei der Sekretion nicht im Sinne der Oxydation verläuft. Da das Licht aber umgekehrt die Lipoide in der Richtung einer erleichterten oxydativen Spaltung modifiziert, so folgt aus dieser Annahme, dass, wie das Beispiel in der Tat zeigt, die durch Belichtung gesteigerte Oxydation bei geringerer Sauerstoffspannung nicht mit lebhafter Sekretion verlaufen kann, da offenbar der vorhandene Sauerstoff ganz im Sinne der Oxydation verwandt wird. Denn die Affinität der Brennstoffe ist gesteigert, so dass möglicherweise nicht nur nicht lebhaftere Sekretion, sondern direkt Hemmung derselben eintreten kann, weil nun die Affinität der Brennstoffe zum $\mathrm{O}_{2}$ gegenüber der der sekretogenen Körper überwiegt. Wenn nun hiermit a uch die Beziehung der Sekretion zur Oxydation nicht abgeklärt ist, so ist doch so viel festgestellt, dass der eine Prozess nicht die direkte Funktion des anderen ist, und dass die chemische Auffassung der Licht-wirkung das Verständnis wesentlich erleichtert.

Wie schon weiter oben bemerkt, ist der Einfluss des Lichtes auf die Lipoide ein ziemlich grosser, $d$. h. der Widerstand derselben gegen die durch das Licht angestrebte Veränderung wird alsbald überwunden, und eine Summierung der einzelnen Lichtwirkungen zur Überwindung des sogenannten Schwellenwertes, wie weiter unten noch eingehender erörtert werden wird, kommt nicht zustande, d. h. es entsteht keine sogenannte Latenzperiode, wie Herte ${ }^{2}$ ) annimmt, nach welcher erst der Lichteinfluss manifest wird, sondern derselbe tritt alsbald ein, wird aber allerdings auch erst nach einiger Zeit deutlich, d. h. nach der Zeitdauer, nach welcher das unbelichtete Präparat beginnende Färbung zeigt, im Gegensatz zum heller belichteten Präparat.

Diese Pseudo-Latenzzeit ist aber eine Folge der Methode und entspricht nicht der nach Hertel bei Mikroorganismen angenommenen,

1) L 0 e b, Katalase. Zeitschr. f. physikal. Chemie Bd. 48 S. 748.

2) Herte1, Über physiologische Wirkung von Strahlen verschiedener Wellenlänge. Zeitschr. f. allgem. Physiologie Bd. 1 Heft 1. 1905. 
"welche dadurch bedingt sein soll, dass die Beeinflussung der Mikroorganismen erst dann eintreten kann, wenn durch das Licht eine gewisse Höhe der Sauerstoffaktivierung in den nach $\mathrm{H}$ èrtel in den Zellen vorhandenen Sauerstoffdepots erreicht ist". Aber auch diese Latenzzeit bei Mikroorganismen scheint mir auf andere Weise erklärt werden zu können, nämlich durch die biologische Selbständigkeit und daher grosse Widerstandsfähigkeit der in Frage kommenden Objekte gegen fremde Einflüsse.

Dadurch muss die Dauer, nach welcher eine Veränderung des Materials wahrgenommen werden kann, bedeutend grösser werden als bei einem aus dem Zusammenhang mit dem Körper gerissenen Organe, das eo ipso vital unselbständig ist und daher eine geringere Widerstandskraft gegen Schädigungen besitzt als selbständige Zellen.

Die Wirkung des Lichtes tritt also sofort ein, d. h. sie greift alsbald in das Getriebe der Oxydation ein, wobei sich der Prozess verändert respektive steigert. Da diese Steigerung bei Erhöhung der Sauerstoffspannung der Zunahme höchstwahrscheinlich logarithmisch proportional ist, so wird dies auch beim Licbte der Fall sein, d. h. der Zunahme ein und desselben Lichtes. Da aber, wie schon hervorgehoben, die einzeinen Lichtstrahlen je nach ihrer Wellenlänge verschieden zu wirken vermögen, so ist zur genauen Charakterisierung der Lichtwirkung auf den Plexus auch eine Analyse der einzelnen Wellenlängen unumgänglich.

Da im allgemeinen mit Abnahme der Wellenlänge die chemische Wirkung wächst, so wird es sich infolgedessen darum handeln, nier zu untersuchen, ob diese Regel auch beim Plexus Geltung hat, und wie die feineren Verhältnisse sich gestalten.

D. h. die einzelnen Wellenlängen müssen isoliert verwendet werden. Da mir nun hierzu keine exakten Apparate zur Verfügung standen, so musste ich mich der, wie ich aus der Literatur ${ }^{1}$ ) sah, immerhin allgemeinere Verwendung findenden, S. 318-323 beschriebenen Methodik bedienen. Wenn die Exaktheit dieses Verfahrens auch vieles zu wünschen übrig lassen dürfte, so kann doch daraus annähernd der Schluss gezogen werden, dass auch bejm Plexus die blauen Strahlen die grösste Wirkung entfalten, d. h. speziell die

1) Tappeiner und Jodlbauer, Über die Wirkung des Lichts auf Enzyme in Sauerstoff- und Wasserstoffatmosphäre, verglichen mit der Wirkung der photodynamischen Stoffe. Deutsches Arch. f. klin. Med. Bd. 85 S. 386 ff. 1905. 
Wellenlängen von $545-400 \mu \mu$, während das Strahlenbündel von $705-545 \mu \mu$ sehwächer und das von $705-590 \mu \mu$ am schwächsten wirkt. D. h. die Wellenlängenbreite von $145 \mu \mu$ des Methylenblaus entfaltet eine grössere Wirkung als die von $235 \mu \mu$ des Hämoglobins. Die Art der Wirkung ist bei allen Strahlenarten dieselbe, $d$. h. es treten Steigerungen der Oxydation ein, die sich nur durch mehr oder weniger grosse Intensität voneinander unterscheiden, wobei die durch Belichtung von weissem Licht erzengte das Maximum darstellt, was begreiflich ist, wenn man bedenkt, dass schliesslich auch die durch Neutralrot passierte Lichtart nicht ohne deutlichen Einfluss bleibt.

Die Tatsache, dass fernerhin (S. 321) die Verdopplung der Schichthöhe nur beim Methylenblauversuch von deutlicher, abschwächender Wirkung ist, zeigt ausserdem, wie intensiv die kurzwelligen Strahlen gegenüber den längerwelligen absorbiert werden, bei denen diese Massnahme keine manifeste Folge aufweist.

Fasst man nun alle die durch Belichtung erzeugten Phänomene zusammen, so dürfte die Berechtigung für die der ganzen Darlegung zugrunde gelegte rein chemiseh theoretische Anschauung sich ohne wesentlichen Widerspruch ergeben. Die Definition der Lichtwirkung würde also folgendermassen lauten:

Das Licht bringt in der Plexuszelle a f chemischem Wege eine nicht näher präzisierbare Veränderung der Lipoide zustande, die derjenigen nicht unähnlich ist, welche bei der Zelloxydation entsteht, und ihr zugrunde liegt. Infolgedessen wird der Widerstand der Lipoid-Plasmaverbindung gegen Zersetzung erniedrigt; das Licht wird dadurch zu einem fördernden Oxydationsreiz. Die Sekretion aber, in deren entgegengesetzter Richtung die Lichtlipoidveränderung liegt, wird gehemmt, d. b. das Licht wirkt als hemmender Reiz auf die Sekretion.

Es ist nun klar, dass neben der Sekretion und der Autolyse, die kaum in Betracht gezogen werden können, auch noch andere Prozesse gehemmt und wieder andere gefördert werden können. Als Beitrag zur ersteren Möglichkeit darf noch die Störung der Zellteilung, die nach Hertel ${ }^{1}$ ) eine regelmässige Folge der Belichtung ist, er-

1) Hertel, Über die Einwirkung der Lichtstrahlen auf den Zellteilungsprozess. Zeitschr. f. allgem. Physiol. Bd. 5 Heft 4. 1905. 
wähnt werden, was vielleicht deswegen grösseres Interesse verdient, als dadurch ohne weiteres ein gewisses Licht auf die so dunklen Prozesse geworfen wird, die der Teilung zugrunde liegen und offenbar synthetischer, nach $\mathrm{Namias^{1 }}$ ) endothermaner Natur sind.

Da das Licht ein fördernder Oxydationsreiz ist, so kann fernerhin die Lipoidveränderung nicht allzu tiefgreifend sein. Denn in diesem. Falle müsste, wie die Autolyse bei Sauerstoffzufuhr zeigt, alsbald der Tod eintreten. Wenn daher auch oben die Radiumwirkung zum Vergleiche herangezogen worden ist, so können die nach Werner ${ }^{2}$ ) dort geltenden Gesetze einer Zersetzung des Lecithins mit Cholinbildung beim Lichte nicht in Erwägung kommen; sie bilden nur eine gewisse Analogie. Die Radiumwirkung dürfte einer gesteigerten Lichtwirkung entsprechen, die eben wegen der tiefgehenden Lecithin- resp. Lipoidzersetzung die intensiven Nekrosen erzeugt im Gegensatz zur leichten Hyperämisierung durch Lichtstrahlen. $\mathrm{Ob}$ die Analogie noch weitergeht, d. h. ob das Radium auch ein Oxydationsreiz ist und nur durch die Verbrennungsprozesse, d. h. auch indirekt wirkt, das zu entscheiden liegt nicht im Rahmen dieser Arbeit.

Der Vollständigkeit halber ist nur noch ein Moment der Lichtwirkung als Oxydationsreiz zu beleuchten, die Tatsache, dass die Steigerung der Verbrennung sich so äussert wie bei Erhöhung der Sauerstoffspannung; d. h. mit anderen Worten, das Licht kann gleichsam vikariierend für einen Teil des Sauerstoffdruckes eintreten, so dass also der Sauerstoffdruck, der gleichsam auch als ein Oxydationsreiz aufgefasst werden kann, zum Teil durch einen anderen Reiz ersetzlich ist und zum Teil nicht, während eine solche unersetzliche Komponente beim Lichtoxydationsreiz sich nicht finden lässt. Beide Oxydationsreize sind daher in ihrer biologischen Wertigkeit verschieden; der eine ist primärer, der andere sekundärer Natur. Da nun, wie oben bemerkt, bei starker Lichtwirkung unter Umständen eine tiefergehendere Spaltung erzeugt werden kann, als durch das vorhandene Sauerstoffquantum ausgenützt wird, wobei

1) Namias, Photochemische und thermochemische Betrachtungen. Gaz. chim. ital. t. 26 fasc. 35.1896.

2) Werner, Zur Kenntnis und Verwertung der Rolle des Lecithins bei der biologischen Wirkung der Radium- und Röntgenstrahlen. Deutsche med. Wochenschr. Nr. 2. 1905. - Zur chemischen Imitation der biologischen Strahlenwirkung. Münchener med. Wochenschr. 1905 Nr. 15. 
alsbald eine Störung des Verhältnisses von Dissimilation und Assimilation entsteht, so heisst dies nun mit anderen Worten:

Der ersetzbare und der unersetzbare Anteil des primären Oxydationsreizes stehen in einem bestimmten Verhältnis zueinander und zur Grösse des Gesamtreizes; und wenn die Spaltung durch Licht grösser wird, als das verfügbare Sauerstoffquantum zu decken imstande ist, so besagt dies nun, dass einmal der gesamte ersetzbare Anteil des primären Reizes ersetzt ist, und dass andrerseits der gesamte Sauerstoffdruck, die frühere ersetzbare und unersetzliche Komponente desselben, nun dem unersetzbaren Anteil des durch das Licht gesteigerten neuen Oxydationsreizes entspricht, aber nur in einem gewissen Grade, nicht vollkommen; d. h. die Störung des Verhältnisses von Assimilation und Dissimilation ist gleichbedeutend mit der Störung des Verhältnisses von ersetzbarer und unersetzlicher Komponente des primären Oxydationsreizes. $\mathrm{Ob}$ dies nur hier in Erscheinung tritt, oder ob, was wahrscheinlich ist, eine solche Beziehung sich auch bei anderen Prozessen zeigt, kann hier, als zu weit führend, nicht entschieden werden.

Von Interesse dürfte nur noch sein, dass eventuell die durch das Licht repräsentierte Sauerstoffspannung sich bestimmen lassen könnte. Wie schon früher ${ }^{1}$ ) angegeben, könnte durch Exposition des vorbehandelten Plexus in Räumen mit verschiedenem bekanntem Sauerstoffdruck der Minimaldruck, bei dem eben eine etwas geschwächte Reduktion stattfindet, d. h. Färbung, auftritt, bestimmt werden. Durch gleichzeitige Belichtung mit einer bekannten, gegenüber dem zu intensiven Sonnenlicht in bestimmter Weise geschwächten Lichtmenge würde dieser Minimaldruck noch tiefer sinken; die Differenz zwischen dem Belichtungs- und Dunkelpräparat aber würde der durch das Licht repräsentierten Sauerstoffspannung entsprechen. Was mit weissem Lichte nun möglich wäre, könnte auch mit farbigem versucht werden. So würde sich eine relativ genaue Skala möglicherweise für das weisse Licht und seine einzelnen Qualitäten aufstellen lassen.

Da nun neben den chemisch wirksamen Strahlen im Spektrum auch thermische Strahlen vorhanden sind, so wird es weiterhin von

1) Schläpfer, Über den Bau und die Funktion der Epithelzellen des Plexus chorioideus des Frosches usw. Beitr. z. allgem. Pathol. u. pathol. Anat. Bd. 7 (Suppl.) S. 143 u. 144. 1905. 
Beiträge zur Frage der oxydativen Leistungen der tierischen Zelle etc. 371

Interesse sein, die Wirkung dieser mit denen des kurzwelligen Teiles zu vergleichen. Während es nun wohl möglich war, die chemischen Strahlen resp. die chemische Komponente der Strahlenwirkung überhaupt isoliert zur Geltung zu bringen, war diese Trennung bei der thermischen Komponente leider nicht zu erzielen.

Da aber offenbar die Wirkung der fortgeleiteten Wärme von derjenigen der strahlenden nicht wesensverschieden sein kann und der grösseren thermischen Energie der langwelligen Strahlen jedenfalls eine Erhöhung der Temperatur ungefähr entsprechen dürfte, so glaube ich in der getroffenen Versuchsanordnung einen fundamentalen Fehler ausschliessen zu können.

Was nun die Wirkung der Wärme in der Biologie anbelangt, so sind die Literaturangaben hierüber, abgesehen von der Bakteriologie, nicht sehr erschöpfend. Nach Jacobson ${ }^{1}$ ) lässt sich durch Erhöhen der Temperatur die Cilienbewegung beleben; nach Abegg ${ }^{2}$ ) entwickeln sich Seeigel bei einem Plus von $10^{\circ} \mathrm{C}$. um das Zweibis Dreifache rascher, und nach $\mathrm{Czapek}^{3}$ ) zeigen die Enzyme ein ausgesprochenes Temperaturoptimum. Über die tieferen Ursachen dieser Erscheinungen finden sich keine Daten.

Da nun, wie die Versuche zeigen, der Ablauf der Reduktionserscheinungen bei hoher und niedriger Temperatur sich ungefähr gleichartig verhält, nur rascher erfolgt bei Erwärmen, so darf daraus offenbar gefolgert werden, dass - zum mindesten innerhalb gewisser. Temperaturgrenzen - beim Frosch Wärme keinen spezifisch chemischen Finfluss besitzt, sondern, wie aus der Physik und Chemie längst bekannt ist, nur den Umsatz in an sich gleicher Weise beschleunigt. $\mathrm{Ob}$ dies auch für die grösseren Temperaturextreme gilt, lässt sich hier nicht entscheiden, ist aber von vornherein sehr unwahrscheinlich, für den Warmblüter sicherlich direkt auszuschliessen.

Für ganz hohe Extreme ist diese Wärmewirkung a priori auch beim Kaltblüter entschieden eine veränderte, da nicht unbedingt anzunehmen ist, dass in diesen Fällen alle intrazellularen chemischen Vorgänge sich in gleicher Weise verändern, wo der Tod durch Gefrieren oder Gerinnen des Eiweisses droht.

1) Jacobson, Über die Wirkung fluoreszierender Stoffe auf Flimmerepithel. Zeitschr. f. Biolog. Bd. 41 S. 444 ff. 1901.

2) A begg, Der Temperatureinfluss auf die Entwicklungsgeschwindigkeit animalischen Lebens. Zeitschr. f. Elektrochemie Bd. 11 S. 528.

3) $\mathrm{Czapek}$, Biochemie der Pflanzen Bd. 1 S. $69 \mathrm{ff} .1905$. 
Die Wärmewirkung der hier in Betracht fallenden Temperaturgrenzen aber ist damit entschieden als keine spezifisch chemische charakterisiert. Sie ist eine Wirkung allgemeinerer Natur, beruhend auf der Tatsache, dass Wärme überhaupt den Umsatz der chemischen Prozesse beschleunigt.

Dadurch entfällt weiterhin endgültig ein Einwand, der in der Wasserkühlung als Absorbent der thermischen Komponente des Lichtes lag, da die Wärmewirkung nach diesen Versuchen grundsätzlich verschieden von der des Lichtes ist. Es ist dies um so wichtiger, als nun die durch verschiedene Lichtintensitäten, wie z. B. das filtrierte Licht, erhaltenen Resultate, die auch durch thermische Unterschiede hätten mitbedingt sein können, eine genauere Einschätzung gestatten und die Berechtigung des Vergleichens derselben nun eine zweifellose Basis erhält.

Während also die Energie der langwelligen Strahlen sich in mehr allgemeinerer Art biologisch äussert, tritt sie bei den kurzwelligen Strahlen durch spezifische Beeinflussung einzelner Zellprozesse biologisch in die Erscheinung.

Bei der Prüfung der biologischen Wertigkeit der einzelnen Wellenlängen war das erwartete Ergebnis zutage getreten, dass mit Abnahme der Wellenlängen der Einfluss der Strahlen auf den Oxydationsprozess in einem ziemlich intensiven Grade steigt, indem das durch Methylenblaulösung passierende Lichtbündel trotz seiner relativ geringeren Spektralbreite mit einem Plus von 70 Längeneinheiten gegen das kurzwellige Ende hin einen bedeutend stärkeren Einfluss entfaltet als das grössere Bündel, das durch die Hämoglobinlösung filtrierte.

Wohl zuerst durch die Arbeiten Finsen's dürte nachgewiesen worden sein, dass in der Tat das sogenannte ultraviolette Spektrum, trotzdem es keine Sehempfindung mehr zu erzeugen vermag, doch ausserordentlich biologisch wirksam ist, dass also die Zunahme der Wirkung nicht etwa mit dem blauen Spektralende Halt macht, und dass Strahlen von ganz ausserordentlicher Wirksamkeit und demselben Charakter wie die üblichen Lichtstrahlen existieren. Die speziell therapeutischen Erfolge mit der sogenannten Uviollampe und ihrem ultravioletten Spektrum, auf die namentlich $A \times \operatorname{man} n^{1}$ ) aufmerksam

1) Axmann, Wundbehandlung mittelst ultravioletten Lichts. Münchner med. Wochenschr. Bd. $52 \mathrm{Nr}$. 36. - Die Uviolquecksilberlampe und Lichtbehandlung mittelst ultravioletter Strahlen. Mediz. Klinik Nr. 4. 1906. 
gemacht hat, haben Finsen's Anschauung weiterhin bestätigt. Aus den Arbeiten Hertel's ${ }^{1}$ ) nun geht hervor, dass wahrscheinlich die Zunahme der Wirkung nur bis zu einer bestimmten Wellenlänge noch steigt, $d . h$. der Wellenlänge $\lambda=280 \mu \mu$, bei der weiteren Abnahme derselben ebenfalls sinkt. Diese Strahlen von einem $\lambda$ von $280 \mu \mu$ sollen nach Hertel geradezu nach Art eines Katalysators wirken; d. h. mit anderen Worten, sie können offenbar mit einer relativ geringen Intensität eine relativ grosse Wirkung erzielen, weil sie den günstigsten Weg einzuschlagen vermögen; ist doch das Licht überhaupt nach der Untersuchung von Grijns und Noyons ${ }^{2}$ ) der feinstempfundene Sinnenreiz, da schon eine Energie von $10^{-10} \mathrm{Erg}$ genügen soll, um eine Empfindung auszulösen, gegenüber $10^{-8} \mathrm{Erg}$ beim Gehör.

Es können also unter Umständen noch sogenannte Lichtstrahlen von a priori sehr geringer Lichtstärke doch eventuell biologisch von Bedeutung sein, wie z. B. die in einer früheren Untersuchung ${ }^{3}$ ) beim Kaninchenblute nachgewiesenen, von $\mathrm{Werner}^{4}$ ) bestätigten und S. 304-306 auch beim Froseh- und Menschenblut konstatierten sogenannten photoaktiven Strahlen, speziell des Blutes, respektive der tierischen Gewebe.

Nach der früher dargelegten Anschauung ${ }^{3}$ ) handelt es sich bei dieser Lichterscheinung um eine sogenannte Chemiluminiszenz, speziell um eine Oxydation besonders oder vielleicht nur des Lecithins, Cholesterins respektive der Lipoide des leuchtenden Körpers, wie sie gerade an diesen Stoffen und noch an zahlreichen anderen von Radziszewski ${ }^{5}$ ) nachgewiesen und auf Grund der Maxwellschen Theorie als Verbrennungserscheinung bei langsamer Zersetzung erklärt worden ist.

1) Hertel, Über physiologische Wirkung von Strahlen verschiedener Wellenlänge. Zeitschr. f. allgem. Physiol. Bd. 5 Heft 4. 1905.

2) Grijns und Noyons, Über die absolute Empfindlichkeit des Auges für Licht. Arch. f. Physiol. 1905 Heft 1 und 2.

3) Schläpfer, Photoaktive Eigenschaften des Kaninchenblutes. Pflüger's Arch. f. Physiol. Bd. 108 S. 537-62.

4) Werner, Erworbene Photoaktivität der Gewebe als Faktor der biologischen Strahlenwirkung und ihrer Imitation. Münchn. med. Wochenschr. $1906 \mathrm{Nr} .1$.

5) Radziszewski, Über die Phosphoreszenz der organischen und organisierten Körper. Liebig's Annalen der Chemie Bd. 203 S. 305-336. 1880. 
Nach Trautz ${ }^{1}$ ) soll diese Chemiluminiszenz mit der Kristalloluminiszenz usw. viele Ähnlichkeit besitzen und durch Steigerung respektive Änderung des erzeugenden Prozesses nicht nur in ihrer Intensität, sondern auch in der Wellenlänge ${ }^{2}$ ) verändert werden.

Aus den Untersuchungen Straub's ${ }^{3}$ ) über photodynamische Körper geht ferner hervor, dass einmal Belichtung die Oxydation derselben steigert, und dass diese Steigerung am meisten durch diejenigen Strahlenarten erzielt wird, in denen diese Stoffe selbst leuchten. Da das Leuchten selbst aber höchstwahrscheinlich auch mit der Oxydation im Zusammenhang steht, in dem Sinne, dass es nach

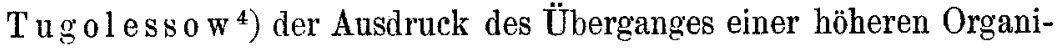
sation in eine niedrigere ist, eines exothermanen Prozesses, so entfaltet die Oxydation dieser Körper gleichsam eine sish selbst steigernde Wirkung.

Unter Berücksichtigung all dieser Tatsachen und Anschauungen wird das Verständnis der sogenannten biologischen Wirkung der Photoaktivität bedeutend erleichtert und kann eine allgemeine Erklärung derselben mit ziemlicher Berechtigung gefunden werden.

Aus den S. 336-337 niedergelegten Untersuchungen geht hervor, dass bei denjenigen Präparaten, die im Dunkeln mit einem Blutdeckgläschen aufbewahrt werden, den Blutpräparaten, die Färbung in der Regel etwas langsamer auftritt als in den Dunkelpräparaten und meist auch nicht denselben Grad erreicht, d. h. die Reduktion respektive die Oxydation ist bei jenen trotz desselben Sauerstoffdruckes etwas energischer als bei diesen, zeigt also Ähnlichkeit mit der der belichteten Präparate.

Die Ursache der energischeren Oxydation muss beim Blutpräparat also jedenfalls im Blutdeckgläschen liegen. Da dieses durch ein anderes Deckgläschen vom Präparat getrennt ist, so kann

1) Trautz, Über neue Luminiszenzerscheinungen. Zeitschr. f. wissensch. Photogr. Bd. 2 S. 217 ff. 1904.

2) Trautz und Schorigin, Kristalloluminiszenz und Triboluminiszenz. Zeitschr. f. wissensch. Photogr. 1905 Heft 2. - Über Chemiluminiszenz. Ebenda Heft 3.

3) Straub, Über chemische Vorgänge bei der Einwirkung von Licht auf fluoreszierende Substanzen (Eosin und Chinin) und die Bedeutung dieser Vorgänge für die Giftwirkung. Münchn. med. Wochenschr. Nr. 25 S. 10931904.

4) Tugolessow, Beiträge zur Frage der chemischen Veränderung unter dem Einflusse des Lichts. Ref. in Zeitschr. f. wissensch. Photogr., Photophysik und Photochemie Bd. 2. 1904. 
der vermittelnde Faktor nicht ein eventuell ausgeströmtes Gas sein, auf Grund der biologischen Bedeutung der Wärme auch keine Wärmezufuhr, sondern er muss ein strahlendes, die Medien durchdringendes Moment sein, d. h. wohl mit grösster Wahrseheinlichkeit die Luminiszenz des Blutes.

Da aber die Natur dieser Lichterscheinung nicht wesensverschieden von der des Sonnenlichtes sein kann, so darf es wohl erlaubt sein, der Erklärung der Erscheinung auch die bei der biologischen Lichtwirkung gewonnene Anschauung zugrunde zu legen, d. h. die Annahme, dass man es auch bei der Luminiszenz mit einer rein chemischen Alteration speziell der Lipoidkomponente der LipoidPlasmaverbindung im Sinne einer Erniedrigung des Widerstands derselben gegen eine oxydative Spaltung zu tun hat.

Aus den Versuchen mit der photographischen Platte geht nun hervor, dass bei dieser Luminiszenzlichtenergie ein offenbar ausserordentlich geringer Energiewert vorliegt, der überhaupt nur dadurch zur Wirkung kommt, dass er unter möglichst günstigen Umständen arbeitet, d. h. mit kurzwelligen Strahlen.

Ebenso ist auch der biologische Effekt dementsprechend sehr gering, aber doch deutlich, was eigentlich nicht $\mathrm{zu}$ erwarten ist, wenn man bedenkt, dass die Verhältnisse hier ungünstiger sind als bei der Bromsilbergelatineplatte, indem die Strahlen hier eine dünne Schicht Kochsalzlösung und zwei Deckgläschen passieren müssen, das Glas aber speziell kurzwellige Strahlen zu absorbieren imstande ist.

Eine weitere Überlegung, die sich aus der Stra u b' schen Untersuchung ergibt, dürfte daher als weiter erklärendes Moment willkommen sein. Wenn auch Straub seine Beobachtung, dass die fluoreszierten oder ihnen ähnlichen Strahlen die Oxydation des emittierenden Körpers am meisten steigern, bei photodynamischen Stoffen gemacht hat, so spricht doch jedenfalls nichts dagegen, dass dies auch bei den in gewisser Hinsicht sich ähnlich verhaltenden Lipoiden Geltung hat. Mit dieser Annahme aber würde alsdann die Luminiszenz, die bei der Lipoidoxydation frei wird, diese selbst fördern, wenn sie auf Lipoide treffen würde bei Sauerstoffanwesenheit. Es macht dies fernerhin wahrscheinlich, dass auch die durch das Licht erzeugte Lipoidveränderung, wie es schon von $\operatorname{Radziszewski}{ }^{1}$ ) für wahrscheinlich gehalten wurde, eine Art Oxydation ist.

1) Radziszewski, Über die Phosphoreszenz der organischen und organisierten Körper. Liebig's Annalen der Chemie Bd. 203 S. 305-336. 1880. 
Da nun das Blut auf Grund der Oxydation seiner Lipoide luminisziert, der Plexus selbst aber ebenfalls, sowobl in seinen Zellen als in den in den Kapillaren vorhandenen Erythrocyten Lipoide enthält, die dort speziell an der Zelloxydation beteiligt sind, also bei Sauerstoffanwesenheit, so ist nicht auszuschliessen, dass die Blutluminiszenz nicht nur wegen ihrer kurzwelligen Strahlen zu wirken vermag, sondern auch deshalb, weil der aufnehmende, strahlenabsorbierende und $z u$ oxydierende Körper eine ganz besondere Affinität zu diesen Strahlen besitzt und sich unter ihrem Einfluss besonders intensiv oxydiert.

Dann ist das gesamte Phänomen einigermassen verständlich, und es ist zur Vervollständigung der Erklärung nur noch nötig, einzelne besondere Erscheinungen mit dem Dargelegten in Einklang zu bringen.

Hier ist vor allem hervorzuheben, dass einmal verschiedene Körper, wie das Blut vom Menschen, von Rana esculenta und temporaria, das Papier und Stanniol, die photographische Platte verändern, dass Belichtung des Blutes oder Vergiftung mit $\mathrm{KClO}_{3}$ diesen photoaktiven Einfluss in der Regel steigern, sodann, dass diese verschiedenen Stoffe biologisch sehr verschieden wirken, ja dass trotz positivem Plattenversuch eine biologische Wirkung kaum wahrzunehmen ist, und umgekehrt diese deutlich ist, jener ganz negativ, ferner dass der Ablauf der Cilienbewegung gegenüber dem Dunkelpräparat gewisse periodische Schwankungen aufweist, und dass im Gegensatz zum Lichte beim Blutpräparat die Cilienbewegung länger dauert und dabei oft die des Dunkelpräparates noch übertrifft.

Die Annahme, dass die Luminiszenz eines Körpers auf Oxydation beruhen kann, muss a priori in sich schliessen, dass Luminiszenz, wie die angegebenen und früheren Versuche ${ }^{1}$ ) und die Arbeiten von Russel ${ }^{2}$, Werner ${ }^{3}$, Molis $\mathrm{ch}^{4}$ ) usw. zeigen, in der Tat bei verschiedenen langsam oxydablen Stoffen vorkommen muss, und wenn die Erklärung Radziszewski's, wonach sich Ätherwellen durch lebhaftere Schwingungen einzelner Moleküle nach der Maxwell'-

1) Schläpfer, Photoaktive Eigenschaften des Kaninchenblutes. Pflüger's Arch. f. d. ges. Physiol. Bd. 108 S. 537-562.

2) Russel, Über Bilder, die im Dunkeln auf photographischen Platten entstehen. Zeitschr. f. physik. Chemie Bd. 37. 1901. Referat.

3) Werner, Erworbene Photoaktivität der Gewebe als Faktor der biologischen Strahlenwirkung und ihrer Imitation. Münchner med. Wochenschr. 1906 Nr. 1.

4) Molis ch, Leuchtende Pflanzen. Eine physiol. Studie. G. Fischer. 1904. 
schen Theorie, also durch die bei der Oxydätion frei werdende Wärme bilden, den Verhältnissen entspricht, kann nicht nur Oxydation, sondern können auch andere Prozesse, wie $\mathrm{Trautz}^{1}$ ) gezeigt hat, Luminiszenz zur Folge baben.

Diese verschiedenen Quellen lassen es daher sehr wabrscheinlich erscheinen, dass die einzelnen Luminiszenzlichtqualitäten an sich verschieden sind, um so mehr, da nach Trautz schon Steigerung desselben Prozesses die Wellenlänge verändert. Es ist aber fernerhin einzuräumen, dass auch dasselbe Luminiszenzlicht aus verschiedenartigen Strahlen bestehen kann, das von Trautz beschriebene Phänomen als eine Vermehrung einzelner Lichtarter zuungunsten anderer alsdann verstanden werden könnte. $\mathrm{Ob}$ dies der Fall ist, darüber werden eo ipso uns weitere Versuche Auskunft geben können, und kann die Tatsache, dass sogenanntes photonegatives Blut, das die Platte nicht veränderte, wohl aber biologisch wirksam, d. h. bioaktiv war, eventuell in diesem Sinne ausgelegt werden, ferner die Steige-

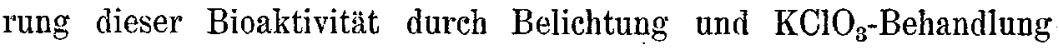
und die Bionegativität des Papiers.

Das Papier besitzt eine relativ ziemlich intensive Luminiszenz, wenigstens in betreff der photographischen Plattenveränderung. Biologisch aber war keine Wirkung zu erkennen; offenbar sind die sogenannten photoaktiven und bioaktiven Strahlen verschieden; die Bromsilbergelatineplatte und das Lipoid der Gewebe sind keine identischen Reagentien für dasselbe Licht, weshalb sogenanntes photonegatives Blut doch bioaktiv sein kann und umgekehrt, also z. B. auch das sogenannte photonegative Blut pigmentierter Kaninchen ${ }^{2}$ ); die Empfindlichkeit beider dürfte aber jedenfalls eine ähnliche sein. Das Stanniol nun scheint sowohl photo- als bioaktiv zu sein, enthält also in seiner Luminiszenz verschiedene Strahlen, und ihm ähnlich ist das Blut, das fast stets bioaktiv, nicht immer aber und stets schwächer: photoaktiv ist, was mit der gesamten Auffassung im Einklang wäre. Trotzdem ist aber auch beim Blute eine gewisse Variation in der Zusammensetzung des Luminiszenzlichtes sicherlich anzunehmen, die sich durch irgendwelche äusseren Einflüsse weiterhin verändern kann. D. h. die Zusammensetzung der Luminiszenz dürfte für ein und die-

1) Trautz und Schorigin, Kristalloluminiszenz und Chemieluminiszenz. Zeitschr. f. wiss. Photogr. Bd. 2 S. 214 ff. 1904.

2) Schläpfer, Photoaktive Eigenschaften des Kaninchenblutes. Pflüger's Arch. f. d. ges. Physiol. Bd. 108 S. 537-562. 
selbe Blutart nur bis zu einem gewissen Grade konstant sein, was einen Vergleich der in Tabelle XI-XIV niedergelegten Versuchsergebnisse der einzelnen Blutarten mit Vorsicht aufnehmen lässt. Durch irgendeinen äusseren Umstand, wie etwas intensivere Belichtung, kaṇ̨ die Bioaktivität eines Präparates sich ändern.

Belichtung und $\mathrm{KClO}_{3}$-Zusatz scheinen nun stets eine Steigerung der Bioaktivität und Photoaktivität zur Folge zu haben. Da Belichtung nach Radziszewski (s. oben) die Oxydation vieler organischer Körper beschleunigt, ist dies ohne weiteres zu verstehen, ebenso wie die Wirkung des als Sauerstofflieferant bekannten Kalichloricums, das nur das Hämoglobin angreift, die Katalase, das Oxydationsferment des Blutes aber, das für die Oxydation eo ipso von Bedeutung ist, nach $\mathrm{Bredig}^{1}$ ) intakt lässt. $\mathrm{Ob}$ schliesslich bei bestimmter Intensität auch die sogenannten photoaktiven Strahlen bioaktiv werden können, und umgekehrt, was nicht unwahrscheinlich ist, d. h. ob die Steigerung durch Belichtung und $\mathrm{KClO}_{3}$-Lösung in der Tat auf einer Erhöhung der bio- und photonktiven Strahlenenergie beruht, kann hier nicht entschieden werden. Eine Antwort auf diese nicht uninteressante Frage aber wird vielleicht eine Filtration der Luminiszenz durch bestimmte Glasarten im Sinne der Methode III (s. S. 305) geben können.

Da nun durch Belichtung die bioaktive Kraft des Blutes wächst, so ist es möglich, dass dies auch intra vitam im Kreislauf eintreten kann. Denn wie Helber und Li is ser ${ }^{2}$ ) an Röntgenversuchen nachgewiesen haben, vermögen Röntgenstrahlen das kreisende Blut zu beeinflussen. Da aber auch das Sonnenlicht bis zu einem gewissen Grade in die Cutis eindringen kann, sicherlich bis zu den Malpighi'schen Gefässschlingen, so wäre eine Blutbeeinflussung auch durch Sonnenlicht und damit eine universelle Wirkung desselben auf die durch das stärker luminiszierende Blut auch stärker oxydierenden Gewebe möglich.

Dadurch kann möglicherweise etwas Licht in die Pathogenese einiger Krankheiten gebracht werden und in die Biologie des Pigmentes, das speziell in der Haut an der oberen Schicht der Subcutis liegt und ein Tieferdringen der Lichtstrahlen verhindern könnte,

1) Bredig and Ikeda, Über anorganische Fermente. II. Lähmung der Platinkatalyse durch .Gifte. Zeitschr. f. physik. Chemie Bd. 37. 1901.

2) Helber und Linser, Experimentelle Untersuchungen über die Einwirkungen von Röntgenstrahlen auf das Blut. Münchener med. Wochenschr. 1905 Heft 15. 
womit die von Schmaedel ${ }^{1}$ ) ausgesprochene Theorie der Schutzwirkung des Pigmentes eine Stütze erfahren würde. Von Interesse wäre es alsdann, zu erfahren, ob das Blut pigmentierter Kaninchen in der Tat bioaktiv und in welcher Intensität die Bioaktivität gegenüber dem Blut albinotischer Kaninchen ausgesprochen wäre.

Auf dieser Anschauung beruht möglicherweise auch die in Tabelle XIII Abschnitt IV kurz angedeutete Tatsache, dass das Blut im Dunkeln gehaltener Frösche von denen im Licht aufbewahrten Unterschiede des bioaktiven Verhaltens zeigt in dem Sinne, dass die Plexusfärbung bei den letzteren eine geringere Intensität zeigt als bei den erstern, beruhend auf einer eventuellen lebhafteren Oxydation in jenen auf Grund einer vorhergehenden intensiveren Bestrablung durch das perkutan belichtete kreisende Blut. Dies Verhalten scheint auch imitiert werden zu können durch lange Exposition der Dunkelfrösche am Lichte. Da aber die Versuche hierüber noch spärlich sind, so soll damit nur eine Vermutung ausgesprochen sein, und muss ich mir weitere Experimente vorbehalten.

So muss es daher noch unentschieden bleiben, worauf die in Tabelle XIII, Abschnitt II und III regelmässig zutage tretende grössere Bioaktivität des Blutes von Rana esculenta beruht, ob auf einer lebhafteren Oxydation infolge intensiverer Belichtung bei der relativ im Gegensatz zu Rana temporaria pigmentärmeren Cutis der Tiere oder auf anderen Momenten.

Es liegt hier auch nahe, an eine sogenannte gegenseitige Anpassung zu denken, d. h. an die Annahme, dass die Lipoide eines Tierkörpers auch wegen ihrer Luminiszenz - der man unmöglich jede biologische Funktion absprechen kann, wie es $\mathrm{Püte} \mathbf{r}^{2}$ ) vielleicht in etwas zu weitgehender Art zu tun scheint - einander entsprechen müssen, speziell im Verhältnis vom Blut zu den Geweben. Denn das Blut wird als das sauerstoffreichste Gewebe auch die lebhafteste Oxydation und Luminiszenz seiner Lipoide besitzen; allerdings ist möglich, dass durch gewisse Fermente im Sinne einer negativen Katalyse $^{3}$ ) der Oxydation durch die Oxydase entgegengearbeitet

1) Wo odruff, Die Wirkung des tropischen Lichts auf Weisse. Münchener med. Wochenschr. $1905 \mathrm{Nr}$. 37. Referat.

2) Pütter, Leuchtende Organismen. Zeitschr. f. allgem. Physiol. Bd. 5 Heft 2 u. 3.

3) Titoff, Beiträge zur Kenntnis der negativen Katalyse im homogenen System. Zeitschr. f. physikal. Chemie Bd. 45. 
werden kann; doch ist das eine rein theoretische Mutmassung. Nach den früheren Versuchen ${ }^{1}$ ) spielt die Vitalität des Blutes keine grosse Rolle, sondern nur die der Plexuszellen, was auch verständlich macht, dass sogenannte blutreiche Präparate sich von blutarmen nicht wesentlich unterscheiden. Sicherlich spielt der Sauerstoffdruck, der bei beiden Präparaten der gleiche, gegenüber dem atmosphärischen Partiardruck aber kleiner ist, die Hauptrolle, weshalb zwischen Blutund Dunkelpräparat sich ein Unterschied ergibt, zwischen blutreichem und blutarmem Plexus dagegen kaum.

Gegen eine solche gegenseitige Anpassung der Lipoide aber lässt sich nun wiederum anführen, dass die grössere Luminiszenzwirkung sich auch beim Plexus von Rana temporaria zeigt; die Anpassung könnte alsdann keine weitgehende sein, um so mehr, da Stanniol auch wirkt. Die Frage nach der grossen Bioaktivität des Esculentablutes dürfte vorderhand noch eine offene bleiben.

Als nächste Aufgabe kommt nun in Betracht die Erklärung der eigentümlichen Periodizität der Cilienbewegung, die einen weiteren Einblick in das. Wesen der Lichtwirkung zu werfen gestatten dürfte.

Nach Engliseh ${ }^{2}$, Quincke ${ }^{3}$ ) u. a. besitzt bekanntlich die Bromsilbergelatine die Eigenschaft, erst auf eine sogenannte Minimalmenge von Lichtenergie, beim sogenannten Schwellenwert, zu reagieren. Lichterscheinungen unterhalb dieses Wertes werden nur dann von der Platte perzipiert, wenn sie längere Zeit unverändert einwirken, d. b. wenn die Exposition so lange dauert, dass durch Summierung der einzelnen in der Zeiteinheit auffallenden Energiemengen der entsprechende Wert erreicht werden kann, so z. B. beim Papier oder Blut nach ca. 1 resp. 10 Stunden, während das Tageslicht in der Regel eine solche Zeit zur Überwindung des Schwellenwertes, d. h. eine sogenannte Latenzzeit, nicht erkennen lässt, da sein Energiekoeffizient stets das nötige Minimum übersteigt.

Da nun nach den bisherigen Beobachtungen eine grosse Ähnlichkeit zwischen Bio- und Photoaktivität zu konstatieren ist, so liegt

1) Schläpfer, Photoaktive Eigenschaften des Kaninchenbluts. Pflüger's Arch. f. d. ges. Physiol. Bd. 108 S. 541 u. 542.

2) Englisch, Schwärzungsgesetz der Bromsilbergelatine. Habilitationsschrift. Stuttgart 1901.

3) Quincke, Die Bedeutung der Oberflächenspannung für die Photographie mit Bromsilbergelatine und eine nene Wirkung des Lichts. Poggendorf's. Annalen Bd. 11. 1903. 
es nahe, anzunehmen, dass auch das lebende Gewebe, resp. die Lipoid-Plasmaverbindung einen solchen Schwellenwert besitzt.

Dies vorausgesetzt, muss nun, falls eine relativ kleine, unter dem Schwellenwert liegende Lichtmenge in konstant bleibender Intensität auf die lebende Plexuszelle, die, wie die photographische Platte, gleichsam in unveränderter Situation der Belichtung exponiert ist, einwirkt, in dem Momente, wo die Summierung der einzelnen Lichteinheiten den Schwellenwert übersteigt, d. h. den minimalsten Widerstand überwindet, eine etwas grössere oxydative Spaltung eintreten resp. eine etwas lebhaftere Reduktion und, da die Cilienbewegung in ihrer Intensität in gewisser Beziehung der Intensität der Oxydation proportional ist, auch eine etwas lebhaftere Cilienbewegung.

Eine solche konstant bleibende Lichtmenge von sehr geringer Intensität aber kann nur in der Blutluminiszenz vorliegen. Unter dieser weiteren, offenbar nicht unwahrscheinlichen Annahme nun ist die Periodizität eine logische Konsequenz.

Während auf der photographischen Platte der durch einen dem Schwellenwert entsprechenden Lichtreiz erzeugte Eindruck unverändert erhalten bleibt, da die Plattenschicht selbst sich kaum und nur in sehr langer Zeit langsam so verändert, dass die erzeugte Veränderung alsdann nicht mehr konserviert ist, liegt im lebenden Gewebe an Stelle der Platte ein sich intensiv verändernder, stets wieder sich restituierender Prozess vor, so dass die in einem Moment erzeugte höhere Spaltung nur in einer kurzen Phase zur Geltung kommt, in der Zeit, in welcher ein und dieselbe Spaltung sich abspielt. Sobald aber dies eingetreten, gelangen wieder frische intakte Flächen zur Exposition, bei denen der Lichtreiz erst nach Summierung resp. nach einer Latenzzeit eine Veränderung hervorzubringen vermag. D. h. mit anderen Worten, beim Plexus wird die durch die Luminiszenz zugeführte Energie in dem Momente, wo sie den Schwellenwert überschreitet, verzehrt, und jedesmal nach Ablauf der Latenzzeit wird eine gewisse Beschleunigung sichtbar, die einige Zeit anhält und wieder dem früheren Zustand Platz macht.

Die Beschleunigung wird einige Zeit dauern, weil immer eine grosse Anzahl von Zellbezirken durch die Luminiszenz verändert ist und in entsprechendem Sinne auch eine Reihe von Spaltungen tiefer verlaufen.

Ob die Tatsache, dass bei niedrigerer Sauerstoffspannung diese Periodizität deutlicher zum Ausdruck kommt als bei höherer, darauf beruht, dass die durch die Luminiszenz bedingte 'Beschleunigung 
der Oxydation im Verhältnis zu der dem anfänglich grossen Sauerstoffdruck entsprechenden sehr gering und daher kaum wahrnehmbar ist, ist wahrscheinlich; sie kann aber ihre tiefere Ursache wiederum auch darin finden, dass bei der an sich relativ tiefen Spaltung die anfangs durch die Luminiszenz gegebene Erleichterung keinen eigentlichen Effekt haben kann, weil bekanntlich der Widerstand mit der Tiefe der Spaltung wächst, bei einer gewissen Tiefe also so gross wird, dass eine kleine vorarbeitende Spaltung ohne irgendwelchen Nutzen sein muss. Bei geringer Sauerstoffspannung aber ist die Spaltung flacher und muss einmal rom Gesichtspunkte des Beobachters aus der ursprünglich nicht bemerkte Zuwachs der Oxydationsbeschleunigung nun auffallen, da das Verhältnis günstiger ist, sodann aber auch auf Grund der theoretischen Überlegung als Faktor berücksichtigt werden, da die jetzt zu überwindenden Widerstände bedeutend kleiner sind, das Verhältnis von Luminiszenzenergie zu demselben also ebenfalls grösser, d. b. günstiger ist.

Dass umgekehrt beim selben Sauerstoffdruck die Zunahme der Beschleunigung und die Steigerung der Oxydation der Grösse der Luminiszenzenergie proportional sein muss, ist ebenfalls eine logische Konsequenz des vorigen. Denn wenn auch stets der Schwellenwert derselbe bleibt, so wird doch bei stärkerer Luminiszenz die schliesslich gerade nach Erreichung des Schwellenwertes wirkende Lichtmenge grösser sein als bei schwächerer Luminiszenz und zudem die Latenzzeit kürzer; d. h. wie die Beobachtung zeigt, muss das $\mathrm{KClO}_{3^{-}}$ Blut am stärksten bioaktiv sein und die deutlichste Periodizität zeigen.

Da nun mit abnehmender Sauerstoffspannung die Oxydation immer schwächer wird, so gewinnt die Luminiszenz immer mehr an Bedeutung, und schliesslich kommt ein Moment, wo das Blutpräparat gegenüber dem Dunkelpräparat ein Plus von Energie besitzt, d. h. beim Herannahen des Minimaldruckes. Wenn auch vorher im Blutpräparat zufolge der Luminiszenz der Sauerstoffkonsum etwas energischer war als im Dunkelpräparat, so konnte das aus den bereits dargelegten Gründen nur von zu vernachlässigender Bedeutung sein, da die energischere Oxydation kaum beobachtet werden konnte. Bei der Minimalspannung aber macht sich nun, wie auch gesagt wurde, die Zunahme des Quotienten von Luminiszenz und Sauerstoffspannung bemerkbar. Da ein Teil der Sauerstoffspannung, wie sich beim Lichte erwies, offenbar nur zur Überwindung des Widerstandes dient und durch andere Einflüsse ersetzbar ist, so kann nun die Luminiszenz für diesen ersetzbaren Anteil der Minimal- 
spannung eintreten, wobei auf Kosten dieses ersetzbaren Teils der unersetzliche Anteil wächst. Da der Sauerstoffkonsum im absoluten Sinne unter den vorwaltenden Umständen bei sogenanntem Minimalleben uberhaupt sehr klein ist, so hat diese Vergrösserung des unersetzlichen Anteils durch Vertretung des ersetzlichen so lange eine Verlängerung der Lebensprozesse zur Folge, bis aller verfügbare Sauerstoff verzehrt ist, d. h. die grösste dann, wenn der ganze ersetzbare Anteil der Sauerstoffspannung durch einen anderen äusseren Faktor ersetzt ist. Sobald der äussere Faktor aber grösser ist, wird auch der absolute Sauerstoffkonsum wieder grösser, die Verlängerung der Lebensprozesse fällt dahin.

Auf dieser Basis berubt offenbar die bereits angeführte, gegenüber der Luminiszenz auffallende Verkürzung der Cilienbewegung, d. h. des Lebens durch Belichtung, womit auch der grosse Unterschied zwischen Licht- und Luminiszenzwirkung, der eine Analogisierung etwas erschwerte, anstandslos aufgehoben sein dürfte.

Sicherlich geht aus diesen letzten Erörterungen hervor, dass die chemische Auffassung der Lichteinwirkung eine befriedigende Erklärung zu geben vermag; sie gibt eine ungefähre Anschauung von der Energiegrösse der Luminiszenz und einen Fingerzeig, in welcher Weise sich eventuell die Komponenten der Sauerstoffspannung in ihrer biologišchen Bedeutung bestimmen liessen, und damit zugleich einen weiteren Einblick in das Wesen der Oxydationsprozesse der Zelle, deren fundamentale Bedeutung zweifellos ist.

\section{Zusammenfassung.}

1. Der Sauerstoff beherrseht in der Zelle vermittelst eines aktivierenden Prinzipes, einer sogenannten Oxydase, die Oxydationsprozesse entsprechend seiner Spannung. Ein Teil dieser Spannung wird dabei zur Überwindung des Spaltungswiderstandes der in Frage kommenden Brennstoffe, die einer zunehmenden Spaltung einen immer grösser werdenden Widerstand entgegensetzen, benutzt und ist durch einen ähnlich wirkenden anderen Faktor ersetzbar. Der andere Teil, der zum ersten in einem konstanten Verhältnis steht, wird konsumiert und ist unersetzlich, weshalb der Sauerstoff ein fundamentaler Zellreiz. ist.

Ausser der Oxydation kann möglicherweise der Sauerstoff speziell beim Plexus chorioideus des Frosches noch in synthetiseher Richtung bei der Sekretion in Frage kommen.

2. Das Licht vermag die Sauerstoffspannung in gewissem Sinne 
zu ersetzen, indem es sehr wahrscheinlich auf rein chemischem, von Sauerstoffgegenwart unabhängigem Wege eine der oxydativen ähnliche Spaltung besonders der Lipoidsubstanzen hervorbringt, welche die biologische Bedeutung des Lichtes involviert, indem eine stärkere Oxydation entsteht durch Erniedrigung des Spaltungswiderstandes der Lipoid-Plasmakörper resp. der Brennstoffe. Die Wirkung des Lichtes ist proportional seiner Intensität, wächst ausserdem mit Abnabme der Wellenlänge und erfolgt ohne sichtbare Latenzzeit.

3. Die Wärme beschleunigt innerhalb gewisser Temperaturgrenzen in gleichmässiger Weise alle Zellprozesse, hat also keine spezifische Wirkung.

4. Die Luminiszenz des Blutes besteht wahrscheinlich aūs verschiedenen Strahlenarten, mehr bio- und mehr photoaktiven. Die bioaktiven haben speziell eine biologische Bedeutung. Ihre Intensität ist sehr gering und liegt unter dem Schwellenwert der Lipoide. Durch Summierung kommt aber eine deutliche, periodisch auftretende Wirkung zustande.

Die Luminiszenz ist wahrseheinlich eine Folge der Lipoidoxydation und beeinflusst dieselbe offenbar spezifisch. Durch Erhöhung der Oxydation entweder durch Belichtung oder Zufuhr oxophorer Stoffe tritt eine Erhöhung der Luminiszenz ein.

Die biologische Wirkung der Luminiszenz ist der des Lichtes ähnlich, indem sie wahrscheinlich auch auf der Lipoidveränderung resp. -oxydationsbeschleunigung beruht.

\section{A nh a n g.}

Das Licht und die Luminiszenz sind Oxydationsreize und können dadurch als Typen grössere Bedeutung gewinnen. Sie besitzen offenbar auch Verwandtschaft zum Radium. Da durch Licht und speziell durch Radium Entzündungen hervorgerufen werden können (auf der Haut), die auf ihrem Charakter als Oxydationsreize beruhen, so ist es möglich, falls weitere Untersuchungen übereinstimmen, in der Entzündung überhaupt eine Wirkung sogenannter Oxydationsreize zu sehen und dieselbe auf eine abnorme Steigerung der Oxydationsprozesse der einzelnen Zellen zurückzuführen, auf die eine Reaktion des Organismus eintritt, welche alsdann der äussere Ausdruck der Entzündung ist.

Das Licht und die Luminiszenz geben fernerhin Einblicke in das Wesen der Reize überhaupt, und dürfte vielleicht speziell das 
Fechner'sche psycho-physische Grundgesetz dadurch eine neue Beleuchtung erfahren (vgl. S. 348).

Fernerhin kann die Auffassung des Lichtes als Oxydationsreiz mit spezifischer oxydabler Wertigkeit der einzelnen Wellenlängen auch für die Lehre des Sehens von Bedeutung sein. Einmal kann die Umsetzung von Licht in Nervenerregung, der nach Herman $\mathbf{n}^{1}$ ) ein noch völlig unbekannter Prozess zugrunde liegt, als Oxydation, mit der Lichtintensität und der Wellenlänge parallel verlaufendem Intensitätsgrad, verstanden werden; ferner wird die Rolle der Stäbchen und Zapfen verständlich unter der Annahme, dass der Sehpurpur ein den photodynamischen Körpern ähnlicher Stoff ist, der die verschiedenen Wellenlängen in einer Richtung zur Wirkung zu bringen vermag, and schliesslich ergibt sich dadurch eine mit einer jüngst von Raehlmann ${ }^{2}$ ) gegebenen Erklärung harmonierende Auffassung vom Bau des Auges, wonach die Verlagerung des Sehepithels in die hintersten Lagen direkt auf die Chorioidea des Auges eine zweckmässige Anordnung sein muss, indem vom Standpunkt der Lichtwirkung als Oxydationsreiz aus die vom Licht erzeugte Oxydationserleichterung einen reichlichen Strom von Sauerstoff verlangt, der durch die gefässreiche Chorioidea am besten ermöglicht wird.

Dass die am Plexus sich äussernde biologische Wirkung der Luminiszenz des Blutes auch im Tierkörper zur Geltung kommt, scheint auch ohne spezielle Untersuchung wahrscheinlich. Denn da das Blut in kontinuierlichem Strome durch alle Gewebe strömt, wird auch eine konstante Strahlung entstehen, so dass, obschon keine Exposition von langer Dauer, wie beim Versuch, eintreten kann, doch auf anderem Wege dasselbe eintritt. Damit aber wäre die Annahme gestattet, dass, wie in der Einleitung angedeutet wurde, der Sauerstoff nicht nur durch Vermittlung einer Oxydase trotz seiner niedrigen Spannung vitalaktiv ist, sondern dass diese Aktivität noch durch ein besonderes, im Blute liegendes Moment, die Luminiszenz, gesteigert würde.

Es wirft diese Überlegung noch weitere Streiflichter einmal in die allgemeine Pathologie und Pharmakologie, dann auf die Wirkung von kolloiden Metallen usw., deren weitere Detaillierung aber zu weit führen würde.

1) Hermann, Lehrb. d. Physiol., 13. Aufl, S. 405. 1905.

2) Ra ehlmann, Eine neue Theorie der Farbenempfindung auf anatomischphysikalischer Grundlage. Pflüger's Arch. Bd. 112 S. $172 \mathrm{ff.}$ 